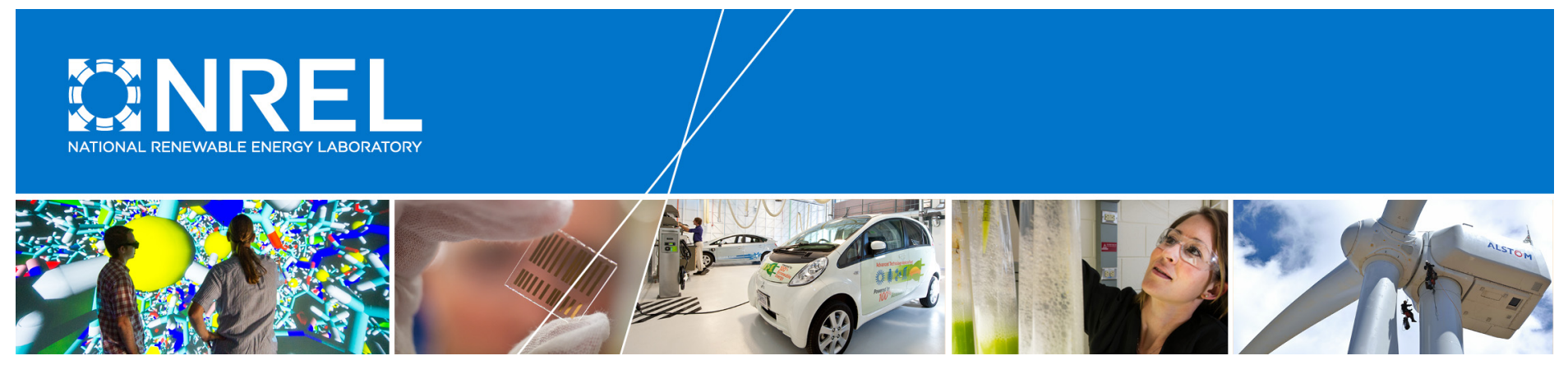

\title{
SAM Photovoltaic Model Technical Reference Update
}

Paul Gilman, Aron Dobos, Nicholas DiOrio, Janine Freeman, Steven Janzou, and David Ryberg National Renewable Energy Laboratory

NREL is a national laboratory of the U.S. Department of Energy Office of Energy Efficiency \& Renewable Energy Operated by the Alliance for Sustainable Energy, LLC

This report is available at no cost from the National Renewable Energy Laboratory (NREL) at www.nrel.gov/publications.

Technical Report

NREL/TP-6A20-67399

March 2018 


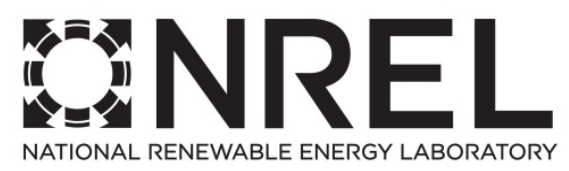

\title{
SAM Photovoltaic Model Technical Reference Update
}

\author{
Paul Gilman, Aron Dobos, Nicholas DiOrio, \\ Janine Freeman, Steven Janzou, \\ and David Ryberg \\ National Renewable Energy Laboratory \\ Prepared under Task No. SETP.10304.24.01.10
}

NREL is a national laboratory of the U.S. Department of Energy

Office of Energy Efficiency \& Renewable Energy

Operated by the Alliance for Sustainable Energy, LLC

This report is available at no cost from the National Renewable Energy Laboratory (NREL) at www.nrel.gov/publications.

National Renewable Energy Laboratory 15013 Denver West Parkway

Golden, CO 80401

303-275-3000 • www.nrel.gov

\section{Technical Report}

NREL/TP-6A20-67399

March 2018

Contract No. DE-AC36-08G028308 


\title{
NOTICE
}

This report was prepared as an account of work sponsored by an agency of the United States government. Neither the United States government nor any agency thereof, nor any of their employees, makes any warranty, express or implied, or assumes any legal liability or responsibility for the accuracy, completeness, or usefulness of any information, apparatus, product, or process disclosed, or represents that its use would not infringe privately owned rights. Reference herein to any specific commercial product, process, or service by trade name, trademark, manufacturer, or otherwise does not necessarily constitute or imply its endorsement, recommendation, or favoring by the United States government or any agency thereof. The views and opinions of authors expressed herein do not necessarily state or reflect those of the United States government or any agency thereof.

This report is available at no cost from the National Renewable Energy Laboratory (NREL) at www.nrel.gov/publications.

Available electronically at SciTech Connect http:/www.osti.gov/scitech

Available for a processing fee to U.S. Department of Energy and its contractors, in paper, from:

\author{
U.S. Department of Energy \\ Office of Scientific and Technical Information \\ P.O. Box 62 \\ Oak Ridge, TN 37831-0062 \\ OSTI http://www.osti.gov \\ Phone: 865.576.8401 \\ Fax: 865.576.5728 \\ Email: reports@osti.gov
}

Available for sale to the public, in paper, from:

\author{
U.S. Department of Commerce \\ National Technical Information Service \\ 5301 Shawnee Road \\ Alexandria, VA 22312 \\ NTIS http://www.ntis.gov \\ Phone: 800.553 .6847 or 703.605 .6000 \\ Fax: 703.605.6900 \\ Email: orders@ntis.gov
}




\section{Executive Summary}

This manual is describes the photovoltaic performance model in the System Advisor Model (SAM) Version 2017.9.5 (SSC 178). It is an update to Gilman (2015), which describes the photovoltaic model in SAM Version 2015.1.30 (SSC 41).

The U.S. Department of Energy's National Renewable Energy Laboratory maintains and distributes SAM, which is available as a free download from https://sam.nrel.gov.

SAM is a techno-economic feasibility model for renewable energy projects. It is designed for a range of different users, including project developers, system designers, policy makers, financial planners, and academic researchers.

SAM's photovoltaic performance model is available both as part of the SAM desktop application, and in the SAM software development kit (SDK). This manual is intended for people who want to understand SAM's photovoltaic model, or for people who are using the SDK to develop their own applications.

SAM runs on Windows 32- and 64-bit, and OS X 64-bit, and Linux 64-bit operating systems, and is a user interface that performs the following functions:

- Organizes and displays the performance and financial model inputs in a user-friendly interface.

- Manages tasks associated with running model simulations.

- Provides options for "advanced" simulations that involve multiple simulation runs for parametric and sensitivity studies.

- Stores arrays of model results.

- Calculates secondary results such as monthly and annual totals, capacity factor, system performance factor, and system losses.

- Displays tables and graphs of results.

- Allows for exporting data in different formats including CSV, graph images, Microsoft Excel, and PDF reports.

The SAM SDK is a package containing the SAM Simulation Core (SSC) libraries and a set of software development tools that allow model developers to create their own interfaces to the simulation modules as either web or desktop applications. 


\section{Table of Contents}

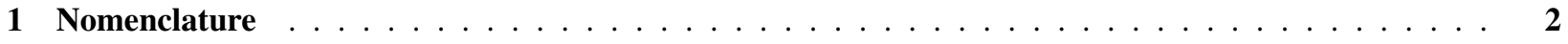

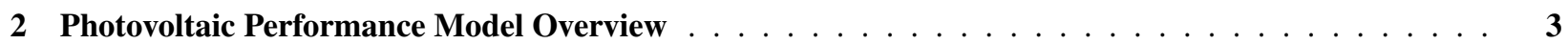

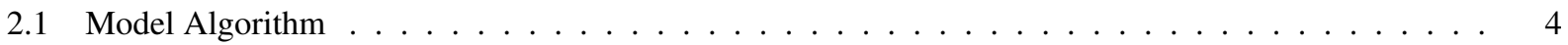

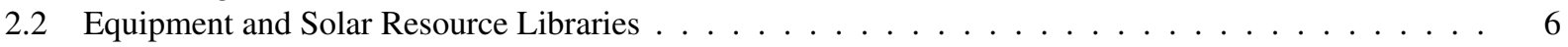

2.3 System Sizing . . . . . . . . . . . . . . . . . . . . . . . . . . . 7

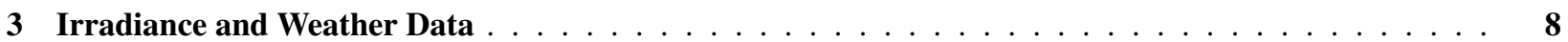

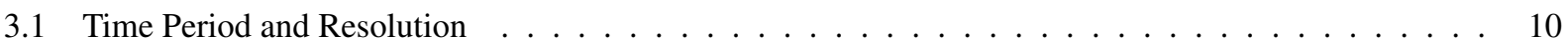

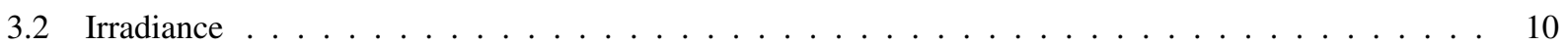

3.3 Weather Observations . . . . . . . . . . . . . . . . . . . . . . . . . . . 10

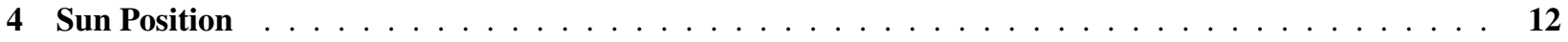

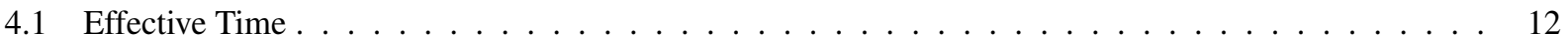

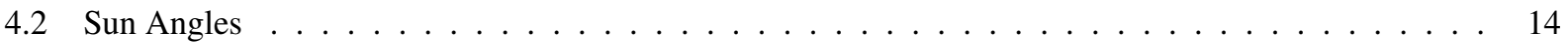

4.3 Sunrise and Sunset Hours . . . . . . . . . . . . . . . . . . . . . . . . . . . . 16

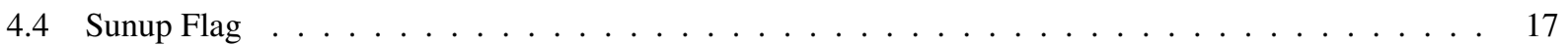

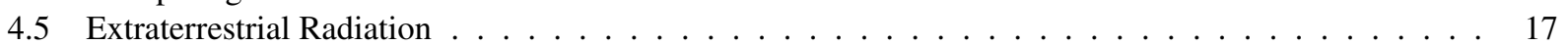

4.6 True Solar Time and Eccentricity Correction Factor . . . . . . . . . . . . . . . . . . . 17

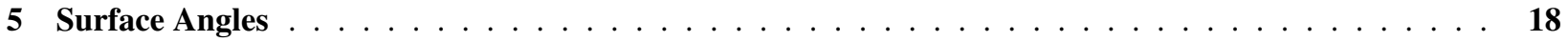

$5.1 \quad$ Angle of Incidence $\ldots \ldots \ldots \ldots \ldots \ldots \ldots \ldots$

5.2 Fixed, Azimuth and Two-axis Tracking $\ldots \ldots \ldots \ldots \ldots \ldots \ldots$

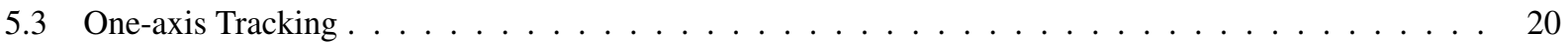

5.3.1 Rotation Angle for One-axis Trackers . . . . . . . . . . . . . . . . . . . . . . . 20

5.3.2 Backtracking for One-axis Trackers $\ldots \ldots \ldots \ldots \ldots \ldots \ldots \ldots$

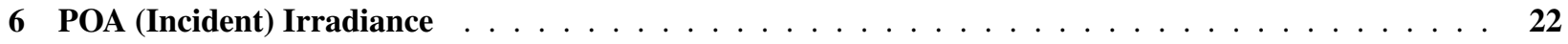

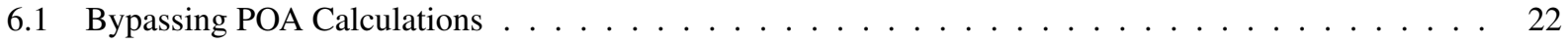

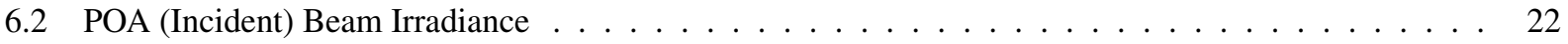

6.3 POA (Incident) Sky Diffuse Irradiance . . . . . . . . . . . . . . . . . . . . . 23

6.3 .1 Isotropic Model . . . . . . . . . . . . . . . . . . . . . . . . . . . . . . . . . . . . . . . . . 24

$6.3 .2 \quad$ HDKR Model . . . . . . . . . . . . . . . . . . . . . . . . . . . . . . . . . . . . . 24

6.3 .3 Perez 1990 Model . . . . . . . . . . . . . . . . . . . . . . . . . . . 25

6.4 POA (Incident) Ground-reflected Irradiance . . . . . . . . . . . . . . . . . . . . . . . . 26

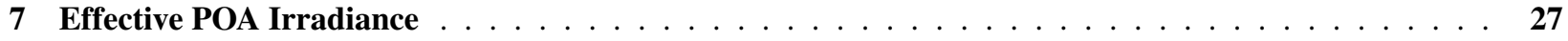

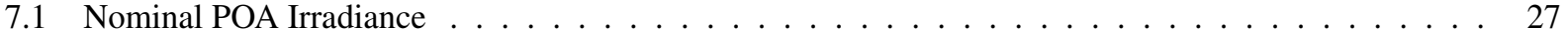

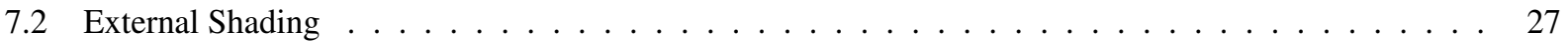

7.3 Partial External Shading and Shading Database Lookup . . . . . . . . . . . . . . . . . . . 29

7.4 Self Shading . . . . . . . . . . . . . . . . . . . . . . . . . . . . . . 29

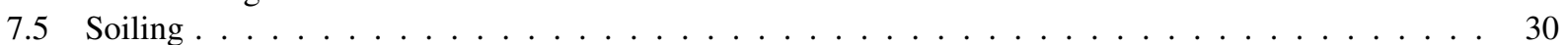

7.6 Effective Irradiance $\ldots \ldots \ldots \ldots \ldots \ldots \ldots$ 


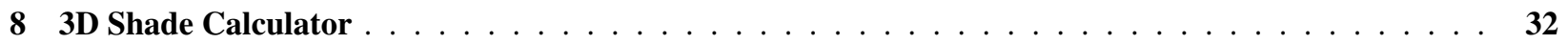

8.1 Beam Irradiance Loss . . . . . . . . . . . . . . . . . . . . . . . . . . . 32

8.2 Diffuse Irradiance Loss $\ldots \ldots \ldots$. . . . . . . . . . . . . . . . . . . . 33

9 Self Shading Algorithm $\ldots \ldots \ldots \ldots \ldots \ldots \ldots$

9.1 Self Shading Assumptions $\ldots \ldots \ldots \ldots \ldots \ldots \ldots \ldots$

9.2 Non-linear Option: Diffuse POA Irradiance Reduction ～. . . . . . . . . . . . . . . . . . . . . 37

9.3 Shadow Dimensions _ . . . . . . . . . . . . . . . . . . . . . . . . . . . . . 39

9.4 Linear Option: Beam POA Irradiance Reduction . . . . . . . . . . . . . . . . . . . . . . 40

9.5 Non-linear Option: DC Loss Factor . . . . . . . . . . . . . . . . . . . . . . . . . . . . . . 40

9.6 One-axis tracking: Shaded Fraction $\ldots \ldots \ldots \ldots \ldots \ldots \ldots$

9.6 .1 Sun Position Unit Vectors . . . . . . . . . . . . . . . . . . . . . . . 42

9.6 .2 Panel Vertices . . . . . . . . . . . . . . . . . . . . . . . . . . . . . . 42

9.6 .3 Shading Panel . . . . . . . . . . . . . . . . . . . . . . . . 44

9.6 .4 Shaded Fraction $\ldots \ldots \ldots \ldots$. . . . . . . . . . . . . . . . . 44

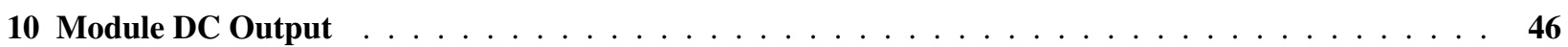

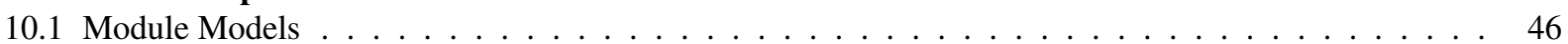

10.2 Cell Temperature Models . . . . . . . . . . . . . . . . . . . . . . . . . . . . . . . . . . 48

10.3 Sandia Module Model . . . . . . . . . . . . . . . . . . . . . . . . . . 48

10.4 CEC Module Model . . . . . . . . . . . . . . . . . . . . . . . . . . . 50

10.5 Simple Efficiency Module Model . . . . . . . . . . . . . . . . . . . . . . . . . 54

10.6 NOCT Cell Temperature Model _ . . . . . . . . . . . . . . . . . . . . . . . . . 54

10.7 Heat Transfer Cell Temperature Model . . . . . . . . . . . . . . . . . . . . . . 55

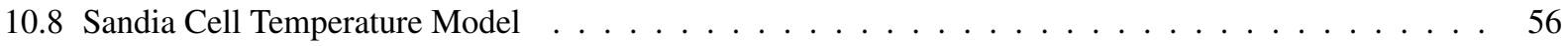

10.9 IEC 61853 Single Diode Module Model $\ldots \ldots \ldots \ldots \ldots$

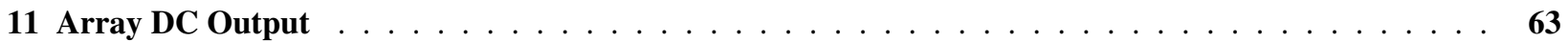

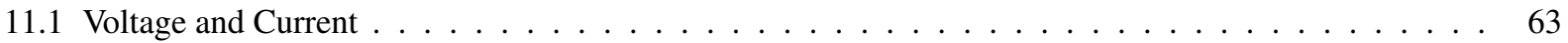

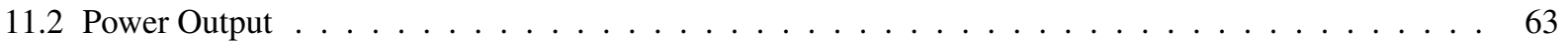

11.3 DC Electrical Losses . . . . . . . . . . . . . . . . . . . . . . . . . . . 64

11.4 DC Snow Losses . . . . . . . . . . . . . . . . . . . . . . . . . . . 64

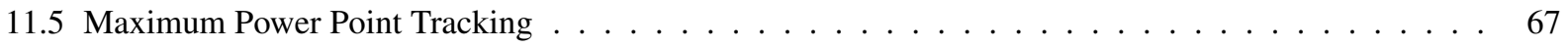

11.6 Subarray Mismatch Losses . . . . . . . . . . . . . . . . . . . . . . . . 67

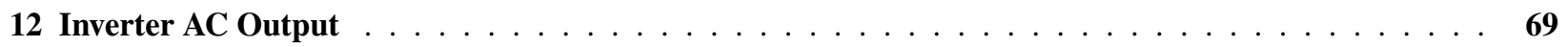

12.1 Inverter Models . . . . . . . . . . . . . . . . . . . . . . . . . . 69

12.2 Sandia Inverter Model . . . . . . . . . . . . . . . . . . . . . . . . . . . . 69

12.3 Inverter Part Load Curve Model _ . . . . . . . . . . . . . . . . . . . . . . 72

12.4 Inverter Clipping Losses and Voltage Checks $\ldots \ldots \ldots \ldots \ldots \ldots \ldots$

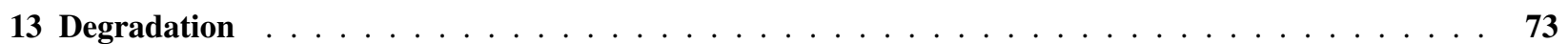

13.1 AC Degradation: PV Simulation Over One Year . . . . . . . . . . . . . . . . . . 73

13.2 DC and AC Degradation: PV Simulation Over Analysis Period . . . . . . . . . . . . . . . 74

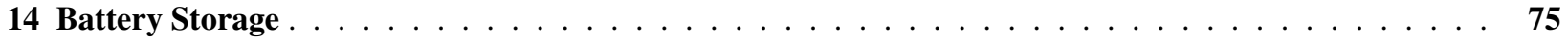

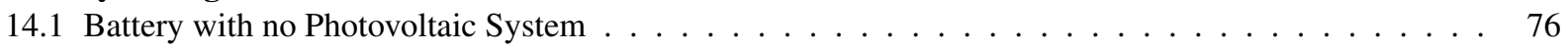

14.2 Battery Model Inputs and Outputs $\ldots \ldots \ldots \ldots \ldots \ldots$

14.3 Dispatch Modes . . . . . . . . . . . . . . . . . . . . . . 76

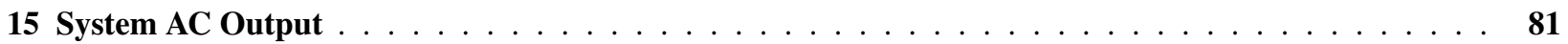

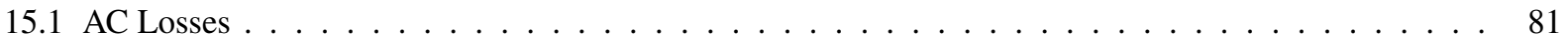




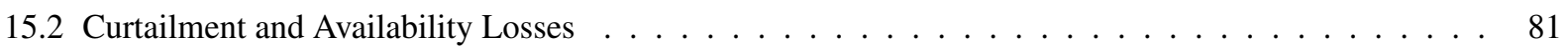

15.3 Power Generated by System ～. . . . . . . . . . . . . . . . . . . 82

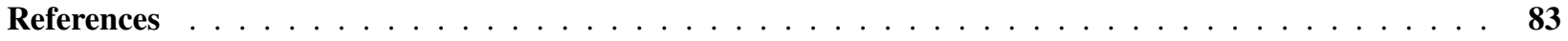

\section{List of Figures}

Figure 1. Photovoltaic Performance Model Simplified Block Diagram . . . . . . . . . . . . . . 5

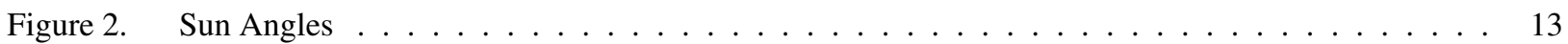

Figure 3. Surface Angles . . . . . . . . . . . . . . . . . . . . . . . . . . 19

Figure $4 . \quad 3 \mathrm{D}$ scene editor for shading calculations $\ldots \ldots \ldots \ldots \ldots \ldots \ldots \ldots \ldots \ldots$

Figure 5. Shadow Dimensions for Portrait Module Orientation . . . . . . . . . . . . . . . . . . . 35

Figure 6. Side View of Two Rows with Self-shading Mask Angle Variables ～. . . . . . . . . . . . 38

Figure 7. Diagram of Two-slab Module Cover Reflection Loss Model _ . . . . . . . . . . . . . . . 61

Figure 8. Normalized Comparison of Angular Response of Two-slab Model to Single-slab Model . . . . . . 62

Figure 9. Diagram of Snow Cover on a Photovoltaic Array $\ldots \ldots \ldots 6$

Figure 10. Simplified Block Diagram for AC-Connected Battery . . . . . . . . . . . . . . . . 75

Figure 11. Simplified Block Diagram for DC-Connected Battery . . . . . . . . . . . . . . . . . . . 76

\section{List of Tables}

Table 1. Primary Models in SAM's Photovoltaic Performance Model . . . . . . . . . . . . . . . . . . . 4

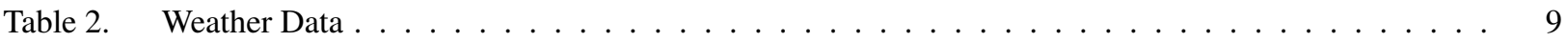

Table 3. Sun Position Variable Definitions $\ldots \ldots \ldots \ldots \ldots \ldots \ldots$

Table 4. Surface Angle Variable Definitions . . . . . . . . . . . . . . . . . . . . . . . . . . . . . 19

Table 5. POA Irradiance Variable Definitions $\ldots \ldots \ldots \ldots \ldots \ldots$

Table 6. Perez Sky Diffuse Irradiance Model Coefficients $\ldots \ldots \ldots \ldots$

Table 7. Effective POA Irradiance Variable Definitions . . . . . . . . . . . . . . . . . . . 28

Table 8. Self Shading Variable Definitions $\ldots \ldots \ldots \ldots \ldots$

Table 9. Module Model Variable Definitions . . . . . . . . . . . . . . . . . . . . . . . 47

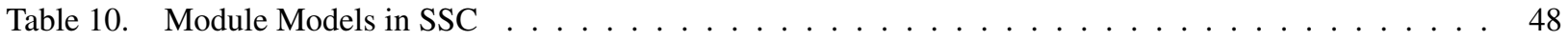

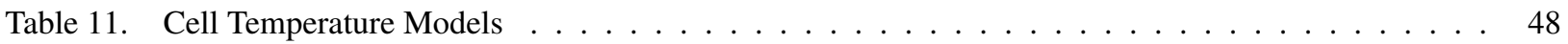

Table 12. Sandia Module Model Inputs ～. . . . . . . . . . . . . . . . . . . . . . . . . 49

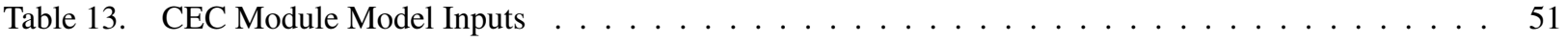


Table 14. Simple Efficiency Module Model Inputs _ . . . . . . . . . . . . . . . . . . . 54

Table 15. NOCT Cell Temperature Model Variable Definitions . . . . . . . . . . . . . . . . . . . . . . 55

Table 16. Heat Transfer Cell Temperature Model Variable Definitions ～. . . . . . . . . . . . . . . . 56

Table 17. Sandia Cell Temperature Model Variable Definitions . . . . . . . . . . . . . . . . . . . . . 57

Table 18. Sandia Module Structure Options _ . . . . . . . . . . . . . . . . . . . . 57

Table 19. IEC 61853 Parameter Calculator Inputs $\ldots \ldots \ldots \ldots \ldots \ldots \ldots$

Table 20. IEC 61853 Module Model Inputs $\ldots \ldots \ldots \ldots \ldots \ldots \ldots$

Table 21. IEC-61853 Module Test Matrix . . . . . . . . . . . . . . . . . . . . . . . . . 59

Table 22. Array DC Output Variable Definitions . . . . . . . . . . . . . . . . . . . . . . 64

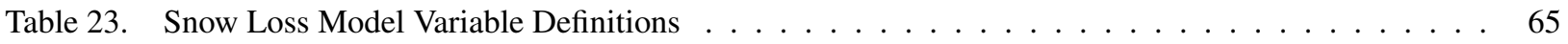

Table 24. Inverter Model Variable Definitions . . . . . . . . . . . . . . . . . . . . . . . . 70

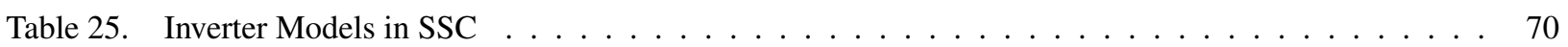

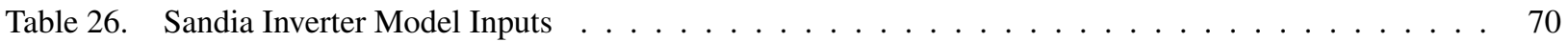

Table 27. Inverter Part Load Curve Model Inputs ～. . . . . . . . . . . . . . . . . . . . . 72

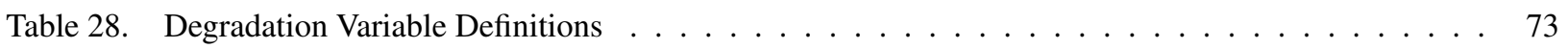

Table 29. Battery Property and Losses Inputs ～. . . . . . . . . . . . . . . . . . . . 77

Table 30. Battery Controller Inputs $\ldots \ldots \ldots \ldots \ldots \ldots \ldots \ldots \ldots$

Table 31. Battery Lifetime and Replacement Inputs . . . . . . . . . . . . . . . . . . 78

Table 32. Battery Outputs . . . . . . . . . . . . . . . . . . . . . . 79

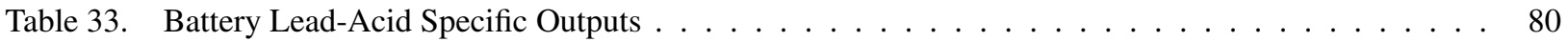

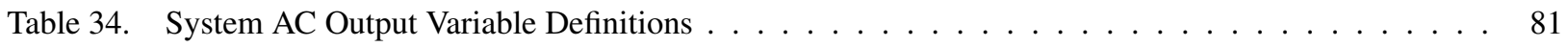




\section{Nomenclature}

The organization of this manual is based roughly on the Sandia National Laboratories PV Performance Modeling Collaborative (PVPMC) website "Modeling Steps" (PVPMC Modeling Steps 2014). The nomenclature and general descriptions also draw from the "PVCDROM" electronic document on the pveducation.org website hosted by the Arizona State University Solar Power Labs (PVCDROM 2014).

Tables at the beginning of each section list the variable names relevant to the section. In some cases, the same variable name might be used in two different sections of the manual to represent two different quantities. That is because we have tried to preserve the variable names used in the original sources. For example, $E$ is used to represent solar irradiance in most equations, and for the band-gap energy in two equations in the Sandia module model section.

For solar irradiance values, the letter $E$ indicates data from the weather file, $I$ indicates irradiance incident on the plane of the photovoltaic array before soiling and shading, and $G$ indicates effective irradiance incident on the plane of the array (at the top of the module cover) after soiling and shading. The subscripts $b, d$, and $g$ indicate beam, diffuse, and global irradiance values.

The variable $P$ indicates an electrical power value in Watts or kilowatts.

The word subarray refers to a group of modules in the photovoltaic array. SAM allows you to divide the array into up to four subarrays to model systems consisting of groups of modules, each with different orientation, tracking and other parameters. When the system consists of a single subarray, then the terms subarray and array are interchangeable. The word module may refer to a photovoltaic module, or to a section of computer code. The word panel describes a geometric surface in the self-shading algorithm (Section 9.6).

The abbreviation $P O A$ stands for "plane of array" and refers to solar irradiance in the plane of the photovoltaic array. It is another way of saying irradiance incident on the array: Beam POA irradiance is the same as incident beam irradiance, and and diffuse POA irradiance is the same as incident diffuse irradiance. 


\section{Photovoltaic Performance Model Overview}

This manual describes the "detailed photovoltaic model" in System Advisor Model (SAM) Version 2017.9.5 Revision 4 (SSC 178), and is an update to Gilman (2015), which describes the photovoltaic model in SAM Version 2014.11.24 (SSC Version 40). This manual covers the detailed photovoltaic model

The following is a list of the new features in SAM 2016.3.14 described in this manual that were not part of SAM when the original manual was written. For a complete list of SAM versions with features and changes, see SAM Release Notes (2016).

- 3D shade calculator

- Battery storage model

- DC power optimizer loss inputs

- Snow loss model

- Plane-of-array irradiance input from weather file option

- Support for sub-hourly simulations

- Self-shading works with all four subarrays, and uses same algorithm for fixed arrays and one-axis tracking

- Linear self-shading algorithm for thin-film modules

- Loss percentages replace derate factors

SAM's performance and financial models are implemented as SAM Simulation Core (SSC) modules. The photovoltaic performance model module is available as part of both the SAM desktop application (SAM Download 2016) and the SAM Software Development Kit (SDK) (SAM SDK 2016). SAM is a desktop application that provides a user-friendly interface to the SSC modules with additional features such as data visualization, macros, and tools for parametric and stochastic simulations (Blair 2014). The SDK provides a set of programming tools and an application programming interface (API) for developing software applications that run the SSC modules.

SAM's photovoltaic performance model combines a module and inverter model with supplementary code to calculate a photovoltaic power system's AC output over one year given a weather file and data describing the physical characteristics of the module, inverter, and array. The main models are listed in Table 1.

The photovoltaic performance model can simulate any size of system, from a small rooftop array and a single inverter to a large system with multiple subarrays and banks of inverters.

The modeled system must consist of a single type of photovoltaic module and a single type of inverter, and must not combine different sizes or types of modules and inverters. The array may consist of up to four subarrays, each with its own set of parameters for tracking, surface angles, shading and soiling, and DC losses. Each subarray can have a different number of modules, but all subarrays must have the same number of modules per string so that all subarrays have the same nominal DC voltage, which serves as the inverter nominal input voltage.

The array must be connected either to a single inverter or to a bank of inverters connected to each other in parallel. It is not possible to model a system with subarrays connected to different inverters.

The module model and inverter model calculate solar-energy-to-DC-electricity and DC-to-AC electricity conversion efficiencies, respectively, and account for losses associated with each component. The self-shading model calculates losses caused by shading of modules in the array by neighboring modules. The snow model calculates losses due to snow covering the array. The photovoltaic performance model does not explicitly calculate the remaining system losses. They are represented by user-specified inputs: 
Table 1. Primary Models in SAM's Photovoltaic Performance Model

\begin{tabular}{lll}
\hline Module & Reference & Section \\
\hline Sun position & Michalsky (1988), Iqbal (1983), NREL* & 4 \\
Surface angles & standard geometry & 5 \\
Backtracking for one-axis trackers & NREL & 5.3 .2 \\
Isotropic incident irradiance & Liu (1963) & 6.3 .1 \\
HDKR incident irradiance & Duffie and Beckman (2013), Reindl (1988) & 6.3 .2 \\
Perez 1990 incident irradiance & Perez (1988), Perez (1990) & 6.3 .3 \\
3D shade calculator & NREL & Section 8 \\
Self-shading & Deline (2013), NREL & 9 \\
Sandia module model & King (2004) & 10.3 \\
CEC module model & De Soto (2004a) & 10.4 \\
Simple efficiency module model & NREL & 10.5 \\
IEC 61853 module model & NREL & 10.9 \\
Subarray mismatch calculator & NREL & 11.6 \\
Sandia inverter model & King (2007) & 12.2 \\
Part load inverter model & NREL & 12.3 \\
Battery & DiOrio (2015a) & 14 \\
\hline
\end{tabular}

* "NREL" indicates a model developed specifically for SAM and documented only in this manual

- Beam and diffuse shading losses for nearby-object shading of the array. These can be specified for each hourly or sub-hourly time step, month-by-hour (288 values), or sun azimuth angle by elevation (number of values varies), and may be generated by shading analysis equipment and software.

- Monthly soiling losses for dust and other accumulation on the array.

- DC losses for module mismatch, DC wiring and connections, tracking, and other losses associated with the array.

- $\mathrm{AC}$ losses for $\mathrm{AC}$ wiring and transformer losses.

The model does not calculate module mismatch losses within a subarray. For systems with more than one subarray, an optional algorithm can estimate mismatch losses between the subarrays.

An optional battery storage model can model a bank of lead-acid or lithium-ion batteries connected to the system's AC bus.

\subsection{Model Algorithm}

This section describes the basic algorithm of SAM's photovoltaic performance model. The details of each step listed below are described in the sections that follow. See Figure 1 for a basic block diagram of the model. he block diagram does not include the subarray mismatch and string voltage calculations described in the steps below to make the diagram easier to follow.

The simulation model performs the following calculations for each time step in one year:

1. For each of up to four subarrays:

A. Calculate sun angles from date, time, and geographic position data from the weather file. (Section 4.2)

B. Calculate the nominal beam and diffuse irradiance incident on the plane of array (POA irradiance). This depends on the solar irradiance data in the weather file, sun angle calculations, user-specified subarray 


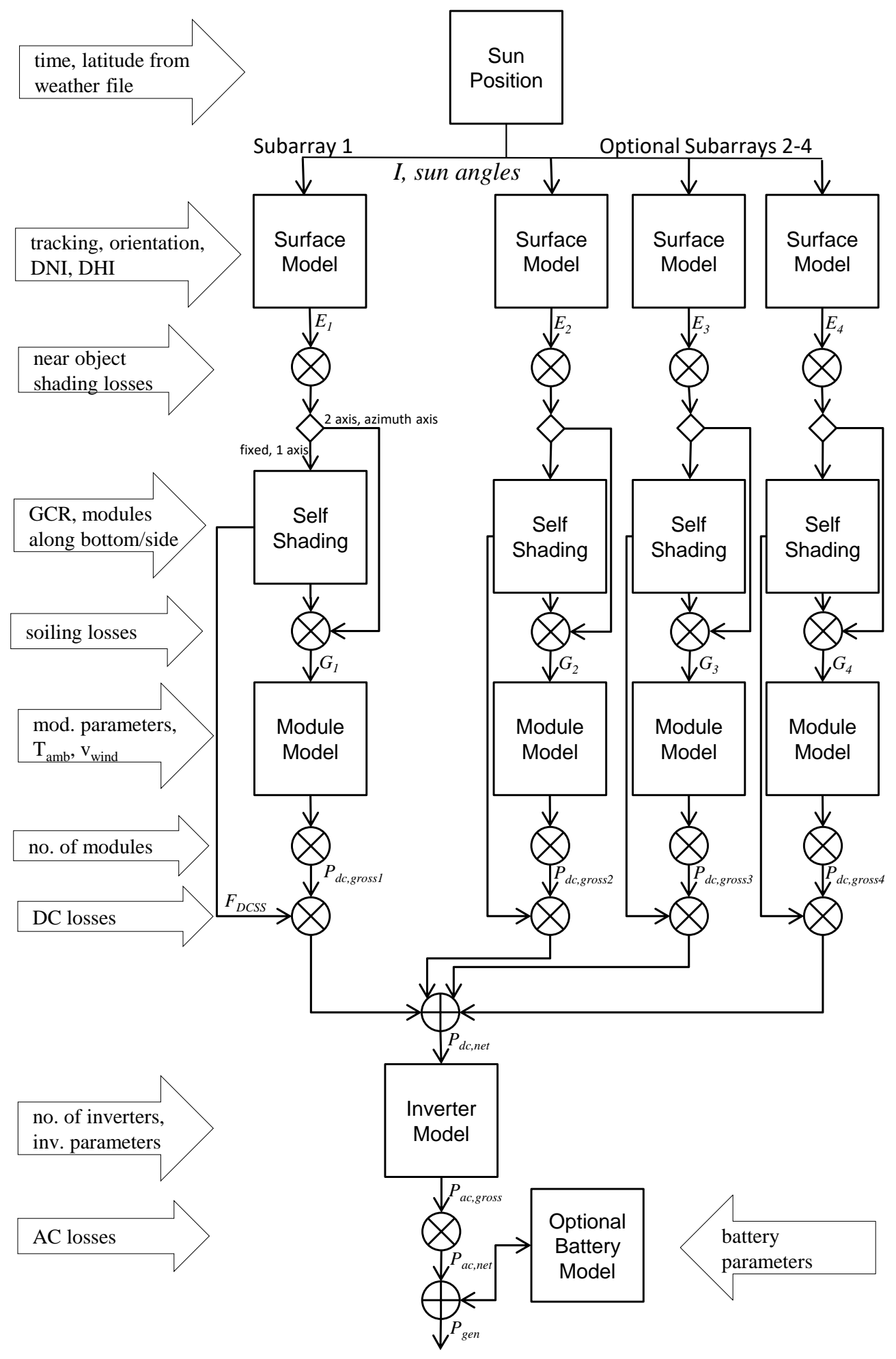

Figure 1. Photovoltaic Performance Model Simplified Block Diagram 
parameters such as tracking and orientation parameters, and backtracking option for one-axis trackers. (Section 7.1)

C. Apply the user-specified beam and diffuse nearby-object shading losses to the nominal beam and diffuse POA irradiance. (Section 7.2)

D. For fixed subarrays and subarrays with one-axis tracking and self-shading enabled, calculate and apply the self-shading loss factors to the nominal beam and diffuse POA irradiance. (Section 7.4)

E. Apply user-specified monthly soiling factors to calculate the effective POA irradiance on the subarray. (Section 7.5)

2. For subarrays with no tracking (fixed) and self-shading enabled, calculate the reduced diffuse POA irradiance and self-shading DC loss. (Section 9)

3. Determine subarray string voltage calculation method (Section 11.1).

4. For each of up to four subarrays, run the module model with the effective beam and diffuse POA irradiance and module parameters as input to calculate the DC output power, module efficiency, DC voltage, and cell temperature of a single module in the subarray.

5. Calculate the subarray string voltage using the method determined in Step 3.

6. For each subarray, calculate the array DC power (Section 11):

A. Apply the fixed self-shading DC loss to the module DC power if it applies.

B. Calculate the subarray gross DC power by multiplying the module DC power by the number of modules in the subarray.

C. Calculate subarray DC power by multiplying the gross subarray power by the DC loss.

D. Calculate the subarray string voltage by multiplying the module voltage by the number of modules per string.

E. Calculate the array DC power by adding up the subarray values.

7. Run the inverter model to calculate the gross AC power and inverter conversion efficiency (Section 12).

8. Calculate the AC power by applying the AC loss to the gross AC power (Section 15).

9. For systems with batteries, calculate power to and from the battery (Section 14).

\subsection{Equipment and Solar Resource Libraries}

SAM comes with libraries that store module and inverter parameters representing the equipment's physical properties. The solar resource library stores weather files with data representing the solar resource at different locations. The data in these libraries are copies of data managed by different organizations.

The following is a list of module and inverter libraries used by SAM's photovoltaic performance model with the source of data each library contains:

- CEC Modules: California Energy Commission Eligible Photovoltaic Modules (Go Solar California 2016a)

- CEC Inverters: California Energy Commission Eligible Inverters (Go Solar California 2016b)

- Sandia Modules: Sandia National Laboratories Module Database (Sandia 2014)

SAM's solar resource library contains data from the following sources:

- NREL National Solar Radiation Database 1961-1990 (TMY2) (NSRDB 1990) 
- NREL National Solar Radiation Database 1991-2010 Update (TMY3) (NSRDB 2010)

- U.S. DOE EnergyPlus Weather Data (EnergyPlus Weather 2016)

SAM also downloads data from the current version of the National Solar Resource Database (NSRDB 2016).

These data collections and download features are not part of SSC. If you are developing a model using the SAM software development kit and want to use parameters from the module or inverter libraries, you will have to write your own code to read the data. The module and inverter libraries are text files that use a simple comma-separated format. The solar resource library is a CSV file that SAM creates when you install the software and uses to display summary information in the library list on the Location and Resource input page, and is separate from the collection of weather files that come with the software. In SSC, you can read the weather files directly, or import weather file data into an array, but you cannot access SAM's library file.

\subsection{System Sizing}

SAM's System Design input page has an option that automatically calculates the number of modules per string, number of parallel strings in the array, and number of inverters given a desired array size in DC kW and a DC-toAC nameplate capacity ratio. The sizing algorithm is described in SAM Help - System Sizing (2016) and uses the module and inverter reference parameters for the capacity calculations.

In SSC, you must provide the number of modules per string, strings in parallel, and number of inverters to specify the system size. The system sizing algorithm is part of the SAM user interface, but not part of SSC. 


\section{Irradiance and Weather Data}

The photovoltaic performance model requires a weather file with solar resource data for one year and information about the location of the measurement site. The data may be hourly, or sub-hourly with a time resolution of up to one minute. See Table 2 for a list of required weather data fields. SAM ignores any additional data elements that may be included in the different weather file formats. Some additional data elements, such as relative humidity, are required for SAM's concentrating solar power performance models, but not for the photovoltaic model. SAM also ignores supporting data, such as the source and uncertainty flags in the TMY3 file format.

In SSC, you can provide either the path to a weather file (solar_resource_file), or a table containing the weather data (solar_resource_data).

The model uses data from the weather file to calculate the following values for each time step in the year:

- Sun position angles (Section 4).

- Plane-of-array (POA) irradiance (Section 6).

- Photovoltaic cell temperature (Section 10.2).

- Array DC loss due to snow cover (Section 11.4).

Solar resource data must include solar irradiance, wind speed, and ambient temperature data, and may include optional snow depth and albedo data. Location data must include latitude, longitude, time zone and elevation, and may include optional fields for location name or number, city, state, region, and country.

By default, SAM calculates the irradiance incident on the plane of the subarray from the beam (DNI) and diffuse (DHI) components of the solar irradiance. For weather files that do not contain data from those components, SAM can estimate the DNI and DHI from the other irradiance components. You must choose the appropriate Weather File Irradiance Data option on the Location and Resource input page (irrad_mode value in SSC):

- DNI and DHI (irrad_mode $=0$ ) is the default option: SAM uses the beam (direct normal) an diffuse horizontal irradiance from the weather file, and ignores the GHI (global horizontal irradiance) data if it exists.

- DNI and GHI (irrad_mode = 1): SAM uses the beam and global horizontal data from the weather file and calculates the DHI using Equation 6.4.

- GHI and DHI (irrad_mode = 2): SAM uses the global horizontal and diffuse horizontal data from the weather file and calculates the DNI using Equation 6.3.

- Plane of array (POA) (irrad_mode $=3$ or 4): SAM uses the POA data in the weather file and bypasses the incident irradiance calculations, unless shading is enabled for the subarray as described in Section 6.1.

Each row in the weather file must have a Year, Month, Day, and Hour column indicating the time for sun position calculations. Sub-hourly data must have an additional Minute column. For hourly data, the Minute column is optional, and may be used to indicate the minute for sun position calculations (Section 3.1).

SAM can read files in the formats listed below. For descriptions of the formats see (SAM Help - Weather File Formats 2016).

- SAM CSV: Comma-separated text format developed by NREL for SAM. This is also the file format for files from the NSRDB (NSRDB 2016) and some other solar resource data sources.

- TMY3: Comma-separated text format originally developed by NREL for the NSRDB 1991-2010 update (NSRDB 2010).

- TMY2: Text format originally developed by NREL for the NSRDB 1961 - 1990 data set (NSRDB 1990). 
Table 2. Weather Data

\begin{tabular}{|c|c|c|}
\hline Symbol & Field & Description \\
\hline \multicolumn{3}{|c|}{ Metadata Location Description } \\
\hline- & Location ID ${ }^{1}$ & numerical identifier [722780] \\
\hline- & City $^{1}$ & location name [Phoenix Sky Harbor Intl Ap] \\
\hline- & State $^{1}$ & two-letter state abbreviation $[A Z]$ \\
\hline$t z$ & Time zone & hours E of GMT [-7.0] \\
\hline lat & Latitude & decimal degree $\mathrm{N}$ of $0[33.450]$ \\
\hline lon & Longitude & decimal degree $\mathrm{E}$ of $0[-11.983]$ \\
\hline elv & Elevation & meters above sea level [337] \\
\hline \multicolumn{3}{|c|}{ Time Series Data Records } \\
\hline$y r$ & Year & typical year [1988] \\
\hline mo & Month & typical month (1-12) \\
\hline day & Day & day of year (1-365) \\
\hline$h r$ & Hour & hour of day (0-23) in local time \\
\hline $\min$ & Minute & minute of hour (0-59) \\
\hline$E_{g}$ & Global horizontal irradiance ${ }^{2}\left(\mathrm{~W} / \mathrm{m}^{2}\right)$ & total radiation on a horizontal surface \\
\hline$E_{b}$ & Direct normal irradiance ${ }^{2}\left(\mathrm{~W} / \mathrm{m}^{2}\right)$ & direct radiation on a surface normal to the sun \\
\hline$E_{d}$ & Diffuse horizontal irradiance ${ }^{2}\left(\mathrm{~W} / \mathrm{m}^{2}\right)$ & radiation on a horizontal surface from the sky \\
\hline POA & Plane-of-array irradiance ${ }^{2}$ & radiation on the plane of the array \\
\hline$v_{\text {wind }}$ & Wind speed $(\mathrm{m} / \mathrm{s})$ & wind speed \\
\hline$T_{a}$ & Dry-bulb temperature $\left({ }^{\circ} \mathrm{C}\right)$ & ambient dry-bulb temperature \\
\hline$D_{\text {snow }}$ & Snow depth ${ }^{3}(\mathrm{~cm})$ & depth of snow \\
\hline$\rho$ & Ground reflectance ${ }^{4}$ & ground reflectance factor or albedo \\
\hline- & Dew-point temperature ${ }^{5}\left({ }^{\circ} \mathrm{C}\right)$ & dew-point temperature \\
\hline- & Atmospheric pressure ${ }^{5}$ (mbar) & atmospheric pressure \\
\hline
\end{tabular}

Table Notes

Italicized values in brackets are sample values.

${ }^{1}$ The model does not use location metadata.

${ }^{2}$ SAM requires either any two irradiance components or POA data.

${ }^{3}$ Snow depth data is required to model snow losses (Section 11.4).

${ }^{4}$ When albedo data is missing, SAM applies a default value of 0.2 (Section 6.4).

${ }^{5}$ Required only for the heat transfer cell temperature model (Section 10.7).

- EPW: Comma-separated text format similar to the TMY3 format, originally developed for the EnergyPlus building modeling software (EnergyPlus Weather 2016).

\subsection{Time Period and Resolution}

The weather file contains one year of time series solar resource data. The time step of the performance model simulations is determined by the weather file. The model will accept a weather file with a time step between one and 60 minutes, as long as 8760 minutes per hour is a multiple of the time step length in minutes. For example, the model will run with a weather file that contains one-minute data, 10-minute data, 15-minute data, or 60-minute (hourly) data, but it will not run with 13-minute or 18-minute data.

The number of data rows in the file determines the simulation time step. For example, a file with 8760 rows of weather data (not including header rows) would result in an hourly simulation. A weather file for a 15-minute simulation time step should have 35,040 data rows in addition to the header rows. A one-minute data file should have 
525,600 data rows.

The first data row in the weather file is for the first time step after midnight on January 1, local standard time. For hourly data, the first row is for the hour ending at 1 a.m. on January 1. For 15-minute data, the first row is for the quarter hour ending at 0:15 a.m. on January 1.

SAM does not account for leap years or daylight savings. If the weather file contains data for February 29 (indicating a leap year), SAM skips the data for that day. To minimize the risk of SAM processing data incorrectly, you should not include February 29 data in weather files you create to use with SAM.

By default for hourly weather data, SAM calculates the sun position (and photovoltaic array surface angles) for the mid-point of the time step. For example, the sun position for the 10:00 a.m. hour would be its position at 10:30 a.m. However, if the weather file contains hourly data and includes a Minute column, SAM uses the minute indicated to calculate the sun position for each hour. Sub-hourly weather data must include a Minute column indicating the time for sun position calculations.

\subsection{Irradiance}

Solar irradiance is a measure of the instantaneous power from the sun on a surface over an area, typically given in the SI units of watts per square meter $\left(\mathrm{W} / \mathrm{m}^{2}\right)$. The weather file may contain some or all of the following data:

- Global horizontal irradiance (GHI): The total solar irradiance on a surface parallel to the ground (horizontal).

- Direct normal irradiance (DNI): The portion of the solar irradiance that reaches a surface normal to the sun in a direct line from the solar disk (typically assuming a measurement device with a $5^{\circ}$ field of view), also called beam normal.

- Diffuse horizontal irradiance (DHI): The solar irradiance on a horizontal surface from the sky excluding the solar disc.

- Plane of array (POA): The total solar irradiance incident on a surface in the plane of the photovoltaic array measured by either a reference cell or pyranometer.

The photovoltaic performance model requires direct normal and diffuse horizontal irradiance data to calculate the plane-of-array irradiance (Section 6). However, it includes functions to estimate either the direct normal (see Equation 6.3) or diffuse horizontal (see Equation 6.4) irradiance when the weather file is missing those data elements. The model will bypass incident irradiance calculations when the weather file contains POA data (Section 6.1). To use a weather file that is missing either the DNI or DHI data, or that contains POA data, you must choose the appropriate Weather File and Irradiance Data option on the Location and Resource input page (irrad_mode in SSC).

\subsection{Weather Observations}

The photovoltaic performance model uses ambient temperature and wind speed data from the weather file (in addition to solar irradiance and module efficiency) to estimate the effect of photovoltaic cell temperature on the array's performance. Although wind direction does have an effect on cell temperature, the photovoltaic performance model assumes that its cumulative effect over the year is negligible (King 2004).

The air temperature or dry-bulb temperature is the temperature in degrees Celsius $\left({ }^{\circ} \mathrm{C}\right)$ of ambient air measured by a thermometer exposed to the air but shielded from the sun and rain.

SAM assumes that the wind speed measurements from the weather file are in $\mathrm{m} / \mathrm{s}$ and measured at a height of $10 \mathrm{~m}$ above the ground. 


\section{Sun Position}

SAM calculates the sun altitude, zenith, and declination angles that define its position for each time step in the weather file. SAM's sun position algorithm is based on the method described in Michalsky (1988), which in turn is based on the Astronomical Almanac's algorithm for the period 1950-2050. NREL modified the Michalsky algorithm to calculate sun azimuth angles for locations south of the equator using the approach described in (Iqbal 1983). The algorithm is further discussed in O'Brien (2012).

The overall sun position algorithm steps are:

1. Calculate the effective time in hours for the time step.

2. Calculate the sun angle for the time step.

3. Determine the current day's sunrise and sunset time.

4. Determine the sunup flag for the time step.

5. Calculate the extraterrestrial radiation for the time step.

Although all of the sun angle input and results variables in SAM are in degrees, most of the internal equations use angle values in radians.

Table 3 lists the sun position algorithm's inputs and outputs. Figure 2, adapted from Dunlap (2007), shows the sun angles. The inputs are for each time step, and come from the weather file.

The sun position algorithm does not include an air mass equation. Instead, each algorithm that needs the value uses its own equation to calculate the value: The Perez incident sky diffuse model uses Equation 6.17, and the Sandia and CEC module models use the same equation, shown in Equations 10.1 and 10.23, respectively.

\subsection{Effective Time}

The first step in the sun position algorithm is to determine the effective time of the current time step. SAM reads the time stamp data for the current time step in the weather file (represented by a data row) as a year, month, day, hour, and minute value.

The standard weather files from the National Solar Radiation Database (NSRDB 2016) start at $h r=1$. The algorithm converts the first hour number to $h r=0$.

For hourly weather files that do not contain a Minute column, the algorithm uses the midpoint of the time step for sun position calculations (except for the hours containing sunrise and sunset, see Section 4.3) so that $\min =30$. Otherwise, for weather data that contains a Minute time step, $\min$ is the value for the current time step from the weather file.

The Julian day of year jdoy is the number of days since Noon on January 1 of the current year (strictly speaking, it should be called the ordinal date). Because some weather files are typical year files, the time stamps in a given file may not all use the same year. For example, all January time stamps may be 1988, while all February time stamps may be 2005 .

To account for leap years:

$$
k=\left\{\begin{array}{lll}
1 & \text { if year } \quad \bmod 4=0 \\
0 & \text { if year } \quad \bmod 4 \neq 0
\end{array}\right.
$$

This accounts for leap years to correctly calculate effective time, but is separate from the energy simulation, which does not account for leap years. 
Table 3. Sun Position Variable Definitions

\begin{tabular}{lll}
\hline Symbol & Description / Name in SAM & Name in SSC \\
\hline & \multicolumn{1}{c}{ Inputs } \\
$t z$ & time zone (hrs E of GMT, $-12<t z<12)$ & tz \\
$l a t$ & latitude $\left(\right.$ decimal ${ }^{\circ}$ of equator, $0<$ lat $\left.<90\right)$ & lat \\
$l o n$ & longitude $\left(\right.$ decimal ${ }^{\circ}$ E of GMT, $-180<$ lon $\left.<180\right)$ & lon \\
$y r$ & year $($ e.g., 1988$)$ & year \\
mo & month year $(1-12)$ & month \\
$d a y$ & day of year $(1-365)$ & day \\
$h r$ & hour of day local time $(0-23)$ & hour \\
min & minute of hour $(0-59)$ & minute \\
\hline & $\quad$ Outputs & \\
$Z$ & Solar zenith angle $(\mathrm{deg})$ & sun_zen \\
$\alpha$ & Solar altitude angle $(\mathrm{deg})$ & sun_elv \\
$\delta$ & solar declination angle $(\mathrm{deg})$ & sun_dec \\
$\gamma$ & Solar azimuth angle $(\mathrm{deg})$ & sun_azm \\
sunup & Sun up over horizon $(0 / 1 / 2 / 3)$ & sunup \\
\hline
\end{tabular}

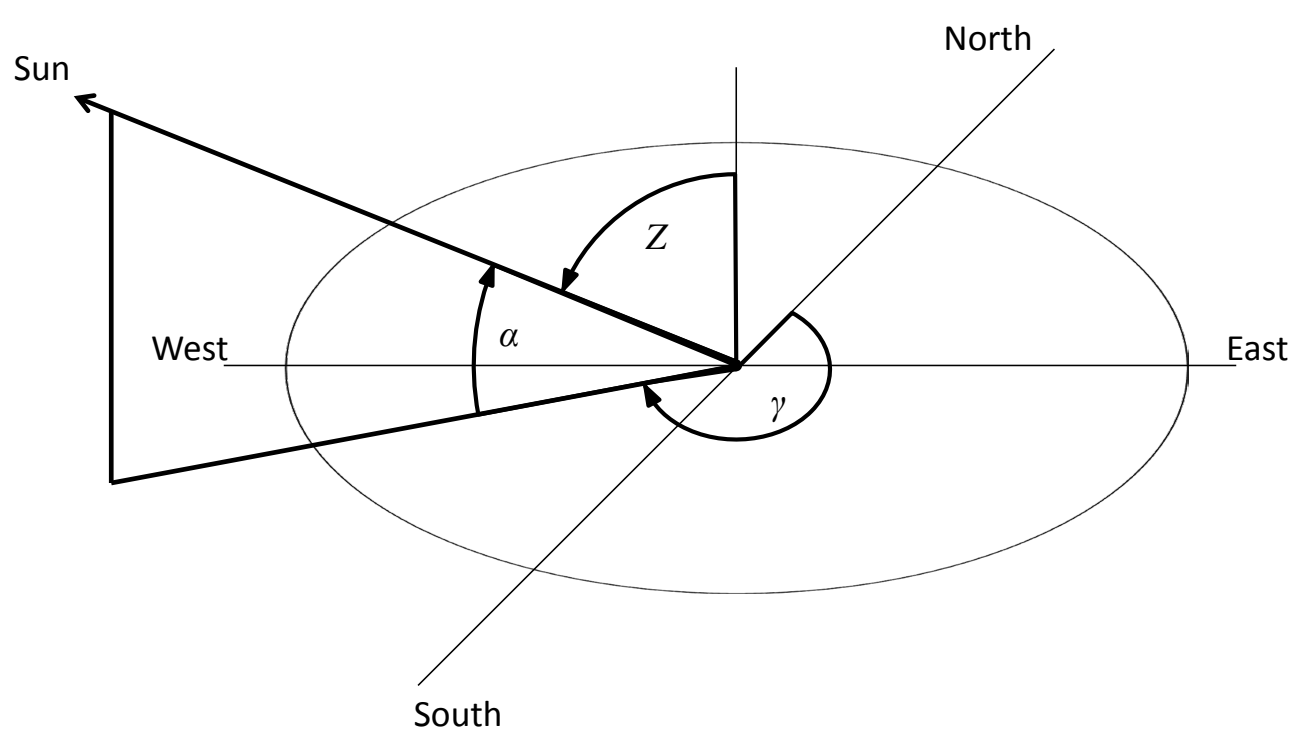

Figure 2. Sun Angles 
SAM calculates the number of days since January $1 a$ from the number of days in each of the months (January $=$ 31 , February $=28$, March $=31$, etc.) before the current month, and the number of days since the first of the current month.

The Julian day of year is then:

$$
j d o y= \begin{cases}d a y+a & \text { for January and February } \\ d a y+a+k & \text { for March through December }\end{cases}
$$

The current decimal time of day expressed as an offset from UTC depends on the hour and minute of the current time stamp, and the location's time zone. Valid values for the time zone are $-12<t z<12$.

$$
t_{u t c}=h r+\frac{\min }{60}-t z
$$

For some combinations of time stamp and time zone, Equation 4.3 may yield a value less than zero or greater than 24 hours, in which case the following correction applies:

$$
t_{u t c}= \begin{cases}t_{u t c}+24 & \text { if } t_{u t c}<0 \\ t_{u t c}-24 & \text { if } t_{u t c}>24\end{cases}
$$

The Julian date julian of the current hour is the Julian day of the preceding noon plus the number of hours since then. The Julian day is defined as the number of days since Noon on January 1, 2000:

$$
\text { julian }=32916.5+365(y r-1949)+\frac{y r-1949}{4}+j d o y+\frac{t_{u t c}}{24}-51545
$$

\subsection{Sun Angles}

The sun angle equations are from Michalsky (1988). The sun angles (Figure 2) are the altitude angle $\alpha$, declination angle $\delta$, and zenith angle $Z$. SAM also calculates the sun azimuth angle $\gamma$ for use in the POA irradiance calculations. The solar declination angle is not used in the POA irradiance calculations, but is required to calculate the sun azimuth angle. The bold font in Table 3 indicates that SAM reports the sun zenith, altitude, and azimuth angles in the results.

The first step in the sun angle calculation for a given time step is to determine the ecliptic coordinates of the location, which define the photovoltaic array's position on the earth relative to the sun. The ecliptic coordinate variables are the mean longitude, mean anomaly, ecliptic longitude, and obliquity of the ecliptic. The algorithm uses ecliptic coordinates instead of equatorial coordinates to include the effect of the earth's inclination in the sun angle calculations.

Where limits are indicated for the equations below, if the variable's value falls outside of the limits, SAM adjusts the value. For example, for a value $x$ with the limits $0 \leq x<360^{\circ}$, SAM divides $x$ by $360^{\circ}$, and checks to see whether the remainder is less than zero, and if it is, adds $360^{\circ}$ to the remainder:

$$
\begin{aligned}
& a=x-360^{\circ} \operatorname{trunc}\left(\frac{x}{360^{\circ}}\right) \\
& x= \begin{cases}a & \text { if } a \geq 0 \\
a+360^{\circ} & \text { if } a<0\end{cases}
\end{aligned}
$$

Mean longitude in degrees $\left(0 \leq\right.$ mnlong $\left.<360^{\circ}\right)$. The mean longitude is the only value not converted to radians:

$$
\text { mnlong }=280.46+0.9856474 \text { julian }
$$


Mean anomaly in radians $(0 \leq$ mnanom $<2 \pi)$ :

$$
\text { mnanom }=\frac{\pi}{180}(357.528+0.9856003 \text { julian })
$$

Ecliptic longitude in radians $(0 \leq$ eclong $<2 \pi)$ :

$$
\text { eclong }=\frac{\pi}{180}[\text { mnlong }+1.915 \sin \text { mnanom }+0.02 \sin (2 \text { mnanom })]
$$

Obliquity of ecliptic in radians:

$$
\text { obleq }=\frac{\pi}{180}(23.439-0.0000004 \text { julian })
$$

The next step is to calculate the celestial coordinates, which are the right ascension and declination.

The right ascension in radians:

$$
r a= \begin{cases}\arctan \left(\frac{\text { cos obleq } \text { sineclong }}{\text { coseclong }}\right)+\pi & \text { if cos eclong }<0 \\ \arctan \left(\frac{\text { os obleqsineclong }}{\text { coseclong }}\right)+2 \pi & \text { if cos obleq sin eclong }<0\end{cases}
$$

The solar declination angle in radians:

$$
\delta=\arcsin (\sin \text { obleq } \sin \text { eclong })
$$

Next are the local coordinates, which require calculating the hour angle.

The Greenwich mean siderial time in hours $(0 \leq$ gmst $<24)$ with limits applied as shown in Equation 4.6 depends on the current time at Greenwich $t_{u t c}$ from Equation 4.3, and the Julian day from Equation 4.5:

$$
\text { gmst }=6.697375+0.0657098242 \text { julian }+t_{\text {utc }}
$$

Local mean siderial time in hours $(0 \leq l m s t<24)$ :

$$
\text { lmst }=\text { gmst }+\frac{l o n}{15}
$$

The hour angle in radians $(-\pi<H A<\pi)$ :

$$
\begin{aligned}
b & =15 \frac{\pi}{180} \text { lmst }-r a \\
H A & = \begin{cases}b+2 \pi & \text { if } b<-\pi \\
b-2 \pi & \text { if } b>\pi\end{cases}
\end{aligned}
$$

The sun altitude angle in radians, not corrected for refraction:

$$
\begin{aligned}
& a=\sin \delta \sin \left(\frac{\pi}{180} \text { lat }\right)+\cos \delta \cos \left(\frac{\pi}{180} \text { lat }\right) \cos H A \\
& \alpha_{0}= \begin{cases}\arcsin a & \text { if }-1 \leq a \leq 1 \\
\frac{\pi}{2} & \text { if } a>1 \\
-\frac{\pi}{2} & \text { if } a<-1\end{cases}
\end{aligned}
$$


The sun altitude angle $\alpha$ in radians corrected for refraction is (these equations use the uncorrected sun altitude angle in degrees, indicated by the subscript $d$ ):

$$
\begin{aligned}
\alpha_{0 d} & =\frac{180}{\pi} \alpha_{0} \\
r & = \begin{cases}3.51561\left(0.1594+0.0196 \alpha_{0 d}+0.00002 \alpha_{0 d}^{2}\right)\left(1+0.505 \alpha_{0 d}+0.0845 \alpha_{0 d}^{2}\right)^{-1} & \text { if } \alpha_{0 d}>-0.56 \\
0.56 & \text { if } \alpha_{0 d} \leq-0.56\end{cases} \\
\alpha & = \begin{cases}\frac{\pi}{2} & \text { if } \alpha_{0 d}+r>90 \\
\frac{\pi}{180}\left(\alpha_{0 d}+r\right) & \text { if } \alpha_{0 d}+r \leq 90\end{cases}
\end{aligned}
$$

The sun azimuth angle $\gamma$ in radians is from (Iqbal 1983) rather than (Michalsky 1988) because the latter is only for Northern Hemisphere locations:

$$
\begin{aligned}
& a=\frac{\sin \alpha_{0} \sin \left(\frac{\pi}{180} \text { lat }\right)-\sin \delta}{\cos \alpha_{0} \cos \left(\frac{\pi}{180} \text { lat }\right)} \\
& b= \begin{cases}\arccos a & \text { if }-1 \leq a \leq 1 \\
\pi & \text { if } \cos \alpha_{0}=0, \text { or if } a<-1 \\
0 & \text { if } a>1\end{cases} \\
& \gamma= \begin{cases}b & \text { if } H A<-\pi \\
\pi-b & \text { if }-\pi \leq H A \leq 0, \text { or if } H A \geq \pi \\
\pi+b & \text { if } 0<H A<\pi\end{cases}
\end{aligned}
$$

The sun zenith angle $Z$ in radians:

$$
Z=\frac{\pi}{2}-\alpha
$$

\subsection{Sunrise and Sunset Hours}

The photovoltaic model assumes that the array generates electricity starting in the hour that contains the sunrise and ending in the hour that contains the sunset.

To determine whether the current time step contains a sunrise, the sunrise hour angle is:

$$
\begin{aligned}
a & =-\tan \text { lat } \tan \delta \\
H A R & =\left\{\begin{array}{lll}
0 & \text { if } a \geq 1 & \text { sun is down } \\
\pi & \text { if } a \leq-1 & \text { sun is up } \\
\arccos a & \text { if }-1<a<1 & \text { sunrise }
\end{array}\right.
\end{aligned}
$$

The equation of time in hours:

$$
\begin{aligned}
a & =\frac{1}{15}\left(\text { mnlong }-\frac{180}{\pi} r a\right) \\
\text { EOT } & = \begin{cases}a & \text { if }-0.33 \leq a \leq 0.33 \\
a+24 & \text { if } a<-0.33 \\
a-24 & \text { if } a>0.33\end{cases}
\end{aligned}
$$

The sunrise hour in local standard decimal time:

$$
h_{\text {sunrise }}=12-\frac{1}{15} \frac{180}{\pi} H A R-\left(\frac{\text { lon }}{15}-t z\right)-\text { EOT }
$$


And, the sunset hour in local standard time:

$$
h_{\text {sunset }}=12+\frac{1}{15} \frac{180}{\pi} H A R-\left(\frac{\text { lon }}{15}-t z\right)-E O T
$$

For hourly data, the sunrise minute is at the midpoint between the minute during which the sun rose and the end of the time step. The sunset minute is at the midpoint between the beginning of the time step and the minute during which the sun set:

$$
\begin{array}{ll}
m_{\text {sunrise }} & =60\left(1-\left(h_{\text {sunrise }}-h r\right)+\frac{\left(t_{\text {sunrise }}-h r\right)}{2}\right) \\
m_{\text {sunset }} & =\frac{60\left(h_{\text {sunset }}-h r\right)}{2}
\end{array}
$$

For sub-hourly data, the sunrise and sunset minute is determined by the minute indicated by the time stamp:

$$
\begin{aligned}
& m_{\text {sunrise }}=\min \\
& m_{\text {sunset }}=\min
\end{aligned}
$$

\subsection{Sunup Flag}

The sunup flag indicates whether the sun is above or below the horizon in the current time step. The photovoltaic model uses this value to determine whether to calculate the cell temperature in the current time step. It only reports the sunrise and sunset hour ( $\operatorname{sunup}=2$ and sunup $=3$, respectively) for hourly data. Its value is determined from the sunrise hour angle (Equation 4.20):

$$
\text { sunup }= \begin{cases}0 & \text { sun is down } \\ 1 & \text { sun is up } \\ 2 & \text { sunrise } \\ 3 & \text { sunset }\end{cases}
$$

\subsection{Extraterrestrial Radiation}

Extra terrestrial radiation $H$ is the solar radiation at the top of the earth's atmosphere in $\mathrm{W} / \mathrm{m}^{2}$. SAM uses the value in the POA irradiance calculations described in Section 6.

The extraterrestrial radiation equation is from Chapter 1.10 of Duffie and Beckman (2013):

$$
\begin{gathered}
G_{\text {on }}=1367\left[1+0.033 \cos \left(\frac{\pi}{180} \frac{360 d o y}{365}\right)\right] \\
H= \begin{cases}G_{\text {on }} \cos Z & \text { if } 0<Z<\frac{\pi}{2} \text { (sun is up) } \\
G_{\text {on }} & \text { if } Z=0 \\
0 & \text { if } Z<0, \text { or if } Z>\frac{\pi}{2}\end{cases}
\end{gathered}
$$

\subsection{True Solar Time and Eccentricity Correction Factor}

The sun position algorithm calculates two values that are not used by the photovoltaic performance model.

True solar or apparent time in decimal hours:

$$
t_{\text {truesolar }}=h r+\frac{\min }{60}+\frac{l o n}{15}-t z+E O T
$$


The eccentricity correction factor:

$$
E_{0}=[1.00014-0.01671 \cos \text { mnanom }-0.00014 \cos (2 \text { mnanom })]^{-2}
$$




\section{Surface Angles}

SAM considers each subarray in the system to be a flat surface with one tilt angle $\beta_{s}$ and one azimuth angle $\gamma_{s}$ that define the surface orientation. The surface angles depend on whether the subarray is fixed, or mounted on one-axis, two-axis, or azimuth-axis trackers. Surfaces with one-axis trackers have a third surface angle $\sigma$ defining its rotation around the tracking axis.

The surface angle equations are based on standard geometric relationships defined by the surface orientation and sun angles (Section 4.2).

SAM calculates the surface angle of each subarray for each time step of the simulation. For systems with trackers, the surface angles in a given time step are fixed over the time step. The surface angles are for the same minute of the hour as the sun position angles: Either the minute indicated in the weather file, or for hourly weather data with no Minute column, the midpoint of the hour (Section 3.1).

Table 4 defines the variables used for the equations in this section. Figure 3, adapted from Dunlap (2007), shows how the surface angles are defined.

\subsection{Angle of Incidence}

The angle of incidence $A O I$ is the sun incidence angle defined as the angle between beam irradiance and a line normal to the subarray surface (See Figure 3). It is a function of the sun azimuth angle $\gamma$, sun zenith angle $Z$, surface azimuth angle $\gamma_{s}$, and the surface tilt angle $\beta_{s}$ :

$$
\begin{aligned}
a & =\sin Z \cos \left(\gamma-\gamma_{s}\right) \sin \beta_{s}+\cos Z \cos \beta_{s} \\
A O I & = \begin{cases}\pi & \text { if } a<-1 \\
0 & \text { if } a>1, \text { or for two-axis tracking } \\
\arccos a & \text { if }-1 \leq a \leq 1\end{cases}
\end{aligned}
$$

\subsection{Fixed, Azimuth and Two-axis Tracking}

The surface azimuth and tilt angle values depend on the tracking option as described below.

For a fixed surface (no tracking):

$$
\begin{aligned}
\beta_{s} & =\beta_{0} \\
\gamma_{s} & =\gamma_{0}
\end{aligned}
$$

For azimuth tracking, the surface tilt angle is fixed, and the surface azimuth angle follows the sun azimuth angle:

$$
\begin{aligned}
\beta_{s} & =\beta_{0} \\
\gamma_{s} & =\gamma
\end{aligned}
$$

For two-axis tracking, the surface tilt and azimuth angles follow the sun zenith and azimuth angles, respectively:

$$
\begin{aligned}
\beta_{s} & =Z \\
\gamma_{s} & =\gamma
\end{aligned}
$$


Table 4. Surface Angle Variable Definitions

\begin{tabular}{|c|c|c|}
\hline Symbol & Description / Name in SAM & Name in SSC \\
\hline \multicolumn{3}{|c|}{ Inputs } \\
\hline- & Fixed, 1 Axis, 2 Axis, Azimuth Axis & track_mode \\
\hline$\beta_{0}$ & Tilt (deg) & tilt \\
\hline$\gamma_{0}$ & Azimuth (deg) & azimuth \\
\hline$\theta_{\lim }$ & Tracker rotation limit $(\mathrm{deg})$ & rotlim \\
\hline$Z$ & sun zenith angle (deg) & sun_zen \\
\hline$\gamma$ & sun azimuth angle (deg) & sun_azm \\
\hline- & Backtracking & backtrack \\
\hline$G C R$ & Ground coverage ratio (GCR) & GCR \\
\hline- & Beam and diffuse, Total and beam & irrad_mode \\
\hline- & Isotropic, HDKR, Perez & sky_model \\
\hline \multicolumn{3}{|c|}{ Outputs } \\
\hline$A O I$ & incidence angle & incidence \\
\hline$\beta_{s}$ & Subarray $[n]$ Surface tilt (deg) & surf_tilt \\
\hline$\gamma_{s}$ & Subarray $[n]$ Surface azimuth (deg) & surf_azm \\
\hline$\theta$ & Subarray $[n]$ Axis rotation for 1 axis trackers $(\mathrm{deg})$ & axis_rotation \\
\hline$\theta_{0}$ & Subarray $[n]$ Ideal axis rotation for 1 axis trackers $(\mathrm{deg})$ & - \\
\hline$\Delta \theta$ & backtracking difference from ideal rotation (deg) & bt_diff \\
\hline
\end{tabular}

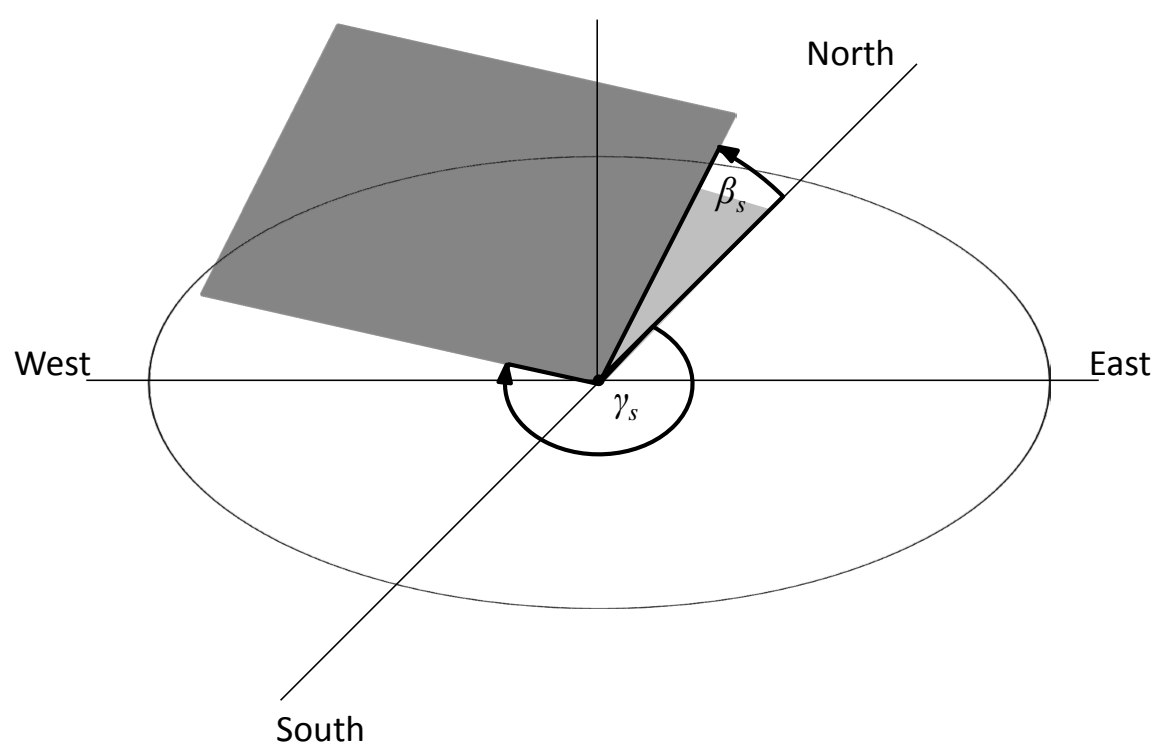

Figure 3. Surface Angles 


\subsection{One-axis Tracking}

One-axis tracking involves the tilt angle $\beta$, azimuth angle $\gamma$ and a third surface angle $\theta$ describing the surface's rotation about the tracking axis and a rotation angle limit $\theta_{\text {lim }}$.

SAM offers three shade modes for the one-axis tracking option on the PV Subarrays input page:

- Self-shaded accounts for shading of modules in one row by those in neighboring rows (see Section 7.4), but does not model backtracking.

- Backtracking adjusts the tracking angle to avoid shading of modules in one row by those in neighboring rows (see Section 5.3.2).

- None does not account for self-shading or backtracking.

All one-axis surface angle equations use angle values converted from degrees to radians.

The one-axis tracking tilt angle in radians (See Sections 5.3.1 and 5.3.2 for rotation angle equations):

$$
\begin{aligned}
& a=\cos \beta_{0} \cos \theta \\
& \beta_{s}= \begin{cases}\pi & \text { if } a<-1 \\
0 & \text { if } a>1 \\
\arccos a & \text { if }-1 \leq a \leq 1\end{cases}
\end{aligned}
$$

The one-axis tracking surface azimuth angle in radians:

$$
\begin{aligned}
& a=\frac{\sin \theta}{\sin \beta} \\
& \gamma_{s}= \begin{cases}\pi & \text { if } \beta_{s}=0 \\
\frac{3 \pi}{2}+\gamma_{0} & \text { if } a<-1 \\
\frac{\pi}{2}+\gamma_{0} & \text { if } a>1 \\
\gamma_{0}-\pi-\arcsin a & \text { if } \theta<-\frac{\pi}{2} \\
\gamma_{0}+\pi-\arcsin a & \text { if } \theta>\frac{\pi}{2} \\
\gamma_{0}+\arcsin a & \text { if }-1 \leq a \leq 1 \text { or }-\frac{\pi}{2} \leq \theta \leq \frac{\pi}{2}\end{cases}
\end{aligned}
$$

The surface azimuth angle in radians must be between zero and $2 \pi$ :

$$
\gamma_{s}= \begin{cases}\gamma_{s}-2 \pi & \text { if } \gamma_{s}>2 \pi \\ \gamma_{s}+2 \pi & \text { if } \gamma_{s}<0\end{cases}
$$

\subsubsection{Rotation Angle for One-axis Trackers}

For a subarray with one-axis tracking, SAM assumes that the tracker rotates about an axis along the line defining the azimuth angle $\gamma_{0}$ tilted from the horizontal at the tilt angle $B_{0}$. For a south-facing array in the Northern Hemisphere $\left(\gamma_{0}=180\right)$, the racker would rotate from east to west throughout the day.

The tracker rotation angle $\theta$ is the angle of the subarray surface from the horizontal about the tracking axis. For a surface tilted as shown Figure 3, the rotation angle is the angle as viewed from the raised end of the surface, with a negative rotation angle indicating counter-clockwise rotation from the horizontal. For a surface in the Northern Hemisphere with a surface azimuth angle of $180^{\circ}$, a negative rotation angle is for a surface facing east toward the morning sun with $-90^{\circ}$ for a vertical, east-facing surface. A positive rotation angle is for an array facing the afternoon sun, with $90^{\circ}$ for a vertical, west-facing surface. In the Southern Hemisphere, for a surface with an azimuth angle of $0^{\circ}$, a negative rotation limit indicates a west-facing surface. 
The tracker rotation limit $\theta_{\text {lim }}$ is the physical limit of the tracker's motion about the tracking axis in degrees with valid values between 0 and $\pm 90^{\circ}$. (SAM's user interface restricts the rotation limit values to $\pm 85^{\circ}$.) For example, a tracker in the Northern Hemisphere with a rotation limit of $45^{\circ}$ would start tracking at a rotation angle of $-45^{\circ}$ in the sunrise time step, and stop tracking at a rotation angle of $45^{\circ}$ in the sunset time step.

SAM adjusts the surface rotation angle as follows:

- If the tracker rotation angle exceeds the user-specified tracker rotation limit, then the tracker rotation is set to the limit.

- If backtracking is enabled and the array is self-shaded, then the surface tilt angle is adjusted to minimize selfshading (See Section 5.3.2).

The one-axis tracking equations described below use angle values converted from degrees to radians. SAM displays surface angle values in the results in degrees.

The "ideal rotation angle" $\theta_{0}$ for one-axis tracking is the rotation angle without application of the rotation limit $\theta_{\text {lim }}$ or backtracking:

$$
\begin{aligned}
a & =\frac{\sin Z \sin \left(\gamma-\gamma_{s}\right)}{\sin Z \cos \left(\gamma-\gamma_{s}\right) \sin \beta+\cos Z \cos \beta} \\
\theta_{01} & = \begin{cases}-\frac{\pi}{2} & \text { if } a<-99,999.9 \\
\frac{\pi}{2} & \text { if } a>99,999.9 \\
\arctan a & \text { if }-99,999.9 \leq a \leq 99,999.9\end{cases}
\end{aligned}
$$

The following corrections ensure that the ideal rotation angle is in the correct quadrant (II or III) when the surface azimuth angle $\gamma_{s}$ is less than or greater than $\pi$ :

$$
\theta_{0}= \begin{cases}\theta_{01}+\pi & \text { if } \gamma_{s}<\pi \text { and } \gamma<\gamma_{s} \leq \gamma_{s}+\pi \text { and } \theta_{0}<0 \text { (quadrant II positive rotation) } \\ \theta_{01}-\pi & \text { if } \gamma_{s}<\pi \text { and } \gamma<\gamma_{s} \leq \gamma_{s}+\pi \text { and } \theta_{0}>0 \text { (quadrant III negative rotation) } \\ \theta_{01}+\pi & \text { if } \gamma_{s}>\pi \text { and } \gamma<\gamma_{s} \leq \gamma_{s}-\pi \text { and } \theta_{0}<0 \text { (quadrant II positive rotation) } \\ \theta_{01}-\pi & \text { if } \gamma_{s}>\pi \text { and } \gamma<\gamma_{s} \leq \gamma_{s}-\pi \text { and } \theta_{0}>0 \text { (quadrant III negative rotation }\end{cases}
$$

The rotation angle in radians is the ideal rotation angle limited by the rotation limit:

$$
\theta= \begin{cases}\theta_{0} & \text { if }-\theta_{\mathrm{lim}} \leq \theta_{0} \leq \theta_{\mathrm{lim}} \\ -\theta_{\mathrm{lim}} & \text { if } \theta_{0}<-\theta_{\mathrm{lim}} \\ \theta_{\mathrm{lim}} & \text { if } \theta_{0}>\theta_{\mathrm{lim}}\end{cases}
$$

\subsubsection{Backtracking for One-axis Trackers}

Backtracking is a technique used with some one-axis trackers to minimize self-shading of neighboring rows of photovoltaic modules during times that the sun is low in the sky. When neighboring rows shade each other, the tracker rotates toward the horizontal to reduce the size of shadows on the array.

SAM's backtracking for one-axis tracking algorithm was developed by NREL for SAM. It involves the following steps:

1. Determine the shaded fraction of the subarray (Section 9.6) given the ground coverage ratio GCR, sun angles (Section 4.2), surface angles (Section 5), and surface rotation angle $\theta$ (Equation 5.9).

2. If the shaded fraction is greater than zero, adjust the tracker rotation angle $\theta$ toward $0^{\circ}$ by $1^{\circ}$.

3. Repeat Steps 1-2 until $F_{\text {shad1x }}=0$, or one hundred times, whichever comes first (to avoid an infinite loop).

The backtracking rotation difference $\Delta \theta$ reported by SSC as bt_diff:

$$
\Delta \theta=\theta-\theta_{0}
$$




\section{POA (Incident) Irradiance}

The plane-of-array irradiance or POA irradiance, also called incident irradiance, is the solar irradiance incident on the plane of the photovoltaic array in a given time step. SAM calculates the POA irradiance for the sunrise, sunup, and sunset time steps. The incident angle algorithm calculates the beam and diffuse irradiance incident on the photovoltaic subarray surface for a given sun position, latitude, and surface orientation. For each time step in the simulation, the POA irradiance algorithm steps are:

1. Calculate the angle of incidence (Section 5.1).

2. Calculate the beam irradiance on a horizontal surface.

3. Check to see if the beam irradiance on a horizontal surface exceeds the extraterrestrial radiation.

4. Calculate the POA beam irradiance.

5. Calculate the sky diffuse horizontal irradiance using one of the three sky diffuse irradiance methods.

6. Calculate the ground-reflected irradiance.

\subsection{Bypassing POA Calculations}

The photovoltaic performance model allows you to use measured plane-of-array (POA) irradiance data as input. When POA data is available, you can create a weather file with a column with the heading "POA" that contains the data. When you choose one of the POA options below, SAM uses the POA data from the weather file instead of calculating it from beam normal and horizontal diffuse irradiance data (Freeman 2016).

To use POA data as input, choose the appropriate PV Albedo and Radiation option on the Location and Resource page:

- POA from reference cell (irrad_mode $=3$ in SSC) for data measured by a reference photovoltaic cell in the same plane as the array surface. With this option, SAM assumes that the reference cell experiences the same module cover effects as the modules in the system, and therefore bypasses all module cover models and spectral corrections (Section 10).

- POA from pyranometer (irrad_mode $=4$ in SSC) for data measured by a pyranometer in the same plane as the array surface. With this option, SAM assumes that the pyranometer does not experience the same module cover effects as the modules, and therefore it needs to use a decomposition model to separate the POA data into its beam and diffuse components so that it can apply the module cover effects. The decomposition model is described in Marion (2015).

Even when using the POA from reference cell option, there are a few instances in which SAM must decompose that input data. If you apply beam or diffuse shading losses (Section 7.2) to POA data, SAM must decompose the POA irradiance into beam and diffuse irradiance components in order to apply the shading loss to the appropriate component. Likewise, if you use the Simple Efficiency Module model (Section 10.5) with a Diffuse utilization factor of less than 1, SAM must decompose the POA irradiance into beam and diffuse components to apply the diffuse utilization factor. Finally, SAM must also decompose the POA irradiance if you use the Heat transfer method temperature correction with the CEC module model (Section 10.2).

\subsection{POA (Incident) Beam Irradiance}

The POA beam irradiance is solar energy that reaches the surface in a straight line from the sun:

$$
I_{b}=E_{b} \cos A O I
$$


Table 5. POA Irradiance Variable Definitions

\begin{tabular}{lll}
\hline Symbol & Description / Name in SAM & Name in SSC \\
\hline$E_{b}$ & Beam irradiance $\left(\mathrm{W} / \mathrm{m}^{2}\right)$ & beam \\
$E_{d}$ & Diffuse irradiance $\left(\mathrm{W} / \mathrm{m}^{2}\right)$ & diffuse \\
$E_{g}$ & Global horizontal irradiance $\left(\mathrm{W} / \mathrm{m}^{2}\right)$ & global \\
$H$ & extraterrestrial irradiance $\left(\mathrm{W} / \mathrm{m}^{2}\right)$ & - \\
$\rho$ & Albedo $($ ground reflectance $)$ & albedo \\
$A O I$ & angle of incidence $(\operatorname{deg})$ & incidence \\
$\beta_{s}$ & Subarray $[\boldsymbol{n}]$ Surface tilt $(\mathrm{deg})$ & tilt \\
$Z$ & Solar zenith angle $(\operatorname{deg})$ & sun_zen \\
- & Beam and diffuse, Total and beam, Total and diffuse & irrad_mode \\
- & Isotropic, HDKR, Perez & sky_model \\
- & Use albedo in weather file if it is specified & use_wf_albedo \\
\hline & $\quad$ Outputs & \\
$I_{b}$ & POA beam irradiance $\left(\mathrm{W} / \mathrm{m}^{2}\right)$ & poa_beam \\
$I_{d}$ & POA sky diffuse irradiance $\left(\mathrm{W} / \mathrm{m}^{2}\right)$ & poa_skydiff \\
$I_{r}$ & POA ground-reflected irradiance $\left(\mathrm{W} / \mathrm{m}^{2}\right)$ & poa_gnddiff \\
$D_{i}$ & isotropic component of POA diffuse irradiance $\left(\mathrm{W} / \mathrm{m}^{2}\right)$ & poa_skydiff_iso \\
$D_{c}$ & circumsolar component of POA diffuse irradiance $\left(\mathrm{W} / \mathrm{m}^{2}\right)$ & poa_skydiff_cir \\
$D_{h}$ & horizon brightening component of POA diffuse irradiance $\left(\mathrm{W} / \mathrm{m}^{2}\right)$ & poa_skydiff_hor \\
\hline
\end{tabular}

The beam irradiance on a horizontal surface:

$$
I_{\mathrm{bh}}=E_{b} \cos Z
$$

SAM compares $I_{\mathrm{bh}}$ to the extraterrestrial radiation $H$ (Equation 4.27). If $I_{\mathrm{bh}}>H$, it generates an error flag that causes the calculations to stop.

The irradiance data option on the Location and Resource input page (irrad_mode in SSC) allows you to choose whether to use the beam irradiance data from the weather file, or whether to calculate it from the global horizontal and diffuse horizontal irradiance values:

$$
E_{b}= \begin{cases}E_{b} & \text { Use weather file value if option is Beam and diffuse (irrad_mode }=0) \\ \left(E_{g}-E_{d}\right) / \cos Z & \text { Calculate for Total and diffuse (irrad_mode }=2)\end{cases}
$$

\subsection{POA (Incident) Sky Diffuse Irradiance}

POA sky diffuse irradiance $I_{d}$ is solar energy that has been scattered by molecules and particles in the earth's atmosphere before reaching the surface of the subarray.

The sky diffuse model calculates values of the components of the sky diffuse irradiance (isotropic, circumsolar, and horizon brightening), but those components are not used by the photovoltaic model. The equations are provided in the sections below for reference.

The Tilted Surface Radiation Model option on the Location and Resource input page in SAM (sky_model in SSC) allows you to choose from three different sky diffuse irradiance models:

- The Isotropic model is the simplest of the three models, and assumes that diffuse radiation is uniformly distributed across the sky, called isotropic diffuse radiation $($ sky_model $=0$ ). 
- HDKR, named for the algorithm developed by Hay, Davies, Klucher and Reindl in 1979, also assumes isotropic diffuse radiation, but accounts for the higher intensity of circumsolar diffuse radiation, which is the diffuse radiation in the area around the sun $($ sky_model $=1)$.

- The Perez model uses a more complex computational method than the other two methods that involves some empirical relationships and calibration. It accounts for both isotropic and circumsolar diffuse radiation, as well as horizon brightening (sky_model $=2$ ).

The Radiation Components option on the Location and Resource input page (irrad_mode in SSC) allows you to choose whether to use the diffuse horizontal irradiance from the weather file, or whether to calculate it from the global horizontal and beam normal irradiance values:

$$
E_{d}= \begin{cases}E_{d} & \text { Use weather file value if option is Beam and diffuse (irrad_mode }=0) \\ E_{g}-E_{b} \cos Z & \text { Calculate for Total and beam (irrad_mode }=1)\end{cases}
$$

\subsubsection{Isotropic Model}

The isotropic diffuse sky irradiance (Liu 1963):

$$
I_{d}=E_{d} \frac{1+\cos \beta_{s}}{2}
$$

The isotropic model does not account for circumsolar diffuse irradiance or horizon brightening:

$$
\begin{aligned}
D_{i} & =I_{d} \\
D_{c} & =0 \\
D_{h} & =0
\end{aligned}
$$

\subsubsection{HDKR Model}

The Hay, Davies, Klucher, Reindl (HDKR) sky diffuse model is from Chapter 2.16 of Duffie and Beckman (2013) and Reindl (1988).

The total irradiance incident on a horizontal surface:

$$
I_{\mathrm{gh}}=I_{\mathrm{bh}}+E_{d}
$$

The ratio of POA beam to horizontal beam:

$$
R_{b}=\frac{\cos A O I}{\cos Z}
$$

The anisotropy index for forward scattering circumsolar diffuse irradiance depends on the beam horizontal irradiance $I_{\text {bh }}$ and extraterrestrial irradiance $H$ (Equation 4.27):

$$
A_{i}=\frac{I_{\mathrm{bh}}}{H}
$$

The modulating factor for horizontal brightening correction:

$$
f=\sqrt{\frac{I_{\mathrm{bh}}}{I_{\mathrm{gh}}}}
$$


The horizon brightening correction factor:

$$
s=\sin ^{3} \frac{\beta_{s}}{2}
$$

The circumsolar, isotropic, and horizon brightening components of the diffuse sky radiation are then:

$$
\begin{aligned}
\text { cir } & =E_{d} A_{i} R_{b} \\
\text { iso } & =E_{d}\left(1-A_{i}\right) \frac{1+\cos \beta_{s}}{2} \\
\text { isohor } & =i s o(1+f s)
\end{aligned}
$$

The isotropic, circumsolar, and horizon brightening components of the POA diffuse irradiance:

$$
\begin{aligned}
D_{i} & =i s o \\
D_{c} & =\text { cir } \\
D_{h} & =i s o h o r-i s o
\end{aligned}
$$

The HDKR sky diffuse irradiance:

$$
I_{d}=i s o h o r+c i r
$$

\subsubsection{Perez 1990 Model}

SAM's Perez sky diffuse irradiance model was adapted from PVWatts Version 1 (Dobos 2013a) and is described in Perez (1988) and (Perez 1990). The SAM (and PVWatts) implementation includes a modification of the Perez model that treats diffuse radiation as isotropic for $87.5^{\circ} \leq Z \leq 90^{\circ}$. See also (Perez Sky Diffuse Model 2014) for a general description of the model.

The Perez model differs from the isotropic and HDKR models in that it uses the empirical coefficients in Table 6 derived from measurements over a range of sky conditions and locations instead of mathematical representations of the sky diffuse components.

The parameters $a$ and $b$ describe the view of the sky from the perspective of the surface:

$$
\begin{aligned}
& a=\max (0, \cos A O I) \\
& b=\max \left(\cos 85^{\circ}, \cos Z\right)
\end{aligned}
$$

The sky clearness $\varepsilon$ with $\kappa=5.534 \times 10^{-6}$ and the sun zenith angle $Z$ in degrees:

$$
\varepsilon=\frac{\left(E_{d}+E_{b}\right) / E_{d}+\kappa Z^{3}}{1+\kappa Z^{3}}
$$

The absolute optical air mass with the incidence angle $b$ and sun zenith angle $Z$ in degrees:

$$
A M_{0}=\left[\cos b+0.15\left(93.9^{\circ}-Z\right)^{-1.253}\right]^{-1}
$$

The sky clearness $\Delta$ assumes an extraterrestrial irradiance value of $1,367.0 \mathrm{~W} / \mathrm{m}^{2}$ :

$$
\Delta=E_{d} \frac{A M_{0}}{1367}
$$


Table 6. Perez Sky Diffuse Irradiance Model Coefficients

\begin{tabular}{l|ccl|lcc}
\hline & $f_{11}$ & $f_{12}$ & \multicolumn{1}{c|}{$f_{13}$} & $f_{21}$ & $f_{22}$ & $f_{23}$ \\
\hline$\varepsilon \leq 1.065$ & -0.0083117 & 0.5877285 & -0.0620636 & -0.0596012 & 0.0721249 & -0.0220216 \\
$\varepsilon \leq 1.23$ & 0.1299457 & 0.6825954 & -0.1513752 & -0.0189325 & 0.065965 & -0.0288748 \\
$\varepsilon \leq 1.5$ & 0.3296958 & 0.4868735 & -0.2210958 & 0.055414 & -0.0639588 & -0.0260542 \\
$\varepsilon \leq 1.95$ & 0.5682053 & 0.1874525 & -0.295129 & 0.1088631 & -0.1519229 & -0.0139754 \\
$\varepsilon \leq 2.8$ & 0.873028 & -0.3920403 & -0.3616149 & 0.2255647 & -0.4620442 & 0.0012448 \\
$\varepsilon \leq 4.5$ & 1.1326077 & -1.2367284 & -0.4118494 & 0.2877813 & -0.8230357 & 0.0558651 \\
$\varepsilon \leq 6.2$ & 1.0601591 & -1.5999137 & -0.3589221 & 0.2642124 & -1.127234 & 0.1310694 \\
$\varepsilon>6.2$ & 0.677747 & -0.3272588 & -0.2504286 & 0.1561313 & -1.3765031 & 0.2506212 \\
\hline
\end{tabular}

The coefficients $F_{1}$ and $F_{2}$ are empirical functions of the sky clearness $\varepsilon$ and describe circumsolar and horizon brightness, respectively. The sun zenith angle $Z$ is in radians:

$$
\begin{aligned}
& F_{1}=\max \left[0,\left(f_{11}(\varepsilon)+\Delta f_{12}(\varepsilon)+Z f_{13}(\varepsilon)\right)\right] \\
& F_{2}=f_{21}(\varepsilon)+\Delta f_{22}(\varepsilon)+Z f_{23}(\varepsilon)
\end{aligned}
$$

SAM uses a lookup table with empirical values shown in Table 6 to determine the value of the $f$ coefficients in Equation 6.19 for a given sky clearness coefficient $\varepsilon$ from Equation 6.16 .

The isotropic, circumsolar, and horizon brightening components of the sky diffuse irradiance:

$$
\begin{array}{lll}
D_{i} & =E_{d}\left(1-F_{1}\right) \frac{1+\cos \beta}{2} \quad \text { if } 0^{\circ} \leq Z \leq 87.5^{\circ} & D_{i}=\frac{1+\cos \beta}{2} \quad \text { if } 87.5^{\circ}<Z<90^{\circ} \quad \text { (isotropic only) } \\
D_{c}=E_{d} F_{1} \frac{a}{b} & D_{c}=0 \\
D_{h}=E_{d} F_{2} \sin \beta & D_{h}=0
\end{array}
$$

The Perez incident diffuse irradiance:

$$
I_{d}=D_{i}+D_{c}+D_{h}
$$

\subsection{POA (Incident) Ground-reflected Irradiance}

The POA ground-reflected irradiance is solar energy that reaches the array surface after reflecting from the ground. The ground reflects light diffusely, so the ground-reflected irradiance is diffuse irradiance. It is a function of the beam normal irradiance and sun zenith angle, sky diffuse irradiance, and ground reflectance (albedo) (Liu 1963):

$$
I_{r}=\rho\left(E_{b} \cos Z+E_{d}\right) \frac{(1-\cos \beta)}{2}
$$

The albedo is either the set of twelve user-specified values from the Location and Resource input page, or the value from the weather file, depending on whether the option on the Location and Resource input page Use albedo in weather file if it is specified is checked (use_wf_albedo=1 in SSC) and there is albedo data in the weather file. NSRDB TMY3 weather files typically include albedo values, while the other formats do not. Otherwise, SAM uses the twelve monthly albedo values from the Location and Resource input page (a lbedo in SSC), assuming that the albedo is constant over a single month. 


\section{Effective POA Irradiance}

The effective plane-of-array (POA) irradiance is the solar irradiance incident on the array less any due to external shading, self shading, and soiling. A set of shading losses represents external shading and soiling, and may be generated outside of SAM by separate computer models or by measuring equipment and its associated software, or by SAM's 3D shade calculator.

SAM calculates self-shading losses (Section 7.4) for fixed arrays and for subarrays with one-axis tracking.

Note that SAM's snow cover model (Section 11.4) calculates a reduction in the subarray's DC output rather than a reduction in the incident irradiance.

The effective POA irradiance is the solar energy that reaches the top of the module cover. The module model (Section 10) accounts for the effect of the module cover on the energy that reaches the photovoltaic cell including angleof-incidence and reflection losses. Each module model uses a different approach to calculating these losses. If you are using POA irradiance data in the weather file as input (Section 6.1), SAM bypasses the module cover loss calculation.

\subsection{Nominal POA Irradiance}

The nominal POA irradiance $I$ in Watts per square meter is the sum of the beam POA irradiance, sky diffuse POA irradiance, and ground-reflected POA irradiance calculated as described in Section 6:

$$
I=I_{b}+I_{d}+I_{r}
$$

\subsection{External Shading}

When objects near the photovoltaic array, such as trees, buildings, roof protrusions and parapets cast shadows on the array, the shadows reduce the array's POA irradiance. This external shading of the array reduces both the beam and sky diffuse POA irradiance, which in turn reduces the array's DC electrical output. External shading is different from self shading of modules by neighboring modules, which is handled separately in SAM (Section 7.4).

On the Shading and Snow input page, for each active subarray in the system, an Edit shading button opens the Edit Shading Data window, where you can specify or import external shading loss data for the subarray. You can also use the 3D Shade Calculator (Section 8) to generate time-series shading data for each subarray in the system from a three-dimensional representation of the subarrays and nearby objects.

SAM represents external shading for each subarray with a set of time-series beam shading losses and a single annual sky diffuse shading loss. During a simulation, for each time step, it applies the beam loss to the nominal beam POA irradiance, and the external sky diffuse loss to the nominal diffuse POA irradiance to calculate the effective POA irradiance in each time step. If you choose the shading database option for partial shading (Section 7.3), SAM also calculates a DC loss that applies to the subarray's electrical output to account for voltage mismatch caused by partial shading of the array. If you bypass SAM's POA calculations by using POA irradiance as input (Section 6.1), SAM uses a decomposition model to determine the beam POA irradiance for shading loss calculations.

Each beam external shading loss is a percentage that represents a reduction in the beam POA irradiance for a given time step. The sky diffuse external shading loss is a single percentage that represents a reduction in the diffuse POA irradiance for the entire year. A shading loss of zero represents no shading. A shading loss of $100 \%$ represents complete blockage of the beam or diffuse irradiance.

The photovoltaic model requires a beam shading loss value for each time step. It can determine that value from a data array of time-series values, or it can determine the value from month-by-hour or sun azimuth-by-altitude 
Table 7. Effective POA Irradiance Variable Definitions

\begin{tabular}{|c|c|c|}
\hline Symbol & Description / Name in SAM & Name in SSC \\
\hline \multicolumn{3}{|c|}{ Inputs } \\
\hline$I_{b}$ & POA beam irradiance $\left(\mathrm{W} / \mathrm{m}^{2}\right)$ & poa_beam \\
\hline$I_{d}$ & POA sky diffuse irradiance $\left(\mathrm{W} / \mathrm{m}^{2}\right)$ & poa_skydiff \\
\hline$I_{r}$ & POA ground-reflected irradiance $\left(\mathrm{W} / \mathrm{m}^{2}\right)$ & poa_gnddiff \\
\hline$L_{t s}$ & table of time step beam shading losses (\%) & subarray $[n]$ _shading:timestep \\
\hline$L_{m h}$ & table of beam shading losses by time step (\%) & subarray $[n]$ _shading:mxh \\
\hline$L_{a z a l}$ & table of sun azimuth-by-altitude beam losses (\%) & subarray $[n]$ _shading:azal \\
\hline$L_{d n s}$ & sky diffuse shading loss $(\%)$ & subarray $[n]$ shading:diff \\
\hline$L_{\text {soilng }}$ & monthly soiling loss $(\%)$ & subarray $[n]$ _soiling \\
\hline \multicolumn{3}{|c|}{ Outputs } \\
\hline$I$ & ...Nominal POA total irradiance $\left(\mathrm{W} / \mathrm{m}^{2}\right)$ & ..poa_nom \\
\hline$G_{g, \text { shad }}$ & ...POA total irradiance after shad. only $\left(\mathrm{W} / \mathrm{m}^{2}\right)$ & ...poa_shaded \\
\hline & ...POA beam irr. after shad. and soiling $\left(\mathrm{W} / \mathrm{m}^{2}\right)$ & ...poa_eff_beam \\
\hline$G_{d}$ & ...POA diffuse irr. after shad. and soiling $\left(\mathrm{W} / \mathrm{m}^{2}\right)$ & ...poa_eff_skydiff \\
\hline$G$ & ...POA total irr. after shad. and soiling $\left(\mathrm{W} / \mathrm{m}^{2}\right)$ & ..ppoa_eff \\
\hline$S_{\text {bns }}$ & ...Beam irr. shad. factor & ...beam_shading_factor \\
\hline$O$ & ...Soiling loss & ...soiling_derate \\
\hline
\end{tabular}

Ellipses (...) indicate Subarray [ $\boldsymbol{n}]$ in SAM, and hourly_subarray [ $n]$ _ in SSC

For self-shading variable definitions, see Section 7.4

shading data arrays as described below. This makes it possible to use data generated by shade analysis tools and modeling software.

SAM's user interface provides access to conversion functions that allow for importing shading data from files created by either the PVsyst, Solmetric SunEye, or SolarPathfinder ${ }^{\mathrm{TM}}$ software as described in SAM Help - Shading and Snow (2016). The 3D Shade Calculator (Section 8), also part of the SAM user interface, can generate shading data from a 3D representation of the photovoltaic array and nearby objects. The 3D Shade Calculator and conversion functions translate the data from the files into the appropriate table listed above. They are not available in SSC.

SAM reads beam external shading losses from three different data arrays:

- Time step (subarray $[n]$ _shading:timestep) is a single column of time series external beam shading loss percentages, one for each time step of the year (8760 for hourly simulations).

In the SAM user interface, when you use the 3D shade calculator (Section 8) to calculate shade loss data, it automatically populates the time series data array based on the 3D shade analysis.

The Time Step option also works with the shading database lookup option to model the effects of partial shading of the array (Section 7.3).

- Month by hour (subarray [ $n]$ _shading: $m x h$ ) is a 24-by-12 table of 288 extermal beam shading loss percentages with one value for each hour of the day by month. For each month, SAM applies the same loss to a given hour of the day.

- Solar azimuth by altitude (subarray $[n]$ shading:azal) is a table of external beam shading loss percentages for a range of sun azimuth and altitude angles. You define the number of rows and columns in the table. SAM uses bilinear interpolation to calculate the shading loss for a given time step based on the solar position angles and shading losses from the table.

The sky diffuse external shading loss is a single value: 
- Constant sky diffuse shading loss (subarray $[n]$ _shading: diff) is a percentage that reduces the POA sky diffuse irradiance in all time steps.

The shading loss inputs are expressed as percentages. SAM converts each percentage to a factor using the equation:

$$
S=1-\frac{L}{100 \%}
$$

The beam external shading factor for a given time step is the product of the values in the three beam shading loss factors:

$$
S_{b n s}=S_{t s} S_{m h} S_{a z a l t}
$$

The sky diffuse external shading factor is $S_{\text {diff }}$.

\subsection{Partial External Shading and Shading Database Lookup}

For external shading, the size of the shadow on the photovoltaic array is expressed as a fraction of each subarray area, and is equal to the beam external shading loss. For example, in a given time step, an external beam shading loss of $20 \%$ means that a shadow prevents beam irradiance from reaching $20 \%$ of the subarray's surface. The effect of this shadow on the subarray's electrical output depends on the system design and type of modules.

For systems with strings of modules connected in parallel to a single inverter's maximum power point tracking input, the array's response to partial shading is non-linear because the shadows may cause the strings to operate at different voltages, introducing an additional loss caused by the voltage mismatch between strings. For this situation, SAM uses the empirical "database lookup" method described in MacAlpine (2015) to determine a loss that applies to the subarray's DC output to account for this effect.

This empirical method avoids the need for a computationally intensive electrical model of each photovoltaic cell in the array. The model uses a lookup table of pre-calculated values. Given the lookup table and 1) the number of parallel strings in a subarray, 2) the linear shade fraction on each string, and 3) the fraction of diffuse, the model estimates the subarray's DC power loss. The lookup table can handle a subarray with up to eight parallel strings. Refer to MacAlpine (2015) for additional details on this model. This method is appropriate for systems without microinverters or power electronics and subarrays with eight or fewer strings of crystalline Silicon modules.

To use this method, in SAM's Edit Shading window, enable beam irradiance shading losses by time step, and enable the partial shading model, and specify the number of strings in the subarray. You then provide a table of beam irradiance shading loss value for each string in the subarray. (You can use the 3D Shade Calculator described in Section 8 to generate the tables). Refer to SAM Help - Edit Shading Data (2018) for details.

For systems with microinverters or module-level power electronics such as DC-DC optimisers that minimize the effect of voltage mismatch caused by partial shading, a reasonable way to model partial external shading is to reduce the array's output by the shaded fraction, so that the DC output has a linear relationship with the beam POA shading loss. For these systems, a $20 \%$ beam shading loss would reduce the subarray's output by $20 \%$, plus any reduction in the sky diffuse POA irradiance caused by external shading. To model external shading for this type of system, you can provide a single table of time series beam irradiance shading loss values for the entire subarray without enabling the partial external shading model.

\subsection{Self Shading}

In SAM, self shading occurs when photovoltaic modules are arranged in parallel rows, and modules in one row cause a shadow on modules in a neighboring row. SAM can model self shading for fixed subarrays (no tracking) and subarrays with one-axis tracking. SAM does not model self shading for subarrays with two-axis or azimuth-axis 
tracking. Self shading is different from external shading caused by shadows on the array caused by nearby objects such as trees and buildings (Section 7.2).

To enable the self shading model for a subarray with no tracking (fixed) or one-axis tracking in SAM, after specifying the tracking and orientation options and ground coverage ratio (GCR) on the System Design page, on the Shading and Snow page, for the subarray's Self shading type input, choose Standard (Non-linear) for a subarray with crystalline silicon photovoltaic cells, or choose Thin film (Linear) for a subarry with thin-film modules. SAM does not automatically choose the correct self-shading option based on the module properties. For a subarray with one-axis tracking, you may also want to enable backtracking (Section 5.3.2) on the System Design page.

In SSC, to enable self shading, set the pvsamv1 input variable subarray $[n]$ _shade_mode $=1$ for the nonlinear option, and subarray $[n]$ _shade_mode $=2$ for the linear option. Set the value to zero to ignore self shading.

The non-linear self-shading option is for modules with mono- or poly-crystalline silicon photovoltaic cells, and assumes that modules consist of photovoltaic cells with three bypass diodes so that a shaded module's output decreases in steps of one third of the module's total output. The linear option is for thin-film modules, and assumes that a shaded module's output decreases linearly with the portion of the module that is shaded.

When you use POA irradiance data in the weather file, SAM must run a POA decomposition model to estimate the beam POA irradiance. If the measured POA data already accounts for the effect of self shading, then you should not enable self shading in SAM.

The self-shading algorithm is described in detail in Section 9.

The self-shading algorithm calculates three factors for the non-linear option:

- Sky diffuse self-shading factor $S_{d s s}$ that reduces the diffuse POA irradiance

- Ground-reflected diffuse self-shading factor $S_{g s s}$ that also reduces the POA diffuse irradiance

- DC self-shading factor $F_{d c s s}$ that accounts for the effect of self shading on the beam POA irradiance by reducing DC electrical output of the subarray

The self-shading algorithm calculates a single factor for the linear option:

- Linear self-shading factor $S_{b s s}$ that reduces the beam POA irradiance

\subsection{Soiling}

Soiling losses are caused by a reduction in the POA irradiance due to dust and dirt on the module surface. SAM accounts for soiling losses using a set of monthly soiling loss percentages that are user inputs on the Losses input page (subarray $[n]$ _soiling in SSC). The soiling loss applies to both the beam and diffuse components of the POA irradiance.

SAM converts each soiling loss percentage to a factor:

$$
O=1-\frac{L}{100 \%}
$$

For each time step of each month, SAM applies that month's soiling factor $O$ to all components of the POA irradiance.

\subsection{Effective Irradiance}

The effective irradiance is the irradiance value that the module models (Section 10) use as input. The effective irradiance is the solar irradiance incident on the plane of the array calculated from the irradiance data in the weather 
file less any shading and soiling losses. SAM reports the effective irradiance for each subarray in Watts per square meter as POA total irradiance after shading and soiling.

SAM also reports the effective irradiance after shading only (and before soiling) for reference. It is an intermediate value that is not used in any calculations. The beam, sky diffuse, and ground-reflected components of the effective irradiance after shading only are:

$$
\begin{aligned}
G_{b s h a d} & =I_{b} S_{b n s} S_{1 x s s} S_{b s s} \\
G_{d s h a d} & =I_{d} S_{d n s} S_{d s s} \\
G_{r s h a d} & =I_{r} S_{r s s}
\end{aligned}
$$

Where the self shading loss factors apply as follows:

$S_{1 x s s}$ non-linear option with one-axis tracking

$S_{b s s}$ linear option

$S_{d s s}$ non-linear option with fixed subarray

$S_{r s s}$ non-linear option with fixed subarray

The global effective irradiance after shading only:

$$
G_{\text {shad }}=G_{b s h a d}+G_{d s h a d}+G_{r s h a d}
$$

The components of the effective irradiance after shading and soiling are, where $O$ is the soiling factor:

$$
\begin{aligned}
G_{b} & =G_{\text {bshad }} O \\
G_{d} & =G_{d \text { shad }} O \\
G_{r} & =G_{\text {rshad }} O
\end{aligned}
$$

SAM reports the global effective irradiance $G$ and the total diffuse effective irradiance $G_{d, t}$ in the results. (The module models use the component values in Equation 7.7 as input rather than the global value.):

$$
\begin{aligned}
G & =G_{b}+G_{d}+G_{r} \\
G_{d, t} & =G_{d}+G_{r}
\end{aligned}
$$

SAM also reports the effective beam shading factor $S_{b}$ in the results $\left(S_{b n s}\right)$ is the nearby-object shading factor from Equation 7.3:

$$
S_{b}= \begin{cases}S_{b n s} S_{s s} O & \text { for fixed self shading } \\ S_{b n s} O & \text { for one-axis self shading }\end{cases}
$$




\section{3D Shade Calculator}

The 3D shade calculator calculates a set of beam and diffuse shading losses from a three-dimensional representation of a "scene" that consists of the photovoltaic array and any nearby objects that might cause shadows to fall on the array. Active surface objects represent the photovoltaic array and a set of pre-defined three-dimensional shapes represent nearby shading objects. The calculator is part of the SAM user interface, but not part of SSC. It is described in detail in SAM Help - 3D Shade Calculator (2018)

Each object in the scene is a set of polygons with $x-y-z$ coordinates. Polygons associated with the photovoltaic array or modules are marked as active surfaces, so that the calculator can determine for which surfaces shading and blocking should be evaluated. The geometry system uses a right-handed coordinate system in which $+x$ points east, $+y$ points north, and $+z$ points normal out of the ground towards the sky.

The calculator's scene editor, shown in Figure 4, allows you to draw the scene using boxes, cylinders, trees, and roof panes for shading objects, and active surfaces for the photovoltaic array. Each object has a set of properties (position, size, and shape) that the calculator uses to generate the polygons for determining the size and shape of shadows on the active surfaces.

The String and Subarray properties of an active surface determine how many tables of shading loss data the calculator generates. If all active surfaces are assigned the same String and Subarray number, the calculator generates a single table for the entire array. For a scene with more than one active surface, the calculator generates a separate table of beam irradiance shade losses for each string in each subarray and associates it with the appropriate subarray in SAM. These properties make it possible to use the 3D Shade Calculator to generate data for SAM's partial external shading model described in Section 7.3.

\subsection{Beam Irradiance Loss}

The beam irradiance loss reduces the beam POA irradiance to represent the effect of shading on a subarray at a given sun position. The 3D Shade Calculator can generate diurnal (hour-by-month) or time series (hourly or sub-hourly) tables of shading loss values. When used to generate shade data for SAM, it passes time series tables to SAM.

The calculator's geometric algorithm assumes a linear relationship between the size of the shadow on the active surface and the beam irradiance incident on the surface. The procedure for each active surface at each time step is as follows:

1. Calculate the solar zenith and azimuth angles for the current time stamp (month, day, hour, minute) and location (latitude, longitude, time zone).

2. Create a list of polygons from the scene objects in untransformed 3D space.

3. Calculate the axis $x, y$, and $z$ rotation angles corresponding to a rotation of the scene associated with the current sun position. In other words, the 3D scene is rotated so that it is shown as if it were observed from the sun.

4. Using this 3D rotation matrix, calculate the rotated coordinates of each polygon vertex to transform the whole scene into the line of sight from the sun using a parallel projection. This assumes the sun is infinitely far away and that the sun rays reaching the scene are essentially parallel to one another.

5. Using a backface culling algorithm, eliminate polygons from the scene that face away from the sun and are not visible.

6. Apply the binary space partitioning (BSP) algorithm to sort all the remaining visible polygons in back-to-front order. Polygons at the "front" are closest to the sun. 


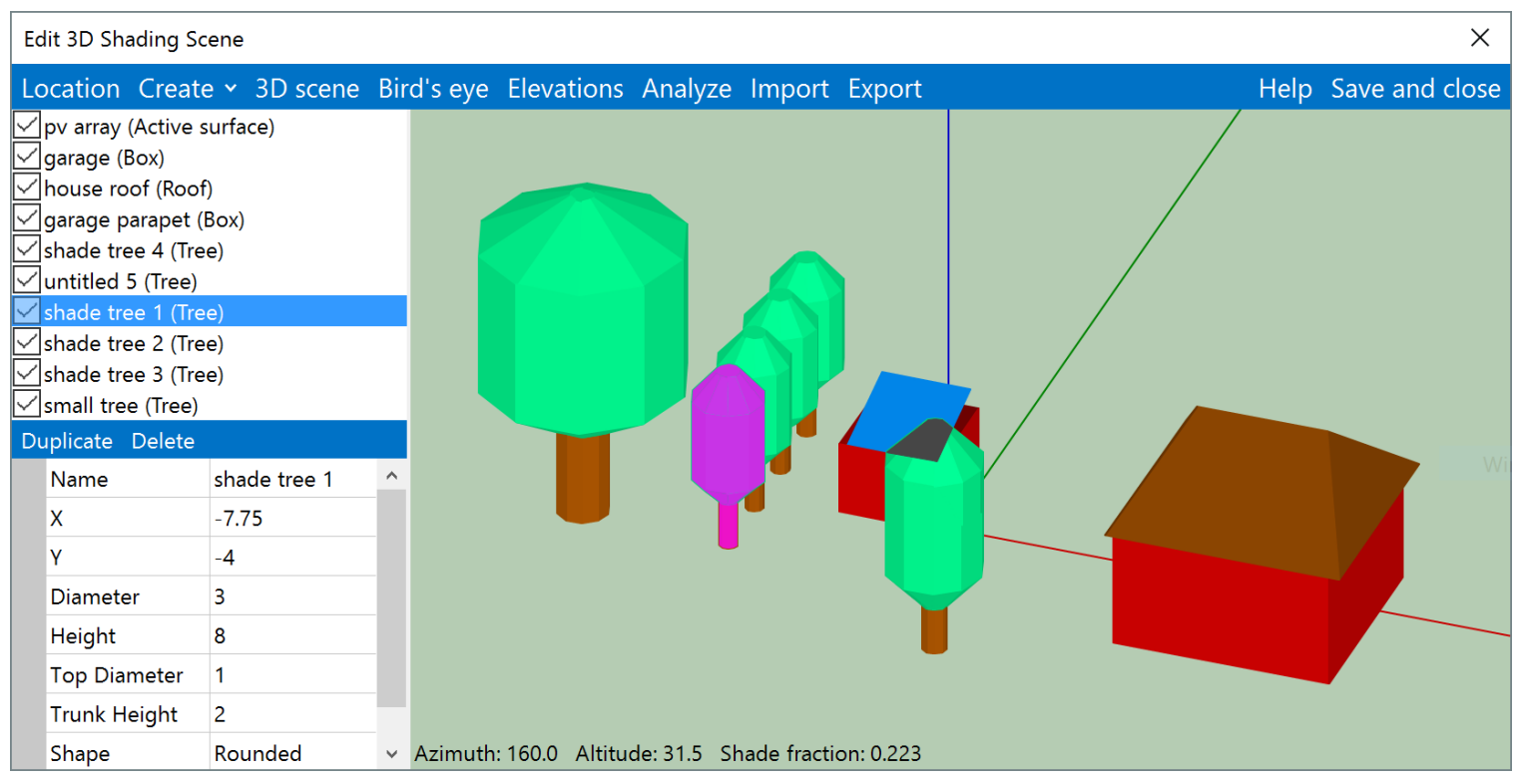

Figure 4. 3D scene editor for shading calculations

7. Discard the transformed $z$ coordinate to effectively "flatten" the scene into two dimensions, as if it were viewed from the infinitely far away sun.

8. For each active surface:

A. Create a list of polygons (regular and other active surfaces) that are in front of the active surface, that is, between it and the sun.

B. Using a 2D polygon clipping algorithm, determine the intersection between the active surface and the list of potential blocking polygons.

C. The resulting intersection polygon's area divided by the active surface polygon area gives the shade fraction for that active surface at the current time (sun position).

9. For each active surface with the same values of the String and Subarray properties, determine the appropriate shade fractions for each piece from the sum total of the intersected (shaded) areas divided by the sum total of the unshaded active surface areas associated with each string or subarray.

Once the shade fraction for each portion of the photovoltaic array is known at each time step, it is converted into a loss percentage and automatically entered into the SAM beam irradiance shading loss table in the user interface. These values are passed directly to the SSC simulation model for calculating system electricity generation.

\subsection{Diffuse Irradiance Loss}

The 3D shading calculator also calculates a single diffuse irradiance loss that applies to each time step of the year for the entire array. Diffuse irradiance loss is caused by blocking of the sky dome by nearby objects. The procedure is as follows:

1. Divide the hemispherical sky dome into sections of some number of azimuth and zenith angle divisions. By default, SAM uses 1 degree increments in both directions, for a total of $360 * 90=32400$ divisions.

2. For each position, transform the scene to the solar azimuth and zenith angle. 
3. Calculate the intersected (shaded) areas on each active surface polygon using the same procedure as for the beam irradiance shading loss.

4. Integrate the shade loss over all positions in the sky dome by multiplying the observed shaded fraction with the solid angle of spherical integration $\sin \left(\theta_{z}\right)$. This accounts for the fact that the sky dome divisions at the top of the hemisphere are much smaller than near $\theta_{z} \approx 0$.

This procedure results in an estimate of the view factor of the active surfaces in each subarray to the sky dome, and hence the effective diffuse irradiance loss. The model assumes an isotropic diffuse sky, and does not adjust for increased circumsolar diffuse irradiance. 


\section{Self Shading Algorithm}

This section describes SAM's self-shading model. See Section 7.4 for a general description and instructions for enabling the model. The algorithm is presented here as a separate section for clarity because of the length of the algorithm.

The non-linear option of the self-shading model is intended for modeling systems with crystalline silicon modules and assumes that blocking diodes cause the module's response to partial shading of the module to be non-linear. The non-linear option assumes that each module contains three blocking diodes $(d=3)$ and characterizes the non-linear response with an empirically determined factor applied to the subarray's electrical output and a reduction in diffuse POA irradiance.

The linear model option is intended for systems with thin-film photovoltaic modules, and assumes that the output of a partially shaded module responds linearly with a reduction in POA irradiance. The linear option characterizes effect of self shading on the module as a reduction in the beam POA irradiance equal to the fraction of the module surface that is shaded.

The self-shading model calculates different loss factors depending on the shade model option, and whether the array is fixed or uses one-axis tracking:

- For a subarray with the non-linear self shading option:

1. Reduction in POA sky diffuse and POA ground-reflected diffuse irradiance.

2. Reduction in the subarray's DC output to account for the effect of self shading on beam POA irradiance.

- For a subarray with the the linear self-shading option:

1. Reduction in beam POA irradiance

Table 8 and Figure 5 show the variables used to calculate the fixed self-shading factors. The equations and algorithm are described in (Appelbaum 1979) and (Deline 2013).

\subsection{Self Shading Assumptions}

The self-shading model makes a set of simplifying assumptions to minimize the number of inputs:

- The module dimensions are determined from the module area $A$ and aspect ratio of $R_{\text {aspect }}$ inputs. The aspect ratio is the ratio of module length to width. The model uses this approach to make it possible to use data from module databases that include module area but not length and width data.

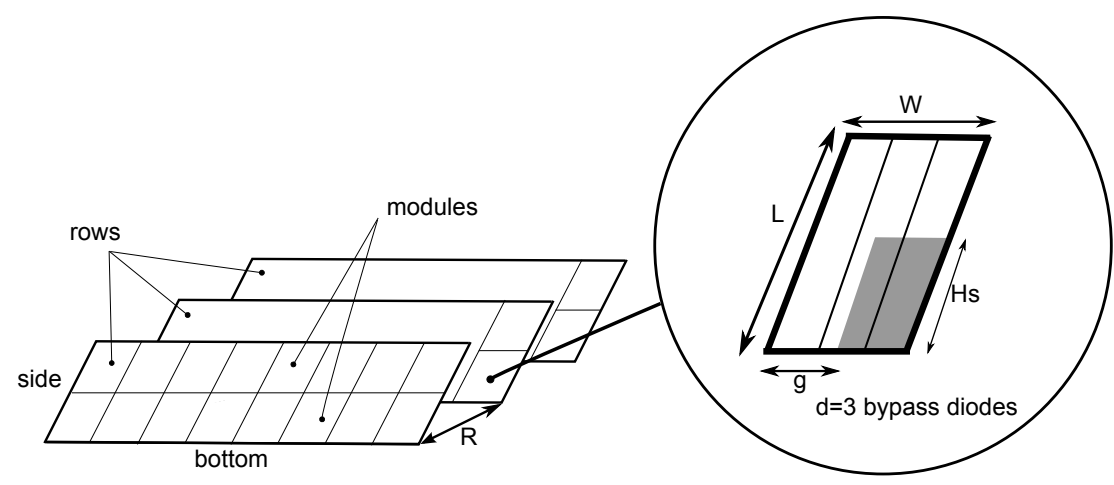

Figure 5. Shadow Dimensions for Portrait Module Orientation 
Table 8. Self Shading Variable Definitions

\begin{tabular}{|c|c|c|}
\hline Symbol & Description / Name in SAM & Name in SSC \\
\hline \multicolumn{3}{|c|}{ Inputs } \\
\hline$M_{\text {total }}$ & Modules in subarray & - \\
\hline$M_{\text {string }}$ & Number of modules per string & - \\
\hline$M_{\text {side }}$ & Number of modules along side of row & subarray [n]_nmody \\
\hline$M_{\text {bottom }}$ & Number of modules along bottom of row & subarray $[n] \_n m o d x$ \\
\hline$N_{\text {strings }}$ & Number of strings in parallel & strings_in_parallel \\
\hline$\sigma_{\text {lim }}$ & Tracker rotation limit & subarrayn_rotlim \\
\hline$G C R$ & GCR, ground coverage ratio & subarray $[n]$ gcr \\
\hline$A_{m}$ & module area $\left(\mathrm{m}^{2}\right)$ & {$[\mathrm{spe}, \mathrm{cec}, 6 \mathrm{par}, \mathrm{snl}]$ _area } \\
\hline$R_{\text {aspect }} m$ & module aspect ratio (length to width) & module_aspect_ratio \\
\hline$\beta_{s}$ & surface tilt angle (deg) & subarray $[n]$ tilt \\
\hline$\gamma_{s}$ & surface azimuth angle (deg) & subarray $[n]$ _azimuth \\
\hline$Z$ & sun zenith angle & - \\
\hline$\gamma$ & sun azimuth angle (deg) & - \\
\hline$E_{b}$ & direct normal irradiance $\left(\mathrm{W} / \mathrm{m}^{2}\right)$ & - \\
\hline$G_{b}$ & beam POA irradiance $\left(\mathrm{W} / \mathrm{m}^{2}\right)$ & - \\
\hline$G_{d}$ & diffuse POA irradiance (sky and ground) $\left(\mathrm{W} / \mathrm{m}^{2}\right)$ & - \\
\hline$\rho$ & albedo* & albedo \\
\hline \multicolumn{3}{|c|}{ Outputs: Non-linear option } \\
\hline$S_{d s s}$ & sky diffuse factor / Self-shading diffuse derate & {$[\ldots]$...s__diffuse_derate } \\
\hline$S_{r s s}$ & ground diffuse factor / Self-shading reflected derate & {$[\ldots]$...ss_reflected_derate } \\
\hline$F_{d c s s}$ & DC loss factor / Self-shading derate & {$[\ldots]_{\text {_. ss_derate }}$} \\
\hline \multicolumn{3}{|c|}{ Outputs: Linear option } \\
\hline$S_{b s s}$ & beam diffuse factor / Self-shading linear derate & {$[\ldots] \_s s \_l i n e a r \_d e r a t e$} \\
\hline
\end{tabular}

Ellipses (...) indicate subarray $[n]$.

For the non-linear option, SAM sets the linear output to 1.

For the linear option, SAM sets the non-linear outputs to 1.

*Albedo may be from weather file or set to default value of 0.2 if file does not contain albedo data. 
- For the non-linear option, each module has three bypass diodes $d=3$ so that the module is made up of three "submodules." A submodule is a string of photovoltaic cells in the module protected by a single bypass diode. For example, a 60-cell module would consist of three submodules of 20 cells each.

- A partially shaded submodule behaves in the same way as it would if the entire submodule were uniformly shaded.

- Modules are wired together in strings parallel to the ground (horizontal strings) so that the number of modules along the bottom of a subarray row is a multiple of the number of modules per string.

- Parallel strings in the subarray are uniformly shaded.

Based on the simplifying assumptions listed above, the number of rows $N_{\text {rows }}$ in a subarray is:

$$
N_{\text {rows }}=\left\lfloor\frac{M_{\text {total }}}{M_{\text {side }} M_{\text {bottom }}}\right\rfloor
$$

where the total number of modules in the array $M_{\text {total }}$ is:

$$
M_{\text {total }}=M_{\text {string }} N_{\text {strings }}
$$

If $M_{\text {total }}$ is not an even multiple of the product $M_{\text {side }} N_{\text {bottom }}$, SAM generates a simulation message indicating that the self-shading configuration does not match the subarray configuration, but still calculates the DC loss factor as described below.

SAM calculates the module length and width from the module area $A$ in $\mathrm{m}^{2}$ and aspect ratio $R_{\text {aspect }}$ :

$$
\begin{gathered}
W=\sqrt{\frac{A_{m}}{R_{\text {aspect }}}} \\
L=W R_{\text {aspect }}
\end{gathered}
$$

The module area is either from the module library, or an input, depending on the module model (see Section 10.1).

The length of the side of a row (distance from the bottom edge to the top edge of a row):

$$
B= \begin{cases}M_{\text {side }} L & \text { portrait module orientation } \\ M_{\text {side }} W & \text { landscape module orientation }\end{cases}
$$

The distance between bottom edges of neighboring rows:

$$
R=\frac{B}{G C R}
$$

where $G C R$ is the ground coverage ratio input.

The sun altitude angle:

$$
\alpha=90^{\circ}-Z
$$

\subsection{Non-linear Option: Diffuse POA Irradiance Reduction}

Some diffuse radiation is always blocked by neighboring rows of modules, regardless of whether the rows block beam radiation (Goswami 1989). The diffuse radiation consists of a sky diffuse component and a ground-reflected component, both of which are affected in this way. 


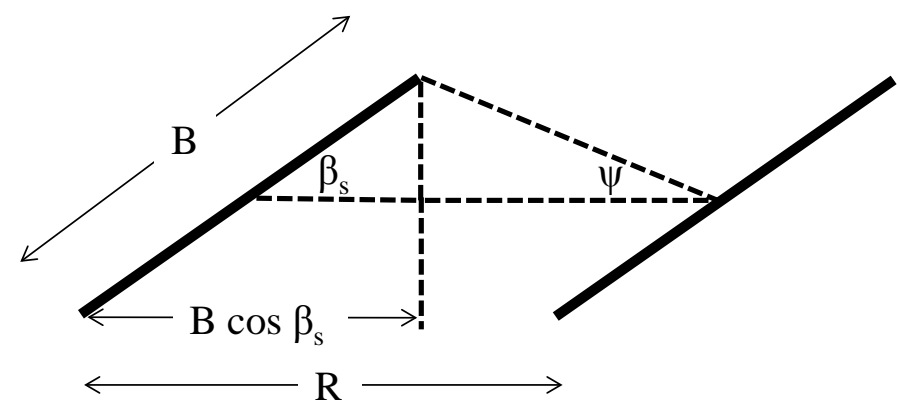

Figure 6. Side View of Two Rows with Self-shading Mask Angle Variables

For the non-linear option, for the purposes of self-shading calculations, SAM assumes isotropic sky diffuse irradiance, so that the total horizontal diffuse irradiance $G_{d h}$ is:

$$
G_{d h}=G_{d}\left(\frac{2}{1+\cos \beta_{s}}\right)
$$

The beam horizontal irradiance is:

$$
G_{b h}=E_{b} \cos Z
$$

The reduction in sky diffuse irradiance incident on the portion of the subarray shaded by neighboring rows is a function of the surface tilt angle $\beta_{s}$ and mask angle $\psi$ with a derating term $\frac{N_{\text {rows }}-1}{N_{\text {rows }}}$ for the number of interior rows in the array:

$$
G_{\text {sky,red }}=G_{d}-G_{d h}\left(1-\cos ^{2} \frac{\psi}{2}\right) \frac{N_{\text {rows }}-1}{N_{\text {rows }}}
$$

The shade mask angle is the minimum array tilt angle at which the view of the sky at a given point along the side of the row is obstructed by a neighboring row as shown in Figure 6 from Passias (1984):

$$
\psi=\arctan \frac{(B) \sin \beta_{s}}{R-B \cos \beta_{s}}
$$

SAM uses the "worst case" approach described in (Deline 2013a), where the diffuse irradiance mask angle is calculated for the bottom of the array rather than averaged across the entire array.

The sky diffuse shading factor for the non-linear option is then:

$$
S_{d s s}=\frac{G_{s k y, \text { red }}}{G_{d}}
$$

Ground diffuse irradiance is beam irradiance reflected onto modules in the subarray from the ground. The first row in the subarray is not affected by self shading. The length of ground in front of each shaded row that reflects beam radiation onto the row, with $Y$ constrained to a minimum value of 0.00001 :

$$
Y=R-B\left(\frac{\sin \left(180^{\circ}-\alpha-\beta_{s}\right)}{\sin \alpha}\right)
$$


The view factor on the first row $F_{1}$, and the beam and diffuse reflected component factors $F_{2}$ and $F_{3}$, respectively:

$$
\begin{aligned}
& F_{1}=\rho \sin ^{2} \frac{\beta_{s}}{2} \\
& F_{2}=\frac{\rho}{2}\left(1+\frac{Y}{B}-\sqrt{\frac{Y^{2}}{B^{2}}-\frac{2 Y}{B} \cos \left(180^{\circ}-\beta_{s}\right)+1}\right) \\
& F_{3}=\frac{\rho}{2}\left(1+\frac{R}{B}-\sqrt{\frac{R^{2}}{B^{2}}-\frac{2 R}{B} \cos \left(180^{\circ}-\beta_{s}\right)+1}\right)
\end{aligned}
$$

The reduced ground-reflected diffuse POA irradiance on the entire subarray:

$$
G_{\text {gnd,red }}=\left(\frac{F_{1}+F_{2}\left(N_{\text {rows }}-1\right)}{N_{\text {rows }}}\right) G_{b h}+\left(\frac{F_{1}+F_{3}\left(N_{\text {rows }}-1\right)}{N_{\text {rows }}}\right) G_{d h}
$$

The ground diffuse shading factor for the non-linear option is then:

$$
S_{r s s}= \begin{cases}S_{r s s}=\frac{G_{g n d, r e d}}{F_{1}\left(G_{b h}+G_{d h}\right)} & \text { if } F_{1}\left(G_{b h}+G_{d h}\right)>0 \\ 1 & \text { if } F_{1}\left(G_{b h}+G_{d h}\right) \leq 0\end{cases}
$$

\subsection{Shadow Dimensions}

The shadow dimensions are defined by a shadow height $H_{S}$ and shadow displacement $g$ as shown in Figure 5. The equations are based on Appelbaum (1979).

The shadow height $H_{S}$ is required to calculate the reduction in beam POA irradiance for both the non-linear (Equations 9.21 and 9.22) and linear (Equation 9.20) options.

The shadow dimensions equations assume that a surface azimuth angle $\gamma_{s}$ of zero is for both a south-facing surface in the Northern Hemisphere and a north-facing surface in the Southern Hemisphere. Because this differs from SAM's convention where $\gamma_{s}=0$ is for a north-facing surface and $\gamma_{s}=180^{\circ}$ is for a south-facing surface regardless of the hemisphere, the equations use the effective surface azimuth $\gamma_{s, e f f}$ :

$$
\gamma_{s, e f f}=\gamma-\gamma_{s}
$$

For an array that is not horizontal and for hours when the sun is up, the shaded portion of the array is:

$$
\begin{aligned}
& P_{y}=B\left(\cos \beta_{s}+\cos \gamma_{s, \text { eff }} \frac{\sin \beta_{s}}{\tan (90-Z)}\right) \\
& P_{x}=B \sin \beta_{s}\left(\frac{\sin \gamma_{s, \text { eff }}}{\tan (90-Z)}\right)
\end{aligned}
$$

The shadow displacement $g$ :

$$
g=R \frac{P_{x}}{P_{y}}
$$

with the following constraints:

$$
g= \begin{cases}|g| & \text { when } g<0 \\ 0 & \text { when } P_{y}=0 \\ 0 & \text { when } M_{\text {bottom }}>M_{\text {string }} \\ B & \text { when } g>B\end{cases}
$$


The shadow height $H_{s}$ in Figure 5 is:

$$
H_{S}= \begin{cases}B\left(1-\frac{R}{P_{y}}\right) & \text { for fixed subarray } \\
B\left(S_{1 x s s}\right) & \text { for one-axis tracking (see Equation 9.52) }\end{cases}
$$

with the following constraints:

$$
H_{S}= \begin{cases}0 & \text { when } P_{y}=0 \\ \left|H_{S}\right| & \text { when } g<0 \\ B & \text { when } H_{S}>B\end{cases}
$$

\subsection{Linear Option: Beam POA Irradiance Reduction}

For the linear self-shading option, the reduction in beam POA irradiance is proportional to the relative shaded area of the subarray:

$$
S_{b s s}= \begin{cases}H_{s} \frac{L-g}{B L} & \text { for fixed subarray } \\
S_{1 x s s} & \text { for one-axis tracking (Equation 9.52) }\end{cases}
$$

\subsection{Non-linear Option: DC Loss Factor}

For the non-linear shading option, the effect of the reduction in beam POA irradiance is modeled as a reduction in the subarray's electrical DC output, and depends on the number of diodes in each module, which SAM assumes to be three $d=3$.

When there is self shading, some fraction $X$ of each row in the subarray is shaded. In each row, a fraction $S$ of the number of modules along the side is of the row is shaded (Deline 2013). The equations for $S$ and $X$ are from Deline (2013a).

For landscape module orientation, the case where $H_{S}>W$ assumes complete shading even though in a given string, some modules will be completely shaded while others are only partly shaded:

$$
\begin{gathered}
X=\left\lceil\frac{H_{S}}{W}\right\rceil \frac{R-1}{R M_{\text {side }}} \\
S= \begin{cases}\left\lceil\frac{H_{S} d}{W}\right\rceil d^{-1}\left(1-\left\lfloor\frac{g}{L}\right\rfloor M_{\text {bottom }}^{-1}\right) & \text { when } H_{S} \leq W \text { for a fixed subarray } \\
1 & \text { when } H_{S}>W, \text { or for one-axis tracking }\end{cases}
\end{gathered}
$$

Note that $\lceil\ldots\rceil$ and $\lfloor\ldots\rfloor$ indicate the ceiling and floor functions, respectively.

For portrait module orientation, the configuration shown in Figure 5:

$$
\begin{gathered}
X=\left\lceil\frac{H_{S}}{L}\right\rceil \frac{R-1}{R M_{\text {side }}} \\
S= \begin{cases}1-\left\lfloor\frac{g d}{W}\right\rfloor\left(d M_{\text {bottom }}\right)^{-1} & \text { for a fixed subarray } \\
1 & \text { for one-axis tracking }\end{cases}
\end{gathered}
$$

SAM assumes that each module has three bypass diodes so that $d=3$ (See Section 9.1).

To calculate the beam self-shading DC loss factor, SAM first determines the shadow dimensions (Section 9.3), and then determines the DC loss factor using empirically determined relationships as described below. 
The self-shading DC loss factor accounts for the reduction in beam POA irradiance caused by self shading. Its calculation is based on the proposed simplified analytical model from (Deline 2013) and requires the following variables:

- The shading fractions $S$ and $X$ described in Section 9.3.

- Fraction of solar irradiance reaching the shaded submodule $E_{e}$, which is a function of the reduction in diffuse POA irradiance from the sky and ground described in Section 9.2.

- Submodule fill factor $F_{\text {fill }}$ determined from the module nameplate parameters.

The ratio of diffuse POA irradiance to total POA irradiance is a measure of the solar irradiance reaching the shaded submodule:

$$
R_{d t}=\frac{G_{s k y, r e d}+G_{\text {gnd }, \text { red }}}{G_{b}+G_{\text {sky,red }}+G_{\text {gnd }, \text { red }}}
$$

The fill factor depends on the photovoltaic module's rated maximum power, open-circuit voltage, and short-circuit current:

$$
F_{f i l l}=\frac{P_{m p 0}}{V_{o c 0} I_{s c 0}}
$$

The DC loss factor equation requires three coefficients, which were determined using the empirical analysis described in Deline (2013):

$$
\begin{aligned}
& C_{1}=\left(109 F_{\text {fill }}-54.3\right) e^{-4.5 X} \\
& \left.C_{2}=-6 X^{2}+5 X+0.28 \quad \text { (if } X>0.65, \text { set } X=0.65\right) \\
& C_{3}=\max \left[\left(-0.05 R_{d t}-0.01\right) X+\left(0.85 F_{\text {fill }}-0.7\right) R_{d t}-0.0855 F_{\text {fill }}+0.05, R_{d t}-1\right]
\end{aligned}
$$

The DC loss factor for fixed self shading is the ratio of the power of the shaded string to the power of the unshaded string. The choice of equation for calculating the DC loss factor equation depends on the magnitude of the shading factors:

- $F_{d c 1} \quad$ Small $X$ and small $S$

- $F_{d c 2} \quad$ Large $X$

- $F_{d c 3} \quad$ Large $S$

The DC loss equations for each shade factor condition are:

$$
\begin{aligned}
& F_{d c 1}=1-C_{1} S^{2}-C_{2} S \\
& F_{d c 2}= \begin{cases}\frac{X-S\left(1+0.5 d V_{m p}^{-1}\right)}{X} & \text { if } X>0 \\
0 & \text { if } X=0\end{cases} \\
& F_{d c 3}=C_{3}(S-1)+R_{d t}
\end{aligned}
$$

SAM chooses the maximum of the three factors to calculate the system DC loss factor accounting for the reduction in beam POA irradiance due to self shading, and constrains the factor to between 0 and 1 :

$$
F_{d c s s}=X \max \left(F_{d c 1}, F_{d c 2}, F_{d c 3}\right)+(1-X)
$$




\subsection{One-axis tracking: Shaded Fraction}

This section describes SAM's self-shading geometry calculations for one-axis trackers $S_{1 x s s}$ for subarrays with oneaxis tracking. SAM uses the shaded fraction to calculate the shadow height (Equation 9.19) and the reduction in beam POA irradiance for the linear option (Equation 9.20).

This model was developed by NREL specifically for SAM, so this section is the only documentation of the model. The source code for these calculations is available for download. For a link to the source code, see the SAM Source Code (2016) citation in the References section of this manual.

For the purpose of determining the shaded fraction for subarrays with one-axis tracking, SAM models the subarray as three surfaces, called panels, with the same tilt, azimuth, and rotation angle as the subarray. The three rectangular surfaces have the same arbitrary dimensions. The algorithm determines the position of the four corners of each panel, and then based on the position of the sun determines whether either of the outside panels blocks beam radiation from the sun to the middle panel.

This approach makes it possible to calculate the shaded fraction of the subarray using only the ground coverage ratio (GCR) in addition to the subarray surface angles (Section 5) and sun angles (Section 4.2). The GCR describes the spacing of rows in the subarray, and is defined as the ratio of area of the subarray when its modules are horizontal to the total ground area, which is defined by the edges of modules at the outer boundary of the array.

\subsubsection{Sun Position Unit Vectors}

The sun position unit vector $\hat{\mathbf{s}}$ represents the direction of the sun calculated from the sun azimuth angle $\alpha$ and zenith angle $\zeta$ in degrees (Section 4.2).

The solar altitude angle in degrees is:

$$
\alpha=90^{\circ}-\zeta
$$

The sun position unit vector depends on the solar altitude and azimuth angles:

$$
\begin{aligned}
0 & \leq \alpha \leq 90^{\circ}: & 90^{\circ}<\alpha \leq 180^{\circ}: \\
\mathbf{s} & =\left[\begin{array}{c}
\cos \alpha \sin \beta \\
\cos \alpha \cos \beta \\
\sin \alpha
\end{array}\right] & \mathbf{s}=\left[\begin{array}{c}
\cos \alpha \sin \left(180^{\circ}-\beta\right) \\
-\cos \alpha \cos \left(180^{\circ}-\beta\right) \\
\sin \alpha
\end{array}\right] \\
180^{\circ} & <\alpha \leq 270^{\circ}: & 270^{\circ}<\alpha \leq 360^{\circ}: \\
\mathbf{s} & =\left[\begin{array}{c}
-\cos \alpha \sin \left(\beta-180^{\circ}\right) \\
-\cos \alpha \cos \left(\beta-180^{\circ}\right) \\
\sin \alpha
\end{array}\right] & \mathbf{s}=\left[\begin{array}{c}
-\cos \alpha \sin \left(360^{\circ}-\beta\right) \\
\cos \alpha \cos \left(360^{\circ}-\beta\right) \\
\sin \alpha
\end{array}\right]
\end{aligned}
$$

The unit vector in the direction of the sun is the Euclidean norm of $\mathbf{s}$ :

$$
\hat{\mathbf{s}}=\|\mathbf{s}\|
$$

\subsubsection{Panel Vertices}

The next step is to find the vertices (corners) of the three rectangular panels. The panels have the same same orientation as the subarray and with spacing defined by the ground coverage ratio.

First, arbitrarily define the panel length and width:

$$
\begin{aligned}
W & =1 \\
L & =10
\end{aligned}
$$


These panel dimensions make it possible to express the distance between rows $D$ in terms of the ground coverage ratio $g c r$, defined as the ratio between the module area $A_{m}$ and ground area $A_{g}$ :

$$
D=\frac{1}{G C R}-1
$$

When each of the three panels is in the horizontal position, the four vertices $(x, y, z)$ of the three panels are:

$$
\begin{aligned}
& \mathbf{P}_{0, \text { horiz }}=\left[\begin{array}{ccc}
W / 2 & 0 & 0 \\
W / 2 & L & 0 \\
-W / 2 & L & 0 \\
-W / 2 & 0 & 0
\end{array}\right] \quad \begin{array}{ll} 
\\
\text { Vertex 0 } & \text { Vertex 1 } \\
\text { Vertex 2 } & \text { Vertex 3 }
\end{array} \\
& \mathbf{P}_{1, \text { horiz }}=\left[\begin{array}{ccc}
W / 2+D+W & 0 & 0 \\
W / 2+D+W & L & 0 \\
-W / 2+D+W & L & 0 \\
-W / 2+D+W & 0 & 0
\end{array}\right] \\
& \mathbf{P}_{2, \text { horiz }}=\left[\begin{array}{ccc}
W / 2+2(D+W) & 0 & 0 \\
W / 2+2(D+W) & L & 0 \\
-W / 2+2(D+W) & L & 0 \\
-W / 2+2(D+W) & 0 & 0
\end{array}\right] \quad \text { Panel 2 }
\end{aligned}
$$

The vertices for Panel 0 rotated about the $y$-axis are given by the matrix product:

$$
\mathbf{P}_{0, \text { rot }}=\mathbf{P}_{0, \text { horiz }}\left[\begin{array}{ccc}
\cos \sigma & 0 & \sin \sigma \\
0 & 1 & 0 \\
-\sin \sigma & 0 & \cos \sigma
\end{array}\right]
$$

The vertices for Panels 1 and 2 rotated about the $y$-axis are:

$$
\begin{aligned}
\mathbf{P}_{1, \text { rot }}=\mathbf{P}_{0, \text { rot }}+ & {\left[\begin{array}{ccc}
D+W & 0 & 0 \\
D+W & 0 & 0 \\
D+W & 0 & 0 \\
D+W & 0 & 0
\end{array}\right] } \\
\mathbf{P}_{2, \text { rot }}=\mathbf{P}_{0, \text { rot }}+ & {\left[\begin{array}{ccc}
2(D+W) & 0 & 0 \\
2(D+W) & 0 & 0 \\
2(D+W) & 0 & 0 \\
2(D+W) & 0 & 0
\end{array}\right] }
\end{aligned}
$$

The vertices for Panels 1, 2 and 3 both rotated about the $y$-axis and tilted from the horizontal at the subarray tilt angle are:

$$
\begin{aligned}
& \mathbf{P}_{0, \text { rot }, \text { tilt }}=\left(\mathbf{P}_{0, \text { rot }}-\left[\begin{array}{lll}
0 & L & 0 \\
0 & L & 0 \\
0 & L & 0 \\
0 & L & 0
\end{array}\right]\right)\left[\begin{array}{ccc}
1 & 0 & 0 \\
0 & \cos \beta & \sin \beta \\
0 & -\sin \beta & \cos \beta
\end{array}\right]+\left[\begin{array}{lll}
0 & L & 0 \\
0 & L & 0 \\
0 & L & 0 \\
0 & L & 0
\end{array}\right] \\
& \mathbf{P}_{1, \text { rot }, \text { tilt }}=\left(\mathbf{P}_{1, \text { rot }}-\left[\begin{array}{lll}
0 & L & 0 \\
0 & L & 0 \\
0 & L & 0 \\
0 & L & 0
\end{array}\right]\right)\left[\begin{array}{ccc}
1 & 0 & 0 \\
0 & \cos \beta & \sin \beta \\
0 & -\sin \beta & \cos \beta
\end{array}\right]+\left[\begin{array}{lll}
0 & L & 0 \\
0 & L & 0 \\
0 & L & 0 \\
0 & L & 0
\end{array}\right] \\
& \mathbf{P}_{2, \text { rot }, \text { tilt }}=\left(\mathbf{P}_{2, r o t}-\left[\begin{array}{lll}
0 & L & 0 \\
0 & L & 0 \\
0 & L & 0 \\
0 & L & 0
\end{array}\right]\right)\left[\begin{array}{ccc}
1 & 0 & 0 \\
0 & \cos \beta & \sin \beta \\
0 & -\sin \beta & \cos \beta
\end{array}\right]+\left[\begin{array}{lll}
0 & L & 0 \\
0 & L & 0 \\
0 & L & 0 \\
0 & L & 0
\end{array}\right]
\end{aligned}
$$


Finally, the vertices of Panels 1, 2 and 3 rotated around the $y$-axis, tilted from the horizontal at the subarray tilt angle, and rotated about the $z$-axis at the subarray azimuth angle are:

$$
\begin{aligned}
& \mathbf{P}_{0, \text { rot }, \text { tilt }, \text { sazm }}=\mathbf{P}_{0, \text { rot }, \text { tilt } l}\left[\begin{array}{ccc}
\cos \Psi & \sin \Psi & 0 \\
-\sin \Psi & \cos \Psi & 0 \\
0 & 0 & 1
\end{array}\right] \\
& \mathbf{P}_{1, \text { rot tilt }, \text { sazm }}=\mathbf{P}_{1, \text { rot }, \text { tilt }}\left[\begin{array}{ccc}
\cos \Psi & \sin \Psi & 0 \\
-\sin \Psi & \cos \Psi & 0 \\
0 & 0 & 1
\end{array}\right] \\
& \mathbf{P}_{2, \text { rot, tilt }, \text { sazm }}=\mathbf{P}_{2, \text { rot }, \text { tilt } l}\left[\begin{array}{ccc}
\cos \Psi & \sin \Psi & 0 \\
-\sin \Psi & \cos \Psi & 0 \\
0 & 0 & 1
\end{array}\right]
\end{aligned}
$$

To make things easier to read, matrices $\mathbf{P}_{0}, \mathbf{P}_{1}$, and $\mathbf{P}_{2}$ indicate the four vertices for each of the three panels:

$$
\begin{aligned}
& \mathbf{P}_{0}=\mathbf{P}_{0, \text { rot }, \text { tilt }, \text { sazm }} \\
& \mathbf{P}_{1}=\mathbf{P}_{1, \text { rot }, \text { tilt }, \text { sazm }} \\
& \mathbf{P}_{2}=\mathbf{P}_{2, \text { rot }, \text { tilt }, \text { sazm }}
\end{aligned}
$$

\subsubsection{Shading Panel}

The shading panel is either Panel 0 or Panel 2, and is the panel that blocks beam solar radiation from Panel 1. Of the two panels, the shading panel iPanel is the panel nearest the sun's direction.

By definition Panel 1 is between Panel 0 and Panel 2. The following vectors are between Vertex 0 of the three panels. The vectors from Panel 1 to Panel 0 (toPrev), and from Panel 2 to Panel 1 (toNext) are:

$$
\begin{aligned}
\mathbf{v}_{\text {toPrev }} & =\mathbf{P}_{0}\left(x_{0}, y_{0}, z_{0}\right)-\mathbf{P}_{1}\left(x_{0}, y_{0}, z_{0}\right) \\
\mathbf{v}_{\text {toNext }} & =\mathbf{P}_{2}\left(x_{0}, y_{0}, z_{0}\right)-\mathbf{P}_{1}\left(x_{0}, y_{0}, z_{0}\right)
\end{aligned}
$$

To determine which of Panel 0 and Panel 2 is in the direction of the sun from Panel 1, compare the dot product of the sun unit vector with the vectors to and from Panel 1 . The dot product with the larger positive value indicates the panel closest to the sun. The shading panel iPanel is either Panel 0 or Panel 1:

$$
P_{\text {iPanel }}= \begin{cases}\mathbf{P}_{0} & \text { if } \mathbf{v}_{\text {toPrev }} \cdot \hat{\mathbf{s}} \geq \mathbf{v}_{\text {toNext }} \cdot \hat{\mathbf{s}} \\ \mathbf{P}_{2} & \text { if } \mathbf{v}_{\text {toPrev }} \cdot \hat{\mathbf{s}}<\mathbf{v}_{\text {toNext }} \cdot \hat{\mathbf{s}}\end{cases}
$$

\subsubsection{Shaded Fraction}

With the shading panel identified, and the position of the sun and panel angles for the current time step angles, the following vector equations determine whether iPanel is shaded.

The midpoint midP is the middle of the edge of iPanel closest to the sun. The edge of iPanel closest to the sun depends on whether the shading panel is Panel 0 or Panel 2. If Panel 0 is shading, then the edge of $i$ Panel closest to the sun is the edge connecting Vertices 2 and 3:

$$
\mathbf{v}_{\text {midP }}=\frac{\mathbf{P}_{1}\left(x_{2}, y_{2}, z_{2}\right)+\mathbf{P}_{1}\left(x_{3}, y_{3}, z_{3}\right)}{2}
$$

If Panel 2 is shading, then the edge of $i$ Panel closest to the sun is defined by Vertices 0 and 1 :

$$
\mathbf{v}_{\text {midP }}=\frac{\mathbf{P}_{1}\left(x_{0}, y_{0}, z_{0}\right)+\mathbf{P}_{1}\left(x_{1}, y_{1}, z_{1}\right)}{2}
$$


The vector normal normal to iPanel is the cross product of any two vectors in the plane of the shading panel:

$$
\mathbf{v}_{\text {normal }}=\left[\mathbf{P}_{\text {iPanel }}\left(x_{1}, y_{1}, z_{1}\right)-\mathbf{P}_{\text {iPanel }}\left(x_{0}, y_{0}, z_{0}\right)\right] \times\left[\mathbf{P}_{\text {iPanel }}\left(x_{3}, y_{3}, z_{3}\right)-\mathbf{P}_{\text {iPanel }}\left(x_{0}, y_{0}, z_{0}\right)\right]
$$

The intersection sunDot of the iPanel normal vector normal and an infinite vector in the direction of the sun vector sun:

$$
\mathbf{v}_{\text {sunDot }}=\mathbf{v}_{\text {normal }} \cdot \mathbf{v}_{\hat{s}}
$$

The distance $t$ along the sun vector from midP to the plane of iPanel:

$$
t=\mathbf{v}_{\text {normal }} \cdot\left[\mathbf{P}_{\text {iPanel }}(x 0, y 0, z 0)-\mathbf{v}_{\text {midP }}\right]
$$

The point of intersection intersectP of the sun vector infinite plane of $i$ Panel:

$$
\mathbf{v}_{\text {intersect } P}=\mathbf{v}_{\text {midP }}+t \hat{\mathbf{s}}
$$

Determine whether the point is within the bounds of the panel. If either of the following conditions is true, the point is outside of the bounds of the panel:

$$
\begin{aligned}
& {\left[\mathbf{P}_{\text {iPanel }}(x 3, y 3, z 3)-\mathbf{P}_{\text {iPanel }}(x 0, y 0, z 0)\right] \cdot\left[\mathbf{v}_{\text {intersectP } P}-\mathbf{P}_{\text {iPanel }}(x 0, y 0, z 0)\right]<0} \\
& {\left[\mathbf{P}_{\text {iPanel }}(x 0, y 0, z 0)-\mathbf{P}_{\text {iPanel }}(x 3, y 3, z 3)\right] \cdot\left[\mathbf{v}_{\text {intersect } P}-\mathbf{P}_{\text {iPanel }}(x 3, y 3, z 3)\right]<0}
\end{aligned}
$$

Next, determine whether $i$ Panel is shaded. It is not shaded when either $\mathbf{v}_{\text {intersect }}$ is outside the bounds of the panel (Equation 9.47), or when the sun vector lies within the plane of the subarray, $\mathbf{v}_{\text {sunDot }}<0.001$ (Equation 9.44).

If $i$ Panel is shaded, it is shaded by either Panel 0 or Panel 2. If it is shaded by Panel 0 , the upper and lower edge midpoints on the adjacent panel are:

$$
\begin{aligned}
\mathbf{v}_{m u} & =\frac{\mathbf{P}_{0}(x 0, y 0, z 0)+\mathbf{P}_{0}(x 1, y 1, z 1)}{2} \\
\mathbf{v}_{m l} & =\frac{\mathbf{P}_{0}(x 2, y 2, z 2)+\mathbf{P}_{0}(x 3, y 3, z 3)}{2}
\end{aligned}
$$

Otherwise, if $i$ Panel is shaded by Panel 2:

$$
\begin{aligned}
\mathbf{v}_{m u} & =\frac{\mathbf{P}_{2}(x 2, y 2, z 2)+\mathbf{P}_{2}(x 3, y 3, z 3)}{2} \\
\mathbf{v}_{m l} & =\frac{\mathbf{P}_{2}(x 0, y 0, z 0)+\mathbf{P}_{2}(x 1, y 1, z 1)}{2}
\end{aligned}
$$

The geometric shaded fraction:

$$
A_{b}=\frac{\left(\mathbf{v}_{\text {intersect } P}-\mathbf{v}_{m u}\right) \cdot\left(\mathbf{v}_{m l}-\mathbf{v}_{m u}\right)}{\left(\mathbf{v}_{m l}-\mathbf{v}_{m u}\right) \cdot\left(\mathbf{v}_{m l}-\mathbf{v}_{m u}\right)}
$$

If $i$ Panel is not shaded, then the geometric shading fraction is zero:

$$
A_{b}=0
$$

The reduction in beam POA irradiance for one-axis tracking:

$$
S_{1 x s s}=1-A_{b}
$$




\section{Module DC Output}

SAM uses one of four module models and one of three cell temperature models to calculate the DC power output of a single module in each subarray. SAM makes the following assumptions:

- All modules in the system operate at their maximum power point voltage, except for the subarray mismatch and inverter operating voltage limit losses described below.

- The subarray maximum power point is determined by the maximum power point of a single module and number of modules per string.

- All subarrays in the system have the same number of modules per string, and therefore operate at the same voltage.

- All modules in each subarray operate uniformly. SAM does not calculate module mismatch losses.

Because the CEC and IEC 61853 module models (Section 10.1) use a continuous function to represent the module's I-V curve, SAM can estimate losses due to subarray mismatch and inverter input operating input voltage limits:

- For an array with multiple subarrays, the optional PV subarray mismatch option adjusts the maximum power voltage to account for mismatch between subarrays as described in Section 11.6.

- When the inverter specifications include maximum and minimum MPPT voltage limits and the string voltage exceeds those limits, SAM clamps the string voltage to those limits.

Calculating the module's DC output in a time step when the sun is up (see Section 4.4) is a two step process:

1. Calculate the photovoltaic cell temperature. SAM assumes that the temperature of cells in all of the modules in each subarray is uniform.

2. Calculate the module's DC power output based on its physical characteristics, the effective irradiance, and cell temperature.

Table 9 lists the input and output variables used by each of SAM's module and cell temperature models. Each model uses an additional set of input parameters listed in each model's section below.

\subsection{Module Models}

SAM calculates the a single photovoltaic module's DC output with one of the module models listed below (Blair 2013). The simple efficiency and Sandia module models are point-value models that calculate module power at one or more discrete points on the module's I-V curve. The CEC and IEC-61853 models are single-diode equivalent circuit models that represent the module I-V curve as a continuous function.

- Simple Efficiency Module Model (Section 10.5) is a simple representation of module performance that calculates the module's DC output at the maximum power point from the module area, a table of conversion efficiency values over a range of irradiance values, and temperature correction parameters. The simple efficiency model is the least accurate of the three models for predicting the performance of specific modules. It is useful for preliminary performance predictions before you have selected a specific module, and allows you to explicitly specify the module efficiency, which is useful for analyses involving sensitivity or parametric analysis.

- California Energy Commission (CEC) Performance Model with Module Database (Section 10.4) is an implementation of the six-parameter, single-diode equivalent circuit model used in the CEC New Solar Homes Partnership Calculator (Go Solar California 2014), and is an extension of the five-parameter model described in De Soto (2004a). The model calculates the photovoltaic module DC output using equations with parameters 


\section{Table 9. Module Model Variable Definitions}

\begin{tabular}{|c|c|}
\hline Symbol & Description / Name in SAM \\
\hline $\begin{array}{l}G_{b} \\
G_{d} \\
G_{r} \\
A O I \\
Z\end{array}$ & $\begin{array}{l}\quad \text { Effective POA Irradiance Inputs } \\
\text { effective beam irradiance }\left(\mathrm{W} / \mathrm{m}^{2}\right) * \\
\text { effective sky diffuse irradiance }\left(\mathrm{W} / \mathrm{m}^{2}\right) * \\
\text { effective ground-reflected diffuse irradiance }\left(\mathrm{W} / \mathrm{m}^{2}\right) * \\
\text { incidence angle (deg) } \\
\text { sun zenith angle (deg) }\end{array}$ \\
\hline $\begin{array}{l}T_{\text {dry }} \\
T_{\text {dew }} \\
p_{\text {atm }} \\
v_{w} \\
h \\
h r\end{array}$ & \begin{tabular}{l}
\multicolumn{1}{c}{ Inputs from Weather File } \\
ambient dry bulb temperature $\left({ }^{\circ} \mathrm{C}\right)$ \\
dew-point temperature $\left({ }^{\circ} \mathrm{C}\right)^{\dagger}$ \\
atmospheric pressure (mbar) \\
wind speed $(\mathrm{m} / \mathrm{s})$ \\
elevation above sea level $(\mathrm{m})$ \\
hour of day local time (h)
\end{tabular} \\
\hline $\begin{array}{l}\beta_{s} \\
\gamma_{s}\end{array}$ & $\begin{array}{l}\text { Subarray Inputs } \\
\text { subarray tilt angle (deg) } \\
\text { subarray azimuth angle (deg) }\end{array}$ \\
\hline $\begin{array}{l}P_{m p} \\
V_{m p} \\
I_{m p} \\
V_{o c} \\
I_{s c}\end{array}$ & $\begin{array}{l}\quad \text { Intermediate Outputs } \\
\text { module power }(\mathrm{W}) \\
\text { module voltage }(\mathrm{V}) \\
\text { module current }(\mathrm{A}) \\
\text { operating open circuit voltage }(\mathrm{V}) \\
\text { operating closed circuit current }(\mathrm{A})\end{array}$ \\
\hline $\begin{array}{l}\eta_{m} \\
T_{c}\end{array}$ & $\begin{array}{l}\text { Outputs } \\
\text { module efficiency }(\%) \\
\text { cell temperature }\left({ }^{\circ} \mathrm{C}\right)\end{array}$ \\
\hline
\end{tabular}

${ }^{*}$ Calculated from solar resource data in weather file (Section 6).

${ }^{\dagger}$ Only required for heat transfer cell temperature model (Section 10.7). 
Table 10. Module Models in SSC

\begin{tabular}{lc}
\hline Name in SAM & module_model \\
\hline Simple Efficiency Module Model & 0 \\
CEC Performance Model with Module Database & 1 \\
CEC Performance Model with User Entered Specifications & 2 \\
Sandia PV Array Performance Model with Module Database & 3 \\
\hline
\end{tabular}

Table 11. Cell Temperature Models

\begin{tabular}{lll}
\hline Module Model & Temperature Model & Section \\
\hline Simple efficiency & Sandia & 10.8 \\
Sandia & Sandia & 10.8 \\
CEC with database parameters & NOCT or Heat Transfer & 10.6 or 10.7 \\
CEC with user-specified parameters & NOCT & 10.6 \\
\hline
\end{tabular}

stored in SAM's CEC module library (see Section 2.2). The library contains data provided by the California Energy Commission (Go Solar California 2014) (Go Solar California 2016a).

- CEC Performance Model with User Entered Specifications (Section 10.4) is the same implementation as the CEC Performance Model with Module Database, but with a coefficient calculator (Dobos 2012a) to calculate the model parameters from the standard module specifications provided on manufacturer data sheets. This makes it possible to use the six-parameter model for modules not included in the CEC module library.

- IEC 68153 Single Diode Model (Section 10.9) is a ten-parameter single-diode model adapted from the fiveparameter single-diode model. It calculates model parameter values from a table of module test data that follow the IEC 61853 rating standard (Dobos 2014).

- Sandia PV Array Performance Model with Module Database (Section 10.3) is an implementation of the Sandia National Laboratories photovoltaic module and array performance model (King 2004). This empirical model calculates module voltage and power at five points on the module's I-V curve using data measured from modules and arrays in realistic outdoor operating conditions. The database stored in SAM's Sandia module library (see Section 2.2) includes modules with different cell types, including crystalline silicon, and various thin film technologies.

In SSC, the pvsamv1 input variable module_model determines the module model as shown in Table 10.

\subsection{Cell Temperature Models}

Each module model uses one of the cell temperature models shown in Table 11 to calculate the photovoltaic cell temperature in a given time step. Each module model uses a single cell temperature model, except for the CEC module model with database parameters, which offers two cell temperature model options.

In each time step, SAM calls the appropriate cell temperature model once before calling the module model. When the subarray mismatch option (Section 11.6) is enabled, it also calls the cell temperature model as part of that set of calculations.

\subsection{Sandia Module Model}

SAM's Sandia Module Model is an implementation of the empirical model of a photovoltaic module described in King (2004). See Section 10.1 for a general description of all of SAM's module models. 
Table 12. Sandia Module Model Inputs

\begin{tabular}{|c|c|c|}
\hline Symbol & Description / Name in SAM & Name in SSC \\
\hline$V_{m p, r e f}$ & reference Max Power Voltage (V) & snl_vmpo \\
\hline$I_{m p, r e f}$ & reference Max Power Current (A) & snl_i_mpo \\
\hline$V_{o c, r e f}$ & reference Open Circuit Voltage (V) & $\mathrm{snl}$ _voco \\
\hline$I_{s c, r e f}$ & reference Short Circuit Current (A) & snl_isco \\
\hline$\alpha_{s c, r e f}$ & normalized short circuit current temperature coefficient $\left(1 /{ }^{\circ} \mathrm{C}\right)$ & snl_aisc \\
\hline$\beta_{o c, r e f}$ & open circuit voltage temperature coefficient $\left(\mathrm{V} /{ }^{\circ} \mathrm{C}\right)$ & snl_bvoco \\
\hline$\beta_{m p, r e f}$ & maximum power voltage temperature coefficient $\left(\mathrm{V} /{ }^{\circ} \mathrm{C}\right)$ & snl_bvmpo \\
\hline$\gamma_{m p, r e f}$ & maximum power temperature coefficient $\left(\mathrm{W} /{ }^{\circ} \mathrm{C}\right)$ & snl_aimp \\
\hline$M_{\beta o c}$ & relates $\beta_{o c, r e f}$ to effective irradiance $\left(\mathrm{V} /{ }^{\circ} \mathrm{C}\right)$ & snl_mbvoc \\
\hline$M_{\beta m p}$ & relates $\beta_{m p, \text { ref }}$ to effective irradiance $\left(\mathrm{V} /{ }^{\circ} \mathrm{C}\right)$ & snl_mbvmp \\
\hline$s$ & number of cells in series & snl_series_cells \\
\hline$C_{0}, C_{1}$ & coefficients relating $I_{m p}$ to $G$ & $\mathrm{snl} \_\mathrm{c} 0, \mathrm{snl}{ }_{-} \mathrm{c}$ \\
\hline$C_{2}, C_{3}$ & coefficients relating $V_{m p}$ to $G\left(C_{3}\right.$ is in $\left.1 / \mathrm{V}\right)$ & $\mathrm{snl} \_\mathrm{c} 2, \mathrm{snl}{ }_{-} \mathrm{c} 3$ \\
\hline$C_{4}, C_{5}$ & coefficients relating $I_{x}$ to $G$ & $\mathrm{snl} \_\mathrm{c} 4, \mathrm{snl} \_\mathrm{c} 5$ \\
\hline$C_{6}, C_{7}$ & coefficients relating $I_{x x}$ to $G$ & $\mathrm{sn} 1 \_\mathrm{c} 6, \mathrm{sn} 1 \_\mathrm{c} 7$ \\
\hline$n$ & diode factor & snl_n \\
\hline$f_{d}$ & fraction of diffuse irradiance used by module & $\mathrm{snl}_{-} \mathrm{fd}$ \\
\hline$a_{0 \ldots 4}$ & air mass coefficients $0 \ldots 4$ & snl_a $[0 \ldots 4]$ \\
\hline$b_{0 \ldots 5}$ & incidence angle modifier coefficients $0 \ldots .5$ & snl_b $[0 \ldots 5]$ \\
\hline
\end{tabular}

For a description of the Sandia cell temperature model, see Section 10.8 .

The Sandia module model uses the module parameters in Table 12 along with the general module input variables in Table 9. The parameters in Table 12 are from the Sandia module database maintained by Sandia National Laboratories (Sandia 2014). In SAM, the parameters are stored in the Sandia module library. In SSC, the implementation of the Sandia module model described here is part of the pvsamv1 module and does not include a parameter library (See Section 2.2).

The reference conditions for the Sandia module model parameters are total POA irradiance of $1,000 \mathrm{~W} / \mathrm{m}^{2}$ and reference cell temperature of $25^{\circ} \mathrm{C}$.

When you choose a module on SAM's Module input page for the Sandia PV Array Performance Model with Module Database, SAM displays some of the module's reference parameters in Table 12 from the Sandia Module library as values that cannot be edited.

The absolute air mass is a relative measure of the optical path length that sunlight travels through the atmosphere and depends on the sun zenith angle in degrees (Section 4.2) and the elevation above sea level ( $A M=1$ at sea level with the sun directly overhead):

$$
A M=\left[\cos \left(\frac{\pi}{180} Z\right)+0.5057(96.08-Z)^{-1.634}\right]^{-1} e^{-0.0001184 h}
$$

The $F_{1}$ polynomial relates the spectral effects on $I_{s c}$ to the variation of air mass over the day:

$$
F_{1}=a_{0}+a_{1} A M+a_{2} A M^{2}+a_{3} A M^{3}+a_{4} A M^{4}
$$

The $F_{2}$ polynomial relates the optical effects on $I_{s c}$ to the angle of incidence $A O I$ (Section 5.1):

$$
F_{2}=b_{0}+b_{1} A O I+b_{2} A O I^{2}+b_{3} A O I^{3}+b_{4} A O I^{4}+b_{5} A O I^{5}
$$


The short circuit current is a function of the cell temperature (Equation, where $T_{c}$ is from Equation 10.40), effective irradiance (Section 7) and the short circuit temperature coefficient in $\mathrm{A} /{ }^{\circ} \mathrm{C}$. The diffuse utilization factor $F_{d}$ is one of the parameters from the Sandia module library, and is equal to one for flat plate modules:

$$
I_{s c}=I_{s c, r e f} F_{1}\left(\frac{G_{b} F_{2}+f_{d}\left(G_{d}+G_{r}\right)}{1000}\right)\left[1+\alpha_{s c, r e f}\left(T_{c}-25\right)\right]
$$

The effective irradiance on the module surface to which the cells respond:

$$
E_{e}=\frac{I_{s c}}{I_{s c, r e f}\left[1+\alpha_{s c, r e f}\left(T_{c}-25\right)\right]}
$$

The current at the maximum power point:

$$
I_{m p}=I_{m p, r e f}\left(C_{0} E_{e}+C_{1} E_{e}^{2}\right)\left[1+\alpha_{s c, r e f}\left(T_{c}-25\right)\right]
$$

The following two intermediate values are required for the maximum power voltage equations:

$$
\begin{aligned}
& \Delta T_{c}=n\left(\frac{1.38066 \times 10^{-23}\left(T_{c}+273.15\right)}{1.60218 \times 10^{-19}}\right) \\
& \beta_{m p}=\beta_{m p, r e f}+M_{\beta m p}\left(1-E_{e}\right) \\
& V_{o c}=V_{o c, r e f}+s \Delta T_{c} \ln \left(E_{e}\right)+\beta_{o c}\left(T_{c}-25\right)
\end{aligned}
$$

The voltage at the maximum power point is zero if $E_{e} \leq 0$. Otherwise:

$$
V_{m p}=V_{m p, r e f}+C_{2} s \Delta T_{c} \ln \left(E_{e}\right)+C_{3} s\left[\Delta T_{c} \ln \left(E_{e}\right)\right]^{2}+\beta_{m p}\left(T_{c}-25\right)
$$

The module's DC power output is at the maximum power point:

$$
P_{m p}=V_{m p} I_{m p}
$$

\subsection{CEC Module Model}

SAM's CEC Module Model is an implementation of the single-diode equivalent circuit model of a photovoltaic module described in De Soto (2004a), and with more detail in De Soto (2004b). It is also described in Section 23.2 of Duffie and Beckman (2013). See Section 10.1 for a general description of all of SAM's module models.

SAM includes two options for the model (see Section 10): It may use a set of reference parameters from the CEC module library with data provided by the California Energy Commission (Go Solar California 2014), or a set of reference parameters generated by SAM's coefficient generator from module specifications that you provide as input to the model. The equations described in this section are for the module's DC output, not for the module coefficients. For a description of the coefficient generator equations, see Dobos (2012a).

Table 13 shows the five module specifications and six parameters that are input variables specific to the CEC module model. The model also uses the general module input variables in Table 9.

In SSC, the implementation of the CEC module model described here is part of the pvsamv1 module. The coefficient generator is available in SSC as a separate compute module called 6parsolve.

The reference conditions for the CEC module model parameters are total POA irradiance of $1,000 \mathrm{~W} / \mathrm{m}^{2}$ and reference cell temperature of $25^{\circ} \mathrm{C}$. 
Table 13. CEC Module Model Inputs

\begin{tabular}{|c|c|c|}
\hline Symbol & Description / Name in SAM & Name in SSC \\
\hline$I_{m p, r e f}$ & reference Max Power Current (A) & cec_i_mp_ref \\
\hline$V_{o c, r e f}$ & reference Open Circuit Voltage (V) & cec_v_oc_ref \\
\hline$I_{s c, r e f}$ & reference Short Circuit Current (A) & cec_i_sc_ref \\
\hline$\alpha_{s c, r e f}$ & short circuit current temperature coefficient $\left(\mathrm{A} /{ }^{\circ} \mathrm{C}\right)$ & cec_alpha_sc \\
\hline$\beta_{o c, r e f}$ & open circuit voltage temperature coefficient $\left(\mathrm{V} /{ }^{\circ} \mathrm{C}\right)$ & cec_beta_oc \\
\hline$I_{L, r e f}$ & reference light current, I_L_ref (A) & cec_i_l_ref \\
\hline$I_{o, r e f}$ & reference diode saturation current, I_o_ref (A) & cec_i_o_ref \\
\hline$R_{s, \text { ref }}$ & reference series resistance, $\mathbf{R} \_\mathbf{s}(\Omega)$ & cec_r_s_ref \\
\hline$a_{r e f}$ & reference ideality factor, $\mathbf{A} \_$ref $(\mathrm{V})$ & cec_a_ref \\
\hline$R_{\text {sh, ref }}$ & reference shunt resistance $\mathbf{R} \_$sh_ref $(\Omega)$ & cec_r_sh_ref \\
\hline adjust & temperature coefficient adjustment factor & cec_adjust \\
\hline
\end{tabular}

When you select a module on SAM's Module input page for the CEC Performance Model with Module Database, SAM displays the module's reference parameters shown in Table 13 from the CEC Module library as uneditable values.

The five-parameter single-diode equivalent circuit equation for the module current $I$ at a given voltage $V$ is:

$$
I=I_{L}-I_{o}\left[\exp \left(\frac{V+I R_{S}}{a}\right)-1\right]-\frac{V+I R_{S}}{R_{s h}}
$$

The temperature coefficient of short circuit current $\mu_{i s c}$ and open circuit voltage $\beta_{v o c}$ in the model are adjusted from the reference coefficients using a sixth parameter, adjust, which may be either from the CEC module library, or calculated by SAM's coefficient generator:

$$
\begin{aligned}
& \mu_{i s c}=\alpha_{s c, \text { ref }}\left(1-\frac{\text { adjust }}{100}\right) \\
& \beta_{v o c}=\beta_{o c, r e f}\left(1+\frac{\text { adjust }}{100}\right)
\end{aligned}
$$

The global effective irradiance at the top of the module cover:

$$
G=G_{b}+G_{d}+G_{r}
$$

Equations for the transmittance through the module cover use three constants:

$$
\begin{aligned}
& n=1.526 \quad \text { (refractive index of glass) } \\
& L=0.002 \quad \text { (thickness of glass cover in meters) } \\
& K=4 \quad \text { (proportionality constant in meters }^{-1} \text { ) }
\end{aligned}
$$

The angle of refraction, assuming that the refractive index of air is one:

$$
\theta_{r}=\arcsin \left(\frac{1}{n} \sin A O I\right)
$$

The transmittance as a function of incidence angle $\theta_{i}$ in radians:

$$
\tau(\theta)=e^{-K L / \cos \theta_{r}}\left[1-\frac{1}{2}\left(\frac{\sin ^{2}\left(\theta_{r}-\theta_{i}\right)}{\sin ^{2}\left(\theta_{r}+\theta_{i}\right)}+\frac{\tan ^{2}\left(\theta_{r}-\theta_{i}\right)}{\tan ^{2}\left(\theta_{r}+\theta_{i}\right)}\right)\right]
$$


The incidence angle for the sky diffuse and ground-reflected components of the effective irradiance:

$$
\begin{aligned}
& \theta_{d}=59.7-0.1388 \beta+0.001497 \beta^{2} \quad \text { (sky diffuse angle) } \\
& \theta_{g}=90-0.5788 \beta+0.002693 \beta^{2} \quad \text { (ground-reflected diffuse angle) }
\end{aligned}
$$

The transmittance for each component of the effective irradiance is calculated using Equation 10.16 with the module cover properties in Equation 10.14 and the following incidence angle values:

$$
\begin{array}{ll}
(\tau \alpha)_{n}: \theta_{i}=1 & \text { (surface normal) } \\
(\tau \alpha)_{b}: \theta_{i}=\theta & \text { (beam) } \\
(\tau \alpha)_{d}: \theta_{i}=\theta_{d} & \text { (sky diffuse) } \\
(\tau \alpha)_{g}: \theta_{i}=\theta_{g} & \text { (ground diffuse) }
\end{array}
$$

Note that $(\tau \alpha)_{n}$ is set to 1 degree (a very small number) instead of zero to avoid potential divide-by-zero errors.

The incidence angle modifier for each component of the effective irradiance is then:

$$
\begin{aligned}
K_{\tau \alpha, b} & =\frac{(\tau \alpha)_{b}}{(\tau \alpha)_{n}} \\
K_{\tau \alpha, d} & =\frac{(\tau \alpha)_{d}}{(\tau \alpha)_{n}} \\
K_{\tau \alpha, g} & =\frac{(\tau \alpha)_{g}}{(\tau \alpha)_{n}}
\end{aligned}
$$

The irradiance absorbed by the photovoltaic cell is:

$$
G_{0}=G_{b} K_{\tau \alpha, b}+G_{d} K_{\tau \alpha, d}+G_{r} K_{\tau \alpha, g}
$$

The model limits sun zenith angle, setting its value to the minimum or maximum when it is exceeded:

$$
0<Z<86^{\circ}
$$

The transmittance-absorptance product:

$$
\tau \alpha=0.9 \frac{G_{0}}{G}
$$

The air mass, with an exponential correction factor adapted from the Sandia model for elevation above sea level:

$$
A M=\left[\cos \left(\frac{\pi}{180} Z\right)+0.5057(96.080-Z)^{-1.634}\right]^{-1} e^{-0.0001184 h}
$$

The air mass modifier $M$ accounts for the effect of air mass on spectral distribution, and is from King (2004) with coefficients for polycrystalline cells:

$$
\begin{aligned}
& a_{0}=0.918093 \\
& a_{1}=0.086257 \\
& a_{2}=-0.024459 \\
& a_{3}=0.002816 \\
& a_{4}=-0.000126 \\
& M=a_{0}+a_{1} A M+a_{2} A M^{2}+a_{3} A M^{3}+a_{4} A M^{4}
\end{aligned}
$$


The adjusted effective transmitted irradiance:

$$
G=M G_{0}
$$

The module DC output is only calculated when $G>1$.

The cell temperature $T_{c}$ is calculated using either the NOCT cell temperature model (Section 10.6) or the heat transfer cell temperature model (Section 10.7) as described in Section 10.2.

For the next set of equations, the cell temperature is in Kelvin, and the reference cell temperature of $25^{\circ} \mathrm{C}$ in Kelvin is $25^{\circ} \mathrm{C}+273.15 \mathrm{~K}=298.15 \mathrm{~K}$. The light current $I_{L}$ :

$$
I_{L}=\frac{G}{1000}\left[I_{L, r e f}+\mu_{i s c}\left(T_{c}-298.15\right)\right]
$$

The diode reverse saturation current $I_{o}$, assuming a reference band-gap energy of silicon of $1.12 \mathrm{eV}$ :

$$
\begin{array}{rlr}
k & =8.618 \times 10^{-5} & \text { Boltzmann constant in } \mathrm{eV} / \mathrm{K} \\
E_{b g} & =1.12\left[1-0.0002677\left(T_{c}-T_{c, \text { ref }}\right)\right] & \text { cell material band-gap energy in } \mathrm{eV}
\end{array}
$$

At the open circuit voltage $V_{o c}, I=0$, and Equation 10.11 reduces to:

$$
I=I_{L}-I_{o}\left[\exp \left(\frac{V_{o c}+I R_{S}}{a}\right)-1\right]-\frac{V_{o c}}{R_{s h}}
$$

SAM uses the bisection method to solve Equation 10.28 for $V_{o c}$ with the reference open circuit voltage $V_{o c, r e f}$ as an initial guess and the following parameter values:

$$
\begin{aligned}
a & =a_{r e f} \frac{T_{c}}{T_{c, r e f}} \\
R_{s h} & =R_{\text {sh }, \text { ref }} \frac{1000}{G}
\end{aligned}
$$

The short circuit current:

$$
I_{s c}=\frac{I_{L}}{1+\frac{R_{s, r e f}}{R_{s} h}}
$$

For the CEC module model, SAM can calculate the module operating voltage either using the string mismatch equations described in Section 11.6, or the equations described below.

For the current at maximum power $I_{m p}$, SAM uses Newton's method to find a solution of Equation 10.11 using the calculated values for $I_{L}, I_{o}, a$, and $R_{S h}$ at the maximum power point voltage. Because the effect of series resistance on the maximum power point is relatively small, for $R_{S}$, the model uses the reference value so that $R_{S}=R_{S, r e f}$. Also, $I_{L}$ from Equation 10.26 is multiplied by a factor of 0.9 .

For systems with one subarray, or for systems with more than one subarray with the subarray mismatch option disabled, SAM calculates the maximum power point voltage using a golden section search to determine the voltage between 0 and $V_{o c}$ that results in the maximum power given the current at maximum power.

For systems with more than one subarray and the subarray mismatch option enabled (Section 11.6, SAM sets the maximum power voltage to the value calculated by the mismatch algorithm.

The module DC output is the power at maximum power:

$$
P_{m p}=V_{m p} I_{m p}
$$


Table 14. Simple Efficiency Module Model Inputs

\begin{tabular}{lll}
\hline Symbol & Description / Name in SAM & Name in SSC \\
\hline$V_{m p, r e f}$ & reference Maximum Power Voltage $(\mathrm{V})$ & - \\
$V_{\text {oc,ref }}$ & reference Open Circuit Voltage $(\mathrm{V})$ & - \\
$A_{m}$ & module Area $\left(\mathrm{m}^{2}\right)$ & spe_area \\
$\gamma_{m p, r e f}$ & maximum power Temperature Coefficient $\left(\% /{ }^{\circ} \mathrm{C}\right)$ & spe_temp_coeff \\
$a$ & Sandia temperature parameter a & spe_a \\
$b$ & Sandia temperature parameter b & spe_b \\
$\Delta T$ & Sandia temperature parameter $\mathbf{d T}\left({ }^{\circ} \mathrm{C}\right)$ & spe_dT \\
$G_{0 . .4}$ & radiation values in efficiency table $\left(\mathrm{W} / \mathrm{m}^{2}\right)$ & spe_rad $[0 \ldots 4]$ \\
$G_{r e f}$ & reference radiation value from efficiency table $\left(\mathrm{W} / \mathrm{m}^{2}\right)$ & spe_reference \\
$\eta_{0 \ldots .}$ & module efficiency values in efficiency table $(\%)$ & spe_eff $[0 \ldots 4]$ \\
$f_{d}$ & Diffuse utilization factor & spe_fd \\
\hline
\end{tabular}

\subsection{Simple Efficiency Module Model}

SAM's Simple Efficiency Module Model (see Section 10.1) is a basic single point efficiency representation of a photovoltaic module that uses an efficiency table and the Sandia cell temperature model (Section 10.8) to calculate the module's DC power output.

The simple efficiency module model uses the module parameters shown in Table 14 along with the general module input variables in Table 9. The model does not use the reference parameters $V_{m p, r e f}$ and $V_{o c, r e f}$. Those values are required by the sizing algorithm that is part of SAM's user interface (Section 2.3).

The cell temperature parameters $a, b$, and $\Delta T$ depend on the Module Structure and Mounting option (spe_module_structure in SSC) as listed in Table 18. The "use database values" option is not available for the simple efficiency module model, so that spe_module_structure $=0$ is for the "glass/cell/polymer sheet - open rack" option instead of the"use database option" as shown in the table for snl_module_structure.

The reference irradiance condition for the simple efficiency module model is the value that you specify, typically $1,000 \mathrm{~W} / \mathrm{m}^{2}$. The reference cell temperature is $25^{\circ} \mathrm{C}$.

The effective total irradiance (the diffuse utilization factor $F_{d}$ is adapted from the Sandia module model, and is equal to one for flat plate modules):

$$
G=G_{b}+f_{d}\left(G_{d}+G_{r}\right)
$$

SAM determines the module's conversion efficiency $\eta_{m}$ by using linear interpolation on the radiation and efficiency values in the efficiency table to estimate the conversion efficiency at the effective total irradiance value $G$.

The module's DC power output:

$$
P_{m p}=G \eta_{m} A_{m} \frac{\gamma_{m p, r e f}}{100}\left(T_{c}-25\right)
$$

\subsection{NOCT Cell Temperature Model}

The NOCT photovoltaic cell temperature model is from Chapter 23.3 of Duffie and Beckman (2013), also described in De Soto (2004b). In SAM's implementation of the model, it is available with the CEC Performance Model with Module Database module model on the Module input page as the NOCT cell temp model option (cec_temp_corr_mode $=0$ in SSC pvsamv1).

The cell temperature is only calculated when the effective transmitted irradiance from Equation 10.25 is greater than zero, $G>0$. 
Table 15. NOCT Cell Temperature Model Variable Definitions

\begin{tabular}{lll}
\hline Symbol & Description / Name in SAM & Name in SSC \\
\hline \multicolumn{3}{c}{ Inputs } \\
$G$ & effective irradiance transmitted to cell $\left(\mathrm{W} / \mathrm{m}^{2}\right)$ & - \\
$\tau \alpha$ & effective transmittance-absorbtance product & - \\
$v_{w}$ & wind speed $(\mathrm{m} / \mathrm{s})$ & - \\
- & Array height $(\mathrm{m})$ & cec_height \\
- & Mounting standoff & cec_standoff \\
$T_{n o c t}$ & module NOCT temperature rating $\left({ }^{\circ} \mathrm{C}\right)$ & 6par_tnoct \\
$I_{m p}$ & module maximum power current rating (A) & 6par_imp \\
$V_{m p}$ & module maximum power voltage rating $(\mathrm{V})$ & 6par_vmp \\
$A_{m}$ & module area in meters $\left(\mathrm{m}^{2}\right)$ & 6par_area \\
\hline \multicolumn{3}{c}{ Output } \\
$T_{c}$ & cell temperature $\left({ }^{\circ} \mathrm{C}\right)$ & subarray $[n] \_c e l l t e m p$ \\
\hline
\end{tabular}

The reference module efficiency is based on the module specifications at $1,000 \mathrm{~W} / \mathrm{m}^{2} \mathrm{POA}$ irradiance:

$$
\eta_{\text {ref }}=\frac{I_{m p} V_{m p}}{1000 A_{m}}
$$

The wind speed adjusted for height above the ground depends on the Array height option on the Module page (cec_height in SSC):

$$
v_{w, a d j}= \begin{cases}0.51 v_{w} & \text { one story or lower } \\ 0.61 v_{w} & \text { two stories or higher }\end{cases}
$$

The NOCT adjusted for mounting stand-off type depends on the Mounting standoff option on the Module page (cec_standoff in SSC):

$$
T_{\text {noct }, \text { adj }}= \begin{cases}T_{\text {noct }} & \text { building integrated, greater than } 3.5 \text { in, or ground/rack mounted } \\ T_{\text {noct }}+2 & 2.5 \text { to } 3.5 \text { in } \\ T_{\text {noct }}+6 & 1.5 \text { to } 2.5 \mathrm{in} \\ T_{\text {noct }}+11 & 0.5 \text { to } 1.5 \mathrm{in} \\ T_{\text {noct }}+18 & \text { less than } 0.5 \mathrm{in}\end{cases}
$$

The cell temperature in degrees Celsius $\left({ }^{\circ} \mathrm{C}\right)$ :

$$
T_{c}=T_{a}+\frac{G}{800}\left(T_{\text {noct }, a d j}-20\right)\left(1-\frac{\eta_{\text {ref }}}{\tau \alpha}\right) \frac{9.5}{5.7+3.8 v_{w, a d j}}
$$

\subsection{Heat Transfer Cell Temperature Model}

The heat transfer cell temperature model is from the descriptions in Chapters 4 and 5 and the FORTRAN implementation in Appendix H of Neises (2011). SAM's model is adapted from this implementation, and its description is omitted from this section because of its length.

In SAM, the heat transfer cell temperature model is available with the CEC Performance Model with Module Database module model on the Module input page as the Mounting specific cell temp model option (cec_temp_corr_mode $=1$ in SSC pvsamv1). 
Table 16. Heat Transfer Cell Temperature Model Variable Definitions

\begin{tabular}{|c|c|}
\hline Description / Name in SAM & Name in SSC \\
\hline \multicolumn{2}{|c|}{ Inputs } \\
\hline Mounting Configuration & cec_mounting_config \\
\hline Heat Transfer Dimensions & cec_heat_transfer \\
\hline Mounting Structure Orientation & cec_mounting_orientation \\
\hline Module Width (m) & cec_module_width \\
\hline Module Length (m) & cec module length \\
\hline Rows of modules in array & cec_array_rows \\
\hline Columns of modules in array & cec_array_cols \\
\hline Temperature behind the module $\left({ }^{\circ} \mathrm{C}\right)$ & cec_backside_temp \\
\hline Gap Spacing $(\mathrm{m})$ & cec_gap_spacing (m) \\
\hline \multicolumn{2}{|c|}{ Irradiance and Weather Inputs } \\
\hline wind speed $(\mathrm{m} / \mathrm{s})$ & - \\
\hline beam POA $\left(\mathrm{W} / \mathrm{m}^{2}\right)$ & - \\
\hline sky diffuse POA $\left(\mathrm{W} / \mathrm{m}^{2}\right)$ & - \\
\hline ground diffuse POA $\left(\mathrm{W} / \mathrm{m}^{2}\right)$ & - \\
\hline atmospheric pressure (mbar) & - \\
\hline dry-bulb temperature $\left({ }^{\circ} \mathrm{C}\right)$ & - \\
\hline dew-point temperature $\left({ }^{\circ} \mathrm{C}\right)$ & - \\
\hline \multicolumn{2}{|c|}{ Output } \\
\hline cell temperature & subarray $[n]$ _celltemp \\
\hline
\end{tabular}

\subsection{Sandia Cell Temperature Model}

The Sandia photovoltaic cell temperature model is the cell temperature model described in King (2004) as part of the Sandia photovoltaic array performance model. In SAM's implementation of the model, it is available with the Sandia PV Array Performance Model with Module Database module model on the Module input page.

The Sandia cell temperature model requires the effective POA irradiance and three empirical parameters from the Sandia module library, which stores data provided by the Sandia National Laboratories Photovoltaic Test and Evaluation program (Sandia 2014).

SAM's Module input page provides the Module Structure and Mounting option, which allows you to choose to use $a, b$, and $\Delta T$ values from the Sandia module library, choose from a set of pre-determined values for different module types and air circulation options, or provide your own "user-defined" values. In SSC, the variable snl_module_structure determines the option, and the variables shown in Table 17 with '_ref' are for userspecified values. Table 18 shows the $a, b$, and $\Delta T$ values associated with each option in both SAM and SSC.

The effective irradiance:

$$
G=G_{b}+G_{d}+G_{r}
$$

The module back temperature in degrees Celsius $\left({ }^{\circ} \mathrm{C}\right)$ :

$$
T_{m}=G e^{a+b v_{w}}+T_{a}
$$

The cell temperature in degrees Celsius $\left({ }^{\circ} \mathrm{C}\right)$ :

$$
T_{c}=T_{m}+\frac{G}{1000} \Delta T
$$


Table 17. Sandia Cell Temperature Model Variable Definitions

\begin{tabular}{|c|c|c|}
\hline Symbol & Description / Name in SAM & Name in SSC \\
\hline \multicolumn{3}{|c|}{ Inputs } \\
\hline$G_{b}$ & effective beam irradiance $\left(\mathrm{W} / \mathrm{m}^{2}\right)$ & - \\
\hline$G_{d}$ & effective sky diffuse irradiance $\left(\mathrm{W} / \mathrm{m}^{2}\right)$ & - \\
\hline$G_{r}$ & effective ground-reflected irradiance $\left(\mathrm{W} / \mathrm{m}^{2}\right)$ & - \\
\hline$v_{w}$ & wind speed $(\mathrm{m} / \mathrm{s})$ & - \\
\hline$T_{a}$ & ambient temperature $\left({ }^{\circ} \mathrm{C}\right)$ & - \\
\hline$a$ & Temperature coefficient a & snl_a or snl_ref_a \\
\hline$b$ & Temperature coefficient $\mathbf{b}$ & snl_borsnl_ref_b \\
\hline$\Delta T$ & Temperature coefficient $\mathbf{d T}\left({ }^{\circ} \mathrm{C}\right)$ & snl_dtcorsnl_ref_dtc \\
\hline \multicolumn{3}{|c|}{ Output } \\
\hline$T_{c}$ & cell temperature & subarray $[n]$ _celltemp \\
\hline
\end{tabular}

Table 18. Sandia Module Structure Options

\begin{tabular}{lcccc}
\hline Structure and Mounting & snl_module_structure & $a$ & $b$ & $\Delta T$ \\
\hline Use Database Values & 0 & - & - & - \\
Glass/Cell Polymer Sheet - Open Rack & 1 & -3.56 & -0.075 & 3 \\
Glass/Cell/Glass - Open Rack & 2 & -3.47 & -0.0594 & 3 \\
Polymer/Thin Film/Steel - Open Rack & 3 & -3.58 & -0.113 & 3 \\
Glass/Cell/Polymer Sheet - Insulated Rack & 4 & -2.81 & -0.0455 & 0 \\
Glass/Cell/Glass - Close Roof Mount & 5 & -2.98 & -0.0471 & 1 \\
User Defined & 6 & - & - & - \\
\hline
\end{tabular}


Table 19. IEC 61853 Parameter Calculator Inputs

\begin{tabular}{lll}
\hline Symbol & Description / Name in SAM & Name in SSC \\
\hline$A_{\text {test }}$ & Array of module test data & input \\
$N_{S}$ & Number of cells in series & nser \\
$A_{\text {type }}$ & Cell Type & type \\
\hline
\end{tabular}

Table 20. IEC 61853 Module Model Inputs

\begin{tabular}{|c|c|c|}
\hline Symbol & Description & Name in SSC \\
\hline$V_{m p, r e f}$ & Reference maximum power voltage $(\mathrm{V})$ & sd11par_Vmp0 \\
\hline$I_{m p, r e f}$ & Reference maximum power current (A) & sdl1par_Imp0 \\
\hline$V_{o c, r e f}$ & Reference open circuit voltage (V) & sdllpar_Voc0 \\
\hline$I_{s c, r e f}$ & Reference short circuit current (A) & sd1lpar_Isc0 \\
\hline$n$ & Diode factor & sd11par_alphaIsc \\
\hline$I_{L}$ & Light current (A) & sdlipar_Il \\
\hline$I_{o}$ & Saturation current (A) & sd11par_Io \\
\hline$\alpha$ & alpha $\left(\mathrm{A} /{ }^{\circ} \mathrm{C}\right)$ & sd11par_alphaIsc \\
\hline$\beta$ & beta $\left(\mathrm{V} /{ }^{\circ} \mathrm{C}\right)$ & sd11par_Il \\
\hline$E_{g}$ & Bandgap voltage $(\mathrm{eV})$ & sdllpar_Egref \\
\hline$\gamma$ & $\operatorname{gamma}\left(\% /{ }^{\circ} \mathrm{C}\right)$ & sd11par_Io \\
\hline$C 1 . .3$ & Rsh parameters & sd11par_c1..3 \\
\hline$D 1 . .3$ & Rs parameters & sd11par_d1...3 \\
\hline \multicolumn{3}{|c|}{ Inputs for Spectral Effects Model } \\
\hline$a_{0 . .4}$ & Air mass modifiers & sd11_AMa $0 . .4$ \\
\hline \multicolumn{3}{|c|}{ Inputs for Angle of Incidence Correction } \\
\hline$a_{0 . .4}$ & Module cover & sd11_glass \\
\hline
\end{tabular}

\subsection{IEC 61853 Single Diode Module Model}

The IEC-61853 Single Diode model is a detailed method for predicting the performance of flat plate photovoltaic modules. The model uses data from modules tested according to the International Electrotechnical Commission (IEC) power and rating standard, IEC 61853, Irradiance and Temperature Performance Measurements and Power Rating. A summary of the model follows, with full details available in Dobos (2014).

In SSC, the IEC-61853 model has two parts: The iec61853par module calculates input parameters for the singlediode model from inputs listed in Table 19, and pvsamv1 calculates the operating characteristics of the module during the simulation from the inputs listed in Table 20. SAM runs iec61853par from calls in the user interface, and passes the calculated parameter values to pvsamv1 before running a simulation.

IEC-61853 defines a matrix of 23 temperature and irradiance pairs (Table 21) at which a module must be tested for maximum power $P_{m p}$, maximum power current $I_{m p}$, open circuit voltage $V_{o c}$, and short circuit current $I_{s c}$.

The IEC-61853 model extends the basic single diode model which represents a photovoltaic module's currentvoltage characteristic by Eqn. 10.41 .

$$
I=I_{L}-I_{o}\left(\exp \left[\frac{V+I R_{s}}{a}\right]-1\right)-\frac{V+I R_{s}}{R_{s h}}
$$

This current-voltage equation is governed by five parameters: the modified diode nonideality factor $a$, the light current $I_{L}$, the reverse saturation current $I_{o}$, the series resistance $R_{s}$, and the shunt resistance $R_{s h}$. The modified 


\begin{tabular}{lllll}
$\mathrm{W} / \mathrm{m}^{2}$ & $15^{\circ} \mathrm{C}$ & $25^{\circ} \mathrm{C}$ & $50^{\circ} \mathrm{C}$ & $75^{\circ} \mathrm{C}$ \\
\hline 1100 & & $\mathrm{x}$ & $\mathrm{x}$ & $\mathrm{x}$ \\
1000 & $\mathrm{x}$ & $\mathrm{x}$ & $\mathrm{x}$ & $\mathrm{x}$ \\
800 & $\mathrm{x}$ & $\mathrm{x}$ & $\mathrm{x}$ & $\mathrm{x}$ \\
600 & $\mathrm{x}$ & $\mathrm{x}$ & $\mathrm{x}$ & $\mathrm{x}$ \\
400 & $\mathrm{x}$ & $\mathrm{x}$ & $\mathrm{x}$ & \\
200 & $\mathrm{x}$ & $\mathrm{x}$ & $\mathrm{x}$ & \\
100 & $\mathrm{x}$ & $\mathrm{x}$ & &
\end{tabular}

Table 21. IEC-61853 Module Test Matrix

nonideality factor representing the whole module is related to the diode factor $n$ of a single cell by Eqn. 10.42, where $N_{s}$ is the number of cells in series.

$$
a=N_{s} \frac{k T}{q} n
$$

The five parameters are measured at STC, and are translated to operating conditions via auxiliary equations. The standard CEC single diode model in SAM implements Eqns. 10.43-10.47 to translate the parameters given effective irradiance $S$ and cell temperature $T_{c}$, with $S_{r e f}=1000 \mathrm{~W} / \mathrm{m}^{2}, T_{r e f}=25^{\circ} \mathrm{C}$, and $E_{g, r e f}=1.121 \mathrm{eV}$. The series resistance $R_{S}$ is assumed to be constant.

$$
\begin{gathered}
a=a_{r e f} \cdot T_{c} / T_{r e f} \\
I_{L}=\frac{S}{S_{r e f}} \cdot\left(I_{L, r e f}+\alpha\left(T_{c}-T_{r e f}\right)\right) \\
\frac{I_{o}}{I_{o, r e f}}=\left[\frac{T_{c}}{T_{r e f}}\right]^{3} \exp \left[\frac{1}{k}\left(\left.\frac{E_{g}}{T}\right|_{T_{r e f}}-\left.\frac{E_{g}}{T}\right|_{T_{c}}\right)\right] \\
\frac{E_{g}}{E_{g, r e f}}=1-0.0002677\left(T_{c}-T_{r e f}\right) \\
R_{s h}=R_{s h, r e f} \cdot \frac{S_{r e f}}{S}
\end{gathered}
$$

Model parameters result from simultaneously solving the diode equation at five points on the STC I-V curve: short circuit $\left(V=0, I=I_{s c}\right)$, open circuit $\left(V=V_{o c}, I=0\right)$, maximum power $\left(V=V_{m p}, I=I_{m p}\right)$, derivative of maximum power $\left.\frac{d(I V)}{d V}\right|_{m p}=0$, and open circuit temperature coefficient $\beta=\left.\frac{d V}{d T}\right|_{I=0}$. Details are given in De Soto (2004a) and Dobos (2012a).

We assume that the standard single diode model equation is capable of representing actual I-V curve data at operating conditions. Experience suggests that the primary reason for the single diode model's inaccuracies emerges from the choices of auxiliary equations that translate the five parameters to operating conditions. Consequently, the five parameters are assumed to be independent functions of temperature and irradiance. We estimate values for $a, I_{L}, I_{o}$, $R_{s}$, and $R_{s h}$ at each IEC-61853 test condition, and fit the results to new auxiliary equations that are functions of both temperature and irradiance .

At each test measurement in the IEC-61853 matrix, three points on the actual I-V curve are known. Additionally, the derivative of maximum power $\left.\frac{d(I V)}{d V}\right|_{m p}=0$ condition can be applied, yielding four constraint equations. Reasonably assuming that the cell diode factor $n$ should remain constant across temperature and irradiance - after all, it aims to represent an intrinsic physical property of the diode junction - the four constraints are sufficient to solve for $I_{L}, I_{o}, R_{S}$, and $R_{s h}$. The modified diode factor $a$ is calculated by Equation 10.42. 
Next, an estimate must be made for the cell diode factor $n$. The empirical Sandia PV Array Performance Model provides an equation for open circuit voltage that incorporates the diode factor, cell temperature, and the open circuit temperature coefficient $\beta$. The Sandia $V_{o c}$ equation is asymptotically equivalent to the single diode model equation, and is analogous to the " $V_{o c}$ Method" for cell temperature described in IEC-60904-9. While this equation is best suited for crystalline silicon modules, the Sandia model has been shown to be suitable for all cell types King (2007), and thus it is readily used here. Rearranging terms yields an equation for $n$ (Equation 10.48) at any temperature $T_{c}$ and irradiance $S$. $V_{T}$ is thermal voltage $V_{T}=k T_{c} / q$. The temperature coefficient $\beta$ at $1000 \mathrm{~W} / \mathrm{m}^{2}$ is obtained directly by calculating the change in $V_{o c}$ as a function of temperature from the test data. Equation 10.48 is evaluated at all temperature $T_{c}$ and irradiance $S$ conditions in the IEC-61853 test matrix, and the average value yields the final diode factor $n$ that is used in subsequent calculations.

$$
n=\frac{\left(V_{o c}-\beta\left(T_{c}-T_{r e f}\right)-V_{o c, r e f}\right)}{N_{s} \cdot V_{T} \cdot \ln \left(S / S_{r e f}\right)}
$$

With an estimate for $n$, the four constraint equations can now be solved at each test condition. The multidimensional nonlinear Newton's method solves $\mathbf{F}(\mathbf{x})=0$, where $\mathbf{x}=\left[I_{L}, I_{o}, R_{S} \cdot R_{s h}\right]^{\prime}$, and

$$
\mathbf{F}=\left[\begin{array}{l}
I_{L}-I_{o}\left(\exp \left[\frac{I_{c} R_{s}}{a}\right]-1\right)-\frac{I_{s c} R_{s}}{R_{s h}}-I_{s c} \\
I_{L}-I_{o}\left(\exp \left[\frac{V_{o c}}{a}\right]-1\right)-\frac{V_{o c}}{R_{s h}} \\
I_{L}-I_{o}\left(\exp \left[\frac{V_{m p}+I_{m p} R_{s}}{a}\right]-1\right)-\frac{V_{m p}+I_{m p} R_{s}}{R_{s h}}-I_{m p} \\
I_{m p}-V_{m p}\left[\frac{\frac{I_{o}}{a} \exp \left[\frac{V_{m p}+I_{m p} R_{s}}{R^{\prime}}\right]+\frac{1}{R_{s h}}}{1+\frac{I_{o} R_{s}}{a} \exp \left[\frac{V_{m p}+I_{m p} R_{s}}{a}\right]+\frac{R_{s}}{R_{s h}}}\right]
\end{array}\right]
$$

With Newton's method successfully solving for $I_{L}, I_{o}, R_{S}$, and $R_{s h}$ at each test irradiance and temperature, we fit new auxiliary equations for series resistance (Equation 10.50) and shunt resistance (Equation 10.51). Successive nonlinear least-squares fitting is applied to estimate the parameters $C_{1,2,3}$ and $D_{1,2,3}$.

$$
\begin{gathered}
R_{s}=D_{1}+D_{2}\left(T_{c}-T_{r e f}\right)+D_{3}\left(1-\frac{S}{S_{r e f}}\right)\left(\frac{S_{r e f}}{S}\right)^{2} \\
R_{s h}=C_{1}+C_{2}\left[\left(\frac{S_{r e f}}{S}\right)^{C_{3}}-1\right]
\end{gathered}
$$

The standard auxiliary equations (EQuations 10.43-10.46) are retained for $a, I_{L}, I_{o}$, and $E_{g}$, though we note that $E_{g, r e f}$ is fitted to the best fit for $I_{o}$ across the operating range.

Finally, with a full set of equations describing the variation of single diode model parameters across the entire range of irradiance and temperature conditions, the model calculates each parameter's value at every time step and uses a golden search maximization process to find the maximum power $(P=I V)$ by iteratively solving the current-voltage relation to determine $I$ and $V$.

The IEC-61853 model gives the user a choice of standard glass or glass with an anti-reflective coating. The model applies an angle of incidence correction to adjust the direct beam irradiance to account for reflection losses. This model is the same as used in PVWatts version 5, and is an extension of approach in De Soto (2004a).

For standard glass, we use a single slab model, calculating the transmittance through glass with index of refraction of 1.526. This follows the treatment in De Soto (2004a), with the simplification of removing the absorptance term which is determined to have a negligible effect. 
For glass with an anti-reflective coating, a two slab approach is used to model the improvement in angular response. The two slab model involves predicting the transmittance of irradiance through two materials using a physical representation for unpolarized radiation described in De Soto (2004a) twice: once for the anti-reflective (AR) coating, and subsequently for the glass cover.

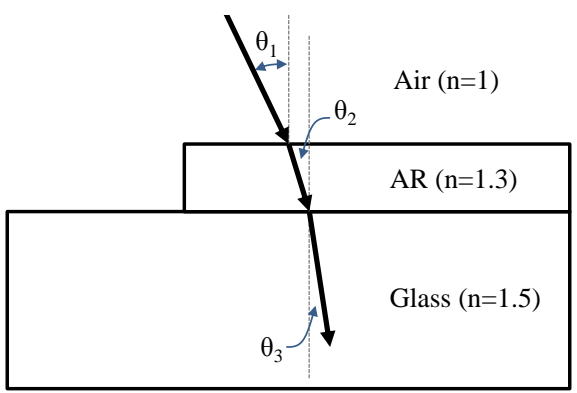

\section{Figure 7. Diagram of Two-slab Module Cover Reflection Loss Model}

First, the angle of refraction $\theta_{2}$ into the AR coating is calculated with Snell's law given angle of incidence $\theta_{1}$ :

$$
\theta_{2}=\arcsin \left(\frac{n_{\text {air }}}{n_{A R}} \sin \left(\theta_{1}\right)\right)
$$

Next, the transmittance through the AR coating is calculated from Fresnel's equation for non-reflected unpolarized radiation, which takes the average of parallel and perpendicular components.

$$
\tau_{A R}=1-0.5\left(\frac{\sin \left(\theta_{2}-\theta_{1}\right)^{2}}{\sin \left(\theta_{2}+\theta_{1}\right)^{2}}+\frac{\tan \left(\theta_{2}-\theta_{1}\right)^{2}}{\tan \left(\theta_{2}+\theta_{1}\right)^{2}}\right)
$$

The angle of refraction into the glass cover $\theta_{3}$ is again determined from Snell's law.

$$
\theta_{3}=\arcsin \left(\frac{n_{A R}}{n_{\text {glass }}} \sin \left(\theta_{2}\right)\right)
$$

The transmittance through the glass is calculated similarly given $\theta_{2}$ and $\theta_{3}$.

$$
\tau_{\text {glass }}=1-0.5\left(\frac{\sin \left(\theta_{3}-\theta_{2}\right)^{2}}{\sin \left(\theta_{3}+\theta_{2}\right)^{2}}+\frac{\tan \left(\theta_{3}-\theta_{2}\right)^{2}}{\tan \left(\theta_{3}+\theta_{2}\right)^{2}}\right)
$$

Finally, the effective transmittance through the AR coated module cover is given by:

$$
\tau_{\text {cover }}=\tau_{A R} \tau_{\text {glass }}
$$

De Soto (2004a) suggests using Bouguer's law to estimate the absorption, but for typical dimensions ( $2 \mathrm{~mm}$ ) and extinction coefficients $(K \approx 4)$ in this application, the absorption is predicted to be less than $0.1 \%$ and is thus ignored.

Normalizing the response curve to normal incidence shows that the model predicts an improvement in light capture at high incidence angles for AR glass, which agrees with data from manufacturers of AR coated modules (Fig. 8). 


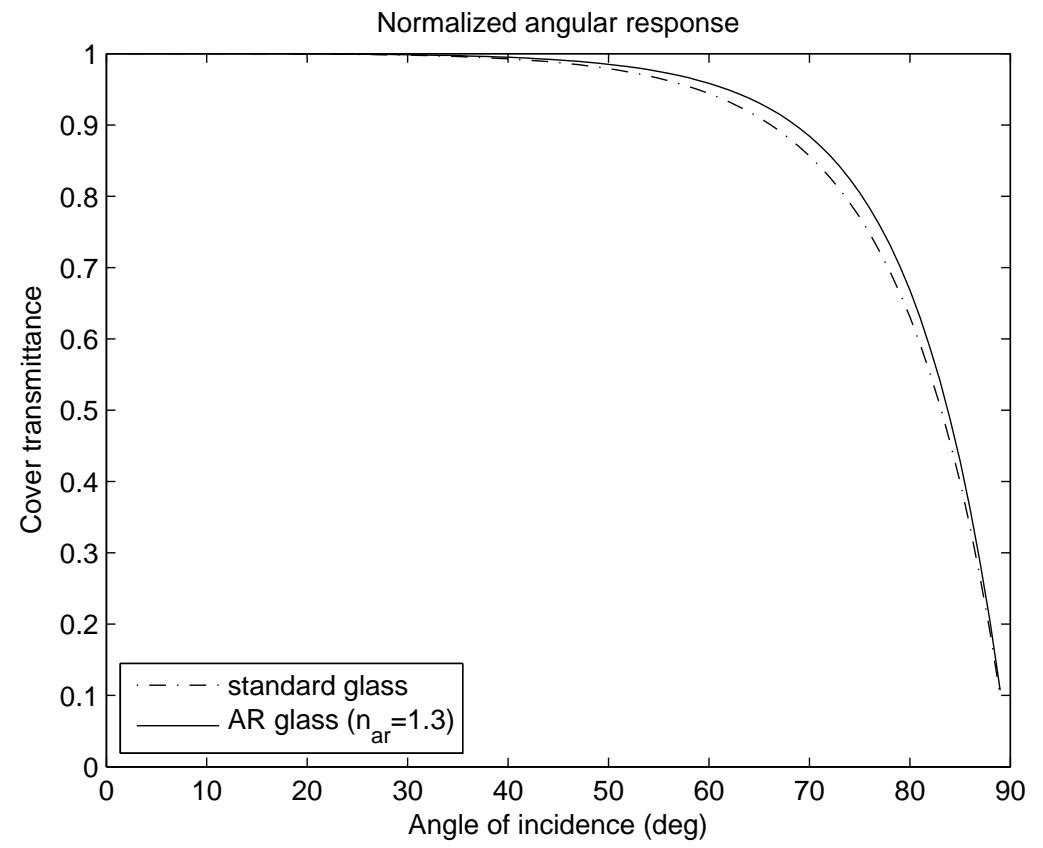

Figure 8. Normalized Comparison of Angular Response of Two-slab Model to Single-slab Model

The AR glass option will predict slightly higher output compared with the standard option due to the improved angular response. The normal incidence transmittance of the module cover is assumed to be captured in the nameplate rating of the system.

Finally, we note that the IEC-61853 module model handles spectral effects using the Sandia effective air mass polynomial to calculate an air mass modifier coefficient that reduces the available effective irradiance to the cell. The module temperature is estimated using the standard CEC single diode model approach. 


\section{Array DC Output}

The photovoltaic array may consist of a single subarray, or up to four subarrays. Each subarray may have different orientation, tracking and ground coverage ratio (GCR). SAM calculates the each subarray's DC output by multiplying a single module's DC output (Section 10) by the number of modules in the array. This assumes that all of the modules in the array operate uniformly at the same maximum power point.

SAM does not explicitly calculate electrical losses due to voltage between modules that would occur in a real system operating at the modules' maximum power point. You can account for those losses using the DC module mismatch loss input (Section 11.3).

For an array with more than one subarray, the array's DC output is the sum of the subarray outputs. In some cases, SAM can estimate losses due to maximum power point mismatches between the subarrays (Sections 11.1 and 11.6).

\subsection{Voltage and Current}

SAM calculates the array's operating voltage in each time step to determine the inverter's input voltage, assuming that each module operates at its maximum power point. For systems with more than one subarray, SAM assumes that all subarrays have the same number of modules per string $N_{\text {modules }}$. The operating voltage $V_{d c}$ in a given time step is the string voltage, equal to the module maximum-power-point voltage times the number of modules per string:

$$
V_{d c}=V_{m p} N_{\text {modules }}
$$

However, under certain conditions, SAM adjusts the array operating voltage:

- The operating voltage falls outside of the range defined by the inverter's minimum and maximum input MPPT voltage ratings (Section 12.4)

- The system consists of more than one subarray, and the subarrays have different maximum power points, for example because of different orientation or type of tracking (Section 11.6).

SAM also reports the open circuit voltage and short circuit current of each subarray for reference, where $V_{o c}$ and $I_{s c}$ are calculated by the module model (Section 10.1):

$$
\begin{aligned}
V_{o c, n} & =V_{o c} N_{\text {modules }} \\
I_{s c, n} & =I_{s c}
\end{aligned}
$$

\subsection{Power Output}

The power output of each subarray is the product of number of modules in the subarray and the DC loss factors associated with the subarray:

$$
P_{d c, n}=N_{\text {modules }} N_{\text {strings }, n} P_{m p, n} F_{d c s s, n} F_{d c, n} F_{\text {snow }, n}
$$

The array's power output is the sum of the subarray DC power output values :

$$
P_{d c}=\sum_{n=1}^{N_{s u b}} P_{d c, n}
$$

The optional self shading DC loss factor $F_{d c s s}$ is from (Equation 9.27). The DC electrical losses $F_{d c, n}$ and DC snow losses $F_{\text {snow }, n}$ are described below. 
Table 22. Array DC Output Variable Definitions

\begin{tabular}{|c|c|c|}
\hline Symbol & Description / Name in SAM & Name in SSC \\
\hline \multicolumn{3}{|c|}{ Inputs } \\
\hline$V_{m p}$ & module DC voltage $(\mathrm{V})$ & - \\
\hline$P_{m p}$ & module DC power $(\mathrm{W})$ & - \\
\hline$N_{\text {modules }}$ & Modules per string & modules_per_string \\
\hline$N_{\text {parstrings }}$ & Strings in parallel & strings_in_parallel \\
\hline$N_{\text {strings }, n}$ & Strings allocated to subarray $n$ & subarray $[n]$ _nstrings \\
\hline$N_{\text {sub }}$ & number of enabled subarrays & - \\
\hline$L_{\text {mismatch }, n}$ & Module mismatch subarray $n(\%)$ & subarray $[n]$ _dcloss \\
\hline$L_{\text {diodeconn }, n}$ & Diodes and connections subarray $n(\%)$ & subarray $[n]$ _dcloss \\
\hline$L_{d c w i r i n g, n}$ & DC wiring subarray $n(\%)$ & subarray $[n]$ _dcloss \\
\hline$L_{\text {tracking }, n}$ & Tracking error subarray $n(\%)$ & subarray $[n]$ _dcloss \\
\hline$L_{\text {nameplate }, n}$ & Nameplate subarray $n(\%)$ & subarray $[n]$ _dcloss \\
\hline$L_{\text {dcoptimizer }, n}$ & DC power optimizer loss subarray $n(\%)$ & subarray $[n]$ _dcloss \\
\hline \multicolumn{3}{|c|}{ Outputs } \\
\hline$V_{d c, n}$ & Subarray $[n]$ Operating voltage $(V)$ & subarray $[n]$ _dc_voltage \\
\hline$V_{o c, n}$ & Subarray $[n]$ Open circuit voltage $(\mathrm{V})$ & subarray $[n]$ _voc \\
\hline$I_{s c, n}$ & Subarray $[n]$ Short circuit current (A) & subarray $[n]$ _isc \\
\hline$V_{d c}$ & Inverter DC input voltage (V) & inverter_dc_voltage \\
\hline$P_{d c}$ & Array power (DC) (kW) & dc_net \\
\hline
\end{tabular}

\subsection{Electrical Losses}

SAM models electrical losses on the DC side of the system using a single DC loss factor for each subarray in the system that applies to the gross DC power output. The DC loss factor for each subarray $F_{d c, n}$ is calculated from the six loss percentages on the Losses input page:

$$
\begin{aligned}
F_{d c, n} & =F_{d c 1, n} F_{d c 2, n} F_{d c 3, n} F_{d c 4, n} F_{d c 5, n} F_{d c 6, n} \\
F_{d c 1, n} & =1-\frac{L_{\text {mismatch }, n}}{100} \\
F_{d c 2, n} & =1-\frac{L_{d i o d e c o n n, n}}{100} \\
F_{d c 3, n} & =1-\frac{L_{d c w i r i n g, n}}{100} \\
F_{d c 4, n} & =1-\frac{L_{\text {tracking, },}}{100} \\
F_{d c 5, n} & =1-\frac{L_{\text {nameplate, }}}{100} \\
F_{d c 6, n} & =1-\frac{L_{d c o p t i m i z e r, n}}{100}
\end{aligned}
$$

The single DC power optimizer loss applies to all subarrays.

\subsection{Snow Losses}

The snow cover model estimates the portion of the array that is covered by snow and calculates a loss caused by the snow that applies to the subarray's gross DC power output. The model calculates a reduction in subarray power 
Table 23. Snow Loss Model Variable Definitions

\begin{tabular}{|c|c|c|}
\hline Symbol & Description / Name in SAM & Name in SSC \\
\hline \multicolumn{3}{|c|}{ Inputs } \\
\hline- & Estimate losses due to snow & en_snow_model \\
\hline$M_{\text {side }, n}$ & Number of modules along side of row & subarray $[n]$ nmody \\
\hline$\beta_{0, n}$ & tilt & subarray $[n]$ ttilt \\
\hline$\beta_{S, n}$ & surface tilt angle (calculated output) & subarray $[n]$ _surf_tilt \\
\hline$D_{\text {snow }}$ & snow depth $(\mathrm{cm})$ & - \\
\hline$T_{d r y}$ & ambient dry bulb temperature $\left({ }^{\circ} \mathrm{C}\right)$ & - \\
\hline$G_{b}$ & beam POA irradiance $\left(\mathrm{W} / \mathrm{m}^{2}\right)$ & - \\
\hline$G_{d}$ & diffuse POA irradiance (sky and ground) & - \\
\hline sunup & Sun up over horizon $(0 / 1)$ & sunup \\
\hline \multicolumn{3}{|c|}{ Outputs } \\
\hline$P_{\text {snow }}$ & Power loss due to snow (W) & de_snow_loss \\
\hline$D_{\text {snow }}$ & Snow depth from weather file $(\mathrm{cm})$ & snowdepth \\
\hline$P_{\text {snow }, n}$ & Subarray $[n]$ Power loss due to snow (W) & subarray $[n]$ _snow_loss \\
\hline$C_{\text {snow }, n}$ & Subarray $[n]$ Snow coverage $(0 . .1)$ & subarray $[n]$ _snow_coverage \\
\hline
\end{tabular}

output instead of a reduction in POA irradiance because it was developed empirically by measuring system electrical output for several photovoltaic systems installed in snowy climates, as described in Marion (2013) and Ryberg (2015).

To use the snow model in SAM, check Estimate losses due to snow on the Shading and Snow input page. Be sure to use a weather file with snow depth data. The Maximum snow depth value on the Location and Resource page indicates whether there is snow depth data in the weather file: A value of "NaN" indicates there is no snow depth data in the file. Also make sure that the Number of modules along side on the Shading and Snow input page is consistent with the number of modules in the subarray. In SSC, set en_snow_model $=1$ to enable the snow model, and check that the value of subarray $[n] \_$nmody is correct.

Snow coverage is a fraction of the height of a subarray row as shown in Figure 9, where $C_{\text {snow }}=1$ represents a subarray fully covered by snow. The snow model only considers snow sliding off of the array as a removal mechanism. It does not consider other snow removal processes such as melting or removal by wind.

The diagram in Figure 9 shows an example of how snow cover is represented in the model. Snow coverage is shown in blue and is measured as the percent of each row's height which is covered (i.e. $0 \%$ coverage corresponds to no snow on the paned while $100 \%$ coverage corresponds to a completely covered panel). The coverage in the figure would correspond to roughly $40 \%$.

The model makes the following checks and issues a simulation message if the subarray tilt angle $\beta_{S, n}$ is out of range, and stops the simulation if the snow depth $D_{\text {snow }}$ is out of range for more than 500 time steps:

$$
\begin{gathered}
10^{\circ}<\beta_{S, n}<45^{\circ} \\
0 \mathrm{~cm}<D_{\text {snow }}<610 \mathrm{~cm}
\end{gathered}
$$

SAM's snow model algorithm is adapted from Marion (2013). For each time step:

\section{Determine snow coverage}

If all of the following conditions are met, then set $C_{\text {snow }}=1$ :

- Snow depth $D_{\text {snow }}$ is greater than its value in the previous time step. 


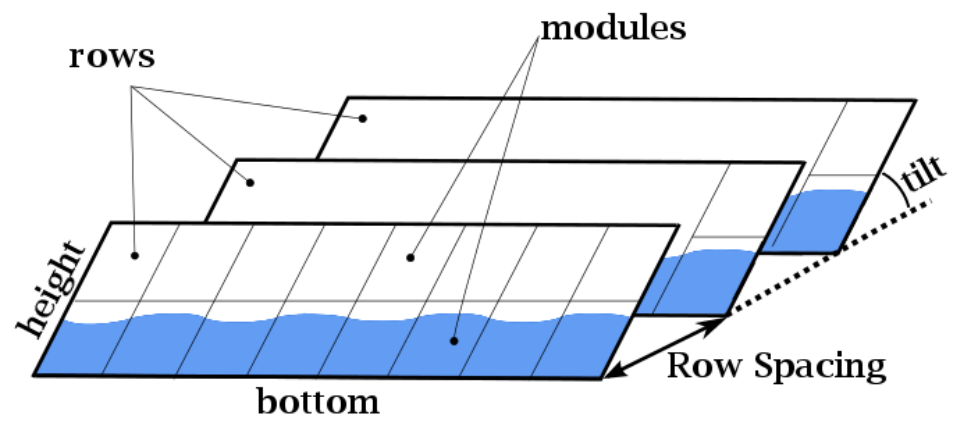

Figure 9. Diagram of Snow Cover on a Photovoltaic Array

- $D_{\text {snow }}$ in the current time step is greater than $1 \mathrm{~cm}$.

- The difference between $D_{\text {snow }}$ in the current and previous time steps is greater than $1 \mathrm{~cm} / \mathrm{hr}$.

If any of the above conditions are not met, set $C_{\text {snow }}$ to the previous time step's value.

In addition, the following modification to the algorithm described in Marion (2013) ensures that snow does not remain on a horizontal or slightly tilted subarray when there is no snow on the ground:

- If $D_{\text {snow }}<1 \mathrm{~cm}$, then set $C_{\text {snow }}=0$.

\section{Decrease amount of snow coverage if sliding occurs}

The following test determines whether the ambient temperature for the current time step is high enough to initiate snow sliding:

$$
T_{d r y}>\frac{G_{b}+G_{d}}{m}
$$

The constant parameter $m=-80 \mathrm{~W} / \mathrm{m}^{2} /{ }^{\circ} \mathrm{C}$ and relationship in Equation 11.6 were determined experimentally as described in Marion (2013).

If snow sliding occurs, then reduce the amount of snow coverage $C_{\text {snow }}$ on the subarray by A. The model divides the row height into ten tenths so that the snow slides in increments of one tenth the length of the row's side:

$$
A=0.10\left(1.97 \sin \beta_{S}\right)
$$

If sliding does not occur, set the snow coverage $C_{\text {snow }}$ for the current time step to its value in the previous time step.

For a simulation with sub-hourly time steps, the snow coverage $C_{\text {snow }}$ is reduced by the time step's fraction of an hour to ensure that the reduction over the hour is $10 \%$ of the previous hours snow coverage value. For example, for 15-minute time steps, the reduction would be $\frac{15}{60} \mathrm{~A}$.

Because SAM does not calculate surface angles for night-time time steps (sunup $=0$ ), the snow model sets the nighttime subarray tilt angle to the base value $\beta_{0}, n$ to ensure it accounts for snow sliding that may occur at night. Note that $\beta_{0}, n$ is the the subarray tilt angle input and, for one-axis tracking arrays, is different from the surface tilt angle $\beta_{S}, n$ calculated based on the position of the sun.

\section{Calculate reduction in subarray's DC output}


After determining the snow coverage $C_{\text {snow }}$, the model calculates the resulting reduction in DC power for the subarray as the loss factor $F_{\text {snow. }}$. SAM assumes that if a string is partially covered by snow, its output is zero. For example, Figure 9 shows three rows of an array with two modules along the side of each row. In this case, SAM considers each row to consist of two parallel strings of modules. One string in each row is partially covered by snow, so the snow loss would be $50 \%$, so that array's DC output would be half of what it would be with no snow.

To calculate the DC snow loss factor for subarray $n$,

$$
F_{\text {snow }, n}=1-\frac{\left\lceil C_{\text {snow }} M_{\text {side }, n}\right\rceil}{M_{\text {side }, n}}
$$

\subsection{Maximum Power Point Tracking}

SAM does not explicitly model a maximum power point tracker or other power conditioning equipment. However, SAM does assume that the array operates at its maximum power point, so it implicitly assumes that photovoltaic system is equipped with a maximum power point tracking system.

You can account for electricity consumption of maximum power point tracking equipment and other related losses using the DC losses (see Section 11.3).

\subsection{Subarray Mismatch Losses}

For systems with more than one subarray, when the subarrays have different orientations, tracking, shading factors, or DC loss factors, the maximum power point of each subarray is different. In such cases, SAM calculates the array's DC output voltage in one of two ways:

- By averaging the values of the subarray string voltages (available with all module models):

$$
V_{d c}=\frac{1}{N_{s u b}} \sum_{n=1}^{N_{s u b}} V_{d c, n}
$$

- By running the module model iteratively for each subarray to determine the array's maximum string voltage (available with the CEC and IEC 61853 module models only) as described below.

When you choose the CEC or IEC 61853 module model, the Calculate maximum power voltage for array and associated losses due to subarray mismatch check box at the bottom of the System Design input page (enable_mismatch_vmax_calc $=1$ in the SSC pvsamv1 module) determines what method SAM uses to calculate the array's maximum power point DC voltage.

For a system with more than one subarray, SAM can estimate losses due to maximum power point mismatches between subarrays, but only for the single-diode equivalent circuit module models (CEC and IEC 61853 models) because they represent the subarray's I-V curve as a continuous function, which makes it possible to estimate the subarray power at points that are off of the maximum power point. The point-value models (simple efficiency and Sandia module) calculate values at discrete points on the subarray's I-V curve, and are not suitable for estimates of module power at other points on the curve (Dobos 2012b).

The subarray mismatch loss algorithm (Dobos 2012b) is intended to model situations that may occur in residential rooftop systems when the array is installed on different parts of the roof with different orientations and connected to a single inverter. The group of modules on each roof surface is a subarray, and may have its own set of parameters defining its tilt and azimuth angles, tracking, shading factors, and DC losses.

In larger systems, modules are typically oriented uniformly across the entire array. SAM's subarray mismatch algorithm is not suitable for such systems. SAM does not calculate mismatch losses due to maximum power point losses between individual modules in the array or in each subarray. 
The algorithm determines the system's maximum power point in a given time step by running the CEC or IEC 61853 module model over a range of maximum power point voltage values to find the voltage that results in the complete array's highest maximum power given each of its subarray's effective POA irradiance, module performance and temperature parameters.

The subarray mismatch algorithm runs the cell temperature model (Section 10.2) and module model separately from the model runs for the main system energy calculations. Therefore, in addition to the input variables listed in Table 28, the algorithm also uses the inputs listed in Tables 9 and 13. 


\section{Inverter AC Output}

SAM uses one of the inverter models listed in Section 12.1 to calculate the total AC power output of all of the inverters in the system. For systems with more than one inverter, SAM models the inverters as a single large inverter that operates with the array DC string voltage as the inverter's input voltage. SAM cannot model a system with more than one type of inverter.

The inverter models calculate the inverter's DC-to-AC power conversion efficiency at rated and part-load operating power. They do not explicitly account for the effect of temperature on inverter performance or for the impact on inverter performance of power factor control or grid outages.

SAM accounts for two kinds of inverter losses, or "clipping" described in Section 12.4.

\subsection{Inverter Models}

SAM calculates the a single inverter's AC output with one of three inverter models (Blair 2013). Table 24 lists the variables that are the same for the all three inverter models. Variables that apply to each specific inverter module are listed in the relevant section:

- Inverter CEC Database (Section 12.2), also called the Sandia inverter model, is an empirical model that uses manufacturer specifications with four empirically derived coefficients $C_{0}, C_{1}, C_{2}, C_{3}$ (King 2007). It uses parameters from a database maintained by the California Energy Commission (Go Solar California 2014).

- Inverter Datasheet (Section 12.2) is an implementation of the Sandia inverter model that sets the values of the empirical coefficients to zero so that the inverter can be modeled with only manufacturer specifications.

- Inverter Part Load Curve) (Section 12.3) is a model developed by NREL for SAM that uses a table of efficiency values at different inverter load levels to represent the inverter's performance.

In SSC pvsamv1, the input variable inverter_model determines the module model as shown in Table 25.

\subsection{Sandia Inverter Model}

SAM's Sandia Inverter model is an implementation of the empirical model described in King (2007). As explained in Section 12.1, SAM has two implementations of the Sandia inverter model: One uses a set of reference parameters from the Sandia Inverters library with data provided by the California Energy Commission (Go Solar California 2014), and the other uses manufacturer specifications without the additional $C$ coefficients included in the library. Both versions are described in this section.

In SSC, the implementation of the Sandia inverter model described here is part of the pvsamv1 module. The SSC module pvsandiainv is a standalone implementation of the Sandia inverter model that is not used by SAM, but is available as part of the SSC software development kit.

The Sandia Inverter model variables are listed in Tables 24 and 26.

For the Inverter Datasheet option (inverter_model $=1$ in SSC), there is an additional input for the inverter's nominal DC-to-AC power conversion efficiency $\eta_{i n v, 0}$. SAM calculates the maximum DC input power from the rated efficiency and rated maximum AC output power values:

$$
P_{d c, 0}=\frac{P_{a c, 0}}{\eta_{i n v, 0}}
$$


Table 24. Inverter Model Variable Definitions

\begin{tabular}{|c|c|c|}
\hline Symbol & Description / Name in SAM & Name in SSC \\
\hline \multicolumn{3}{|c|}{ Inputs } \\
\hline$P_{d c}$ & Array power (DC) $(\mathrm{kW})$ & \\
\hline$N$ & number of inverters & inverter_count \\
\hline$V_{d c}$ & DC string voltage $(\mathrm{V})$ & - \\
\hline$V_{d c, \max }$ & Maximum DC voltage (V) & {$[\ldots] \_v d c m a x$} \\
\hline$I_{d c, \max }$ & Maximum DC current $(\mathrm{A})^{*}$ & {$[\ldots]$ idco } \\
\hline$V_{d c, 0}$ & Nominal DC voltage (V) & {$[\ldots] \_\mathrm{vdcO}$} \\
\hline$P_{S, 0}$ & Power consumption during operation (W) & {$[\ldots] \_p s o$} \\
\hline$P_{n t, 0}$ & Power consumption at night (W) & {$[\ldots] \_p n t$} \\
\hline$P_{a c, 0}$ & Maximum AC power $(\mathrm{W})$ & {$[\ldots] \_$paco } \\
\hline$P_{d c, 0}$ & Maximum DC power $(\mathrm{W})$ & {$[\ldots] \_p d c o$} \\
\hline$V_{a c, 0}$ & Nominal AC voltage $(\mathrm{V})$ & {$[\ldots]$ ac_voltage } \\
\hline$V_{d c, \text { mpptmax }}$ & Minimum MPPT DC voltage (V) & mppt_low_inverter \\
\hline$V_{d c, \text { mpptmin }}$ & Maximum MPPT DC voltage (V) & mppt_hi_inverter \\
\hline \multicolumn{3}{|c|}{ Outputs } \\
\hline$P_{a c}$ & Power generated by system (kW) & gen \\
\hline$\eta_{\text {inv }}$ & Inverter efficiency $(\%)$ & inv_eff \\
\hline$P_{\text {clip }}$ & Inverter clipping loss $(\mathrm{kW})$ & inv_cliploss \\
\hline$P_{s o}$ & Inverter power consumption loss $(\mathrm{kW})$ & inv_psoloss \\
\hline$P_{n t}$ & Inverter night time loss (kW) & inv_ntloss \\
\hline
\end{tabular}

[...] indicates the inverter model name in SSC: inv_snl, inv_ds, or inv_pd.

* The maximum DC current rating is not used by any of the inverter models.

Table 25. Inverter Models in SSC

\begin{tabular}{lc}
\hline Name in SAM & inverter_model \\
\hline Inverter CEC Database (Sandia) & 0 \\
Inverter Datasheet & 1 \\
Inverter Part Load Curve & 2 \\
\hline
\end{tabular}

Table 26. Sandia Inverter Model Inputs

\begin{tabular}{|c|c|c|}
\hline Symbol & Description / Name in SAM & Name in SSC \\
\hline$c_{0}$ & Curvature between AC power and DC power (1/W) & inv_snl_co \\
\hline$c_{1}$ & Coefficient of $P_{d} c, 0$ variation with DC input voltage $(1 / \mathrm{V})$ & inv_snl_cl \\
\hline$c_{2}$ & Coefficient of $P_{s o}$ variation with DC input voltage $(1 / \mathrm{V})$ & inv_snl_c2 \\
\hline$c_{3}$ & Coefficient of $C_{0}$ variation with DC input voltage $(1 / \mathrm{V})$ & inv_snl_c3 \\
\hline
\end{tabular}


The Sandia inverter model parameters:

$$
\begin{aligned}
A & =P_{d c, 0}\left[1+C_{1}\left(V_{d c}-V_{d c, 0}\right)\right] \\
B & =P_{s, 0}\left[1+C_{2}\left(V_{d c}-V_{d c, 0}\right)\right] \\
C & =C_{0}\left[1+C_{3}\left(V_{d c}-V_{d c, 0}\right)\right]
\end{aligned}
$$

The Sandia inverter model equation:

$$
P_{a c}=\left[\frac{P_{a c, 0}}{A-B}-C(A-B)\right]\left(P_{d c}-B\right)+C\left(P_{d c}-B\right)^{2}
$$

For the special case of the model that is the Inverter Datasheet option in SAM (inverter_model $=1$ in SSC), the Sandia model $C$ coefficients are all set to zero so that Equation 12.3 reduces to:

$$
P_{a c}=\frac{P_{a c, 0}}{P_{d c, 0}-P_{s, 0}}\left(P_{d c}-P_{s o, 0}\right)^{2}
$$

The coefficient $B$ accounts for operating power loss. By setting $B=0$ in Equation 12.3, the operating power less operating power losses is:

$$
P_{a c, s=0}=\left[\frac{P_{a c, 0}}{A}-C A\right] P_{d c}+C P_{d c}^{2}
$$

The operating power losses (inverter self-consumption):

$$
P_{s}= \begin{cases}P_{a c, s=0}-P_{a c} & \begin{array}{l}
\text { Inverter CEC Database option, and } \\
\text { Inverter Datasheet option with manufacturer efficiency) }
\end{array} \\
0 & \text { (Inverter Datasheet option with weighted efficiency) }\end{cases}
$$

For the Inverter Datasheet option, the operating losses are zero.

SAM considers the inverter to be operating at night when the DC input power is less than the operating power losses $P_{d c}<P_{s o}$. At night:

$$
\begin{aligned}
P_{a c} & =-P_{n t, 0} \\
P_{n t} & =P_{n t, 0}
\end{aligned}
$$

When the inverter's output power exceeds the inverter's rated capacity (maximum AC power) $P_{a c}>P_{a c, 0}$, SAM clips the inverter's output to the rated capacity and records the remaining power as the clipping loss:

$$
\begin{aligned}
P_{a c, \text { noclip }} & =P_{a c} \\
P_{a c} & =P_{a c, 0} \\
P_{c l i p} & =P_{a c, \text { noclip }}-P_{a c}
\end{aligned}
$$

The inverter's DC-to-AC power conversion efficiency:

$$
\eta_{i n v}=\frac{P_{a c}}{P_{d c}}
$$


Table 27. Inverter Part Load Curve Model Inputs

\begin{tabular}{lll}
\hline Symbol & Description / Name in SAM & Name in SSC \\
\hline$\eta_{\text {inv }, 0-N}$ & column of $N$ efficiency values $(\%)$ & inv_ds_efficiency \\
$P_{a c, 0-N}$ & column of $N$ AC power output values (W) & inv_ds_partload \\
\hline
\end{tabular}

\subsection{Inverter Part Load Curve Model}

NREL developed the Inverter Part Load Curve model specifically for SAM. The model's variables are listed in Tables 24 and 27.

The part-load ratio for the current time step depends on the inverter's DC input power and its maximum rated DC power:

$$
x=\frac{P_{d c}}{P d c, 0}
$$

The model then uses linear interpolation to calculate the inverter's DC-to-AC conversion efficiency $\eta_{i n v}$ at the DC input power.

The inverter's AC power output for hours when $P_{d c}>0$ :

$$
P_{a c}= \begin{cases}\eta_{i n v} P_{d c} & \text { if } \eta_{i n v} P_{d c} \leq P_{a c, 0} \\ P_{a c, 0} & \text { if } \eta_{i n v} P_{d c}>P_{a c, 0}\end{cases}
$$

For hours when the $\mathrm{AC}$ power is greater than the maximum rated value, the clipping loss value is:

$$
P_{c l i p}=P_{a c}-P_{a c, 0}
$$

At night when $P_{d c} \leq 0$ :

$$
\begin{array}{r}
P_{a c}=-P_{n t, 0} \\
P_{n t}=P_{n t, 0}
\end{array}
$$

\subsection{Inverter Clipping Losses and Voltage Checks}

The photovoltaic performance model calculates two types of inverter clipping losses:

- MPPT clipping is a reduction in the inverter DC input power when the input voltage (DC string voltage) falls outside of the operating range defined by the inverter's minimum and maximum MPPT DC voltage ratings.

- Power clipping is a reduction in the inverter output $\mathrm{AC}$ power caused by inverter saturation when the inverter power exceeds its nameplate rating.

When the DC string voltage is less than the inverter's minimum MPPT voltage rating, SAM sets the DC string voltage to the minimum rating. Similarly, when the DC string voltage is greater than the inverter's maximum MPPT voltage rating, SAM sets the DC string voltage to the maximum rating.

Power clipping is handled by the inverter model as described in the sections above for each inverter model.

The model also compares the DC string voltage to the inverter's rated maximum DC voltage for each time step and issues a warning message at the end of the simulation if the string voltage exceeds the rated voltage for one or more time steps. The model does not attempt to adjust the string voltage to prevent it from exceeding the inverter rating. 


\section{Degradation}

The photovoltaic model offers two options for modeling the reduction in the array's output over time due to degradation of the module cover and other causes. These options are on SAM's Lifetime input page:

- AC degradation: PV simulation over one year (system_use_lifetime_output $=0$ ) applies an annual $\mathrm{AC}$ degradation rate to the system's AC output.

- DC or AC degradation: PV simulation over analysis period (system_use_lifetime_output = 1) applies DC degradation rates to the array's DC output and additional losses to the array DC output or system AC output.

These options are only available in SAM for the Detailed Photovoltaic model with a financial model. They are not available for the model with the "No financial model" option'.

\subsection{AC Degradation: PV Simulation Over One Year}

For this option, Degradation rate is an input to the financial model and is not available as an input to pvsamv1. The photovoltaic performance model calculates the AC output (Section 15.3) of the photovoltaic system for each time step in one year, and the financial model adds up the time series values to calculate the system's total AC output in one year, which it treats as the first year of the system's operation.

The total annual output (AC electricity) of the system in Year One of the project cash flow $Q_{1}$ is the sum of the time series power generated by the system $P_{g e n}$ (Equation 15.3), where $N$ is the number of time steps in the simulation ( $N=8760$ for hourly simulations).

$$
Q_{1}=\sum_{n=0}^{N} \frac{P_{\text {gen }}}{8760 / N}
$$

The AC degradation rate $L_{\text {acdegradation }}$ is an array. When it has one value, the total annual output in Years $n=2$ and later is:

$$
Q_{n}=Q_{n-1}\left(1-L_{\text {acdegradation }, 0}\right)
$$

When the AC degradation is an array of length analysis period, the total annual output in Years $n=2$ and later is:

$$
Q_{n}=Q_{1}\left(1-L_{\text {acdegradation }, n}\right)
$$

This approach accounts for expected decrease in the system's total annual output over time, but because the model applies an AC degradation loss to the AC output, it does not accurately represent scenarios where an inverter or

Table 28. Degradation Variable Definitions

\begin{tabular}{lll}
\hline Symbol & Description / Name in SAM & Name in SSC \\
\hline & \multicolumn{1}{c}{ Inputs } & \\
$L_{\text {acannual }}$ & Degradation rate $(\%)$ & not in pvsamv1 \\
$L_{\text {dcannual }}$ & Module degradation rate $(\%)$ & dc_degradation \\
$L_{\text {dclifetime }}$ & Lifetime daily DC losses $(\%)$ & dc_lifetime_losses \\
$L_{\text {aclifetime }}$ & Lifetime daily AC losses $(\%)$ & ac_lifetime_losses \\
\hline
\end{tabular}


inverter bank might be replaced with a different size inverter in later years to account for the lower DC output of the photovoltaic array, or for the effect of module degradation on battery life for a photovoltaic system with batteries.

If the weather file for a given analysis contains typical-year data (rather than data for a specific year), using the AC degradation factor to represent module degradation is further complicated by the fact that the solar resource input to the module model represents the resource over a multi-year period.

\subsection{DC and AC Degradation: PV Simulation Over Analysis Period}

To model a photovoltaic system with battery storage, where the replacement cost of the battery bank is an important factor in design decisions, SAM provides an option to run the performance model for each year of the analysis period, and to apply a DC degradation rate to the array's DC output to accurately model the effect of module degradation on battery life. It also provides options for an additional set of "lifetime daily losses" that can apply to either the AC or DC output of the system.

Because the battery model is part of the photovoltaic performance model, the inputs required to calculate this reduction in DC and AC output part of the performance model rather than the financial model. That is different from the AC degradation rate described in Section 13.1, which is an input to the financial model.

The DC and AC degradation option does not require that the battery model be enabled.

SAM treats the module annual DC degradation rate $L_{d c a n n u a l}$ as a DC electrical loss and applies it to the DC output of the array in each time step. It can be defined as a single value (an array of length one), in which case the degradation loss is compounded annually, or an array of values (an array of length analysis period), where the degradation loss for each time step is applied to the Year One DC electrical output in that time step.

The lifetime daily DC and AC loss inputs are arrays of length $365 \times$ analysis_period, and are treated as DC and AC electrical losses, respectively. The first loss value is applied to each timestep in the first 24 hours, the second loss value to the second 24 hours, and so one over the entire analysis period.

The DC degradation and lifetime daily DC loss is applied to the DC output of the array $P_{d c}$ (Equation 11.4). The lifetime daily AC loss is applied to the inverter output $P_{a} c$ (Equation 15.3). 


\section{Battery Storage}

SAM's battery storage model calculates power to and from a bank of lead-acid or lithium-ion batteries and estimates battery lifetime. It can also model Vanadium and Iron flow batteries. The model is described briefly here. For a more detailed description of the model with equations, see DiOrio (2015a). For a description of a battery modeling application with cost and financial analysis, see DiOrio (2015b). For a detailed overview of the automated dispatch controller algorithms, see DiOrio (2017).

The battery model is part of SAM's Detailed Photovoltaic model, but only when coupled with one of SAM's cash flow financial models because the battery model involves battery replacements that require a financial model. The battery model requires information about the photovoltaic system, battery parameters, and, for behind-the-meter applications, building electric load data.

For behind-the-meter applications where a building's electric load is met by a photovoltaic system, battery, and grid, use the Residential or Commercial financial model. For these systems, the timing of battery charging by either excess photovoltaic power or the grid and discharges of battery power to meet the building load is determined by either the "manual dispatch model," which is a set of dispatch profiles that you can assign to up to six periods in a hour-by-month matrices for the weekday and weekend, or by your choice of one of the automated dispatch options.

For utility storage applications where the photovoltaic system and battery are connected directly to the grid and do not interact with a building or facility electric load, use one of the Power Purchase Agreement (PPA) financial models. For these systems, the timing of battery charging and discharging is determined by the manual dispatch model.

For an AC-connected battery as shown in Figure 10, the battery is connected to the system's AC bus with singlepoint AC-to-DC and DC-to-AC conversion efficiency inputs to represent electric conversion losses. For a DCconnected battery shown in Figure 11 the battery is connected to a battery management system represented by a single-point DC-DC conversion effiicency.

For both AC- and DC-connected batteries, the model calculates losses caused by degradation over time, thermal effects, and differences in charging and discharging voltages.

To enable the battery model in SAM, choose Enable Battery on SAM's Battery Storage input page. If you want SAM to calculate the timing of battery replacements based on the number of charge and discharge cycles, then you should also choose the PV simulation over analysis period option on the Lifetime input page, which will cause SAM to run a separate 8760 simulation for each year in the analysis period.

In SSC, the battery model is part of the pvsamv1 module or as a standalone battery within the battery module. To enable the battery model in SSC, set en_batt $=1$. See the tables on the following pages for lists of the battery input and output variables in SSC.

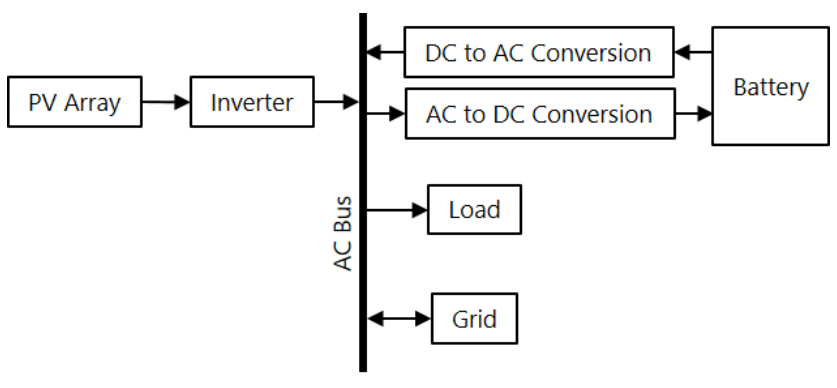

Figure 10. Simplified Block Diagram for AC-Connected Battery 


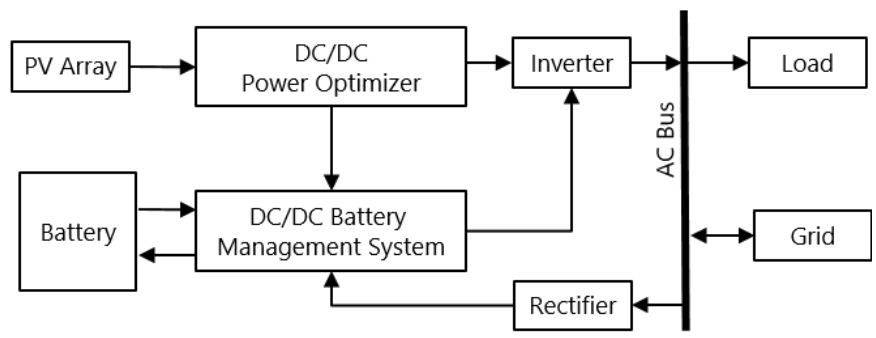

Figure 11. Simplified Block Diagram for DC-Connected Battery

\subsection{Battery with no Photovoltaic System}

Within the user-interface, SAM's battery model is part of the photovoltaic model. It is possible to model a batteryonly system by modeling the battery with the photovoltaic system and removing the photovoltaic system's output by setting the Curtailment and Availability constant loss on the Losses input page to 100\% the photovoltaic system's output to zero (adjust : constant $=100$ in SSC). Within the SDK, SAM's battery model is available as a standalone compute module and accepts a generic generation profile and electricity load as input in addition to the other battery system and dispatch parameters.

\subsection{Battery Model Inputs and Outputs}

The battery model inputs and outputs are listed in Tables 29 through 32 as a reference for programmers working with the SAM API to access the inputs for the pvsamv1 or battery modules of SSC. In the event that the battery is DC-connected, it will share the PV inverter and requires information about the inverter and dc optimizer loss. If code is generated using the SAM user interface, these values will automatically be genenerated, otherwise you will need to specify the inverter model, inverter efficiencies, and DC power optimizer loss.

\subsection{Dispatch Modes}

In the version of SAM described in this manual, there are four dispatch modes: Three automated modes and one manual dispatch mode.

For all of the dispatch modes, you must specify the minimum and maximum states of charge, the minimum time at charge state. For the manual dispatch model, you must also specify the photovoltaic priority: You can choose to prioritize charging the battery over meeting the building load, or vice versa. In SSC, to prioritize meeting the load over charging the battery, set batt_pv_choice $=0$, and to prioritize battery charging, set batt_pv_choice = 1.

The automated dispatch options are:

- Peak shaving: 1-day look ahead (batt_dispatch_choice $=0$ ) option looks at the photovoltaic system's output over the next 24-hours to generate a battery dispatch that minimizes the grid power consumption over the 24-hours period within the state-of-charge and power constraints that you specify.

- Peak shaving: one-day look behind (batt_dispatch_choice $=1$ ) The one-day look behind option assumes that the previous 24 hours are a good indication of what to expect for the next 24 hours and generates a battery dispatch strategy for the next 24 hours based on minimizing grid power consumption in the previous 24-hour period. The one-day look ahead approach might represent an ideal controller that can perfectly predict the future to give results for a best case scenario. The one-day look behind approach might more realistically represent an actual controller that uses historical information to predict the future. 
Table 29. Battery Property and Losses Inputs

\begin{tabular}{|c|c|}
\hline Description / Name in SAM & Name in SSC \\
\hline \multicolumn{2}{|c|}{$\begin{array}{c}\text { Enable Battery Model } \\
\text { en_batt }\end{array}$} \\
\hline \multicolumn{2}{|r|}{$\begin{array}{l}\text { Battery Chemistry } \\
\text { batt_chem }(0=\text { lead acid, 1=Li-ion, 2=Vanadium, 3=Iron })\end{array}$} \\
\hline $\begin{array}{l}\text { Cell nominal voltage }(\mathrm{V}) \\
\text { Internal resistance }(\Omega) \\
\text { C-rate of discharge curve } \\
\text { Fully charged cell-voltage }(\mathrm{V}) \\
\text { Exponential zone cell voltage }(\mathrm{V}) \\
\text { Nominal zone cell voltage }(\mathrm{V})\end{array}$ & $\begin{array}{l}\text { ge Properites } \\
\text { batt_Vnom_default } \\
\text { batt_resistance } \\
\text { batt_C_rate } \\
\text { batt_Vfull } \\
\text { batt_Vexp } \\
\text { batt_Vnom }\end{array}$ \\
\hline $\begin{array}{l}\text { Cell capacity }(\mathrm{Ah}) \\
\text { Nominal bank capacity (DC kWh) } \\
\text { Nominal bank voltage (DC V) } \\
\text { Total number of cells } \\
\text { Cells in series } \\
\text { Strings in parallel } \\
\text { Stacks in series } \\
\text { Maximum discharge power }(\mathrm{DC} \text { kW) } \\
\text { Maximum charge power }(\mathrm{DC} \text { kW) } \\
\text { Time at maximum power (hour) } \\
\text { Maximum discharge current }(\mathrm{A}) \\
\text { Maximum charge current (A) } \\
\text { Max C-rate of discharge (per hour) } \\
\text { Max C-rate of charge (per hour) }\end{array}$ & $\begin{array}{l}\text { t and Capacity } \\
\text { batt_efull } \\
\text { batt_computed_bank_capacity } \\
\text { batt_computed_voltage } \\
\text { batt_num_cells } \\
\text { batt_computed_series } \\
\text { batt_computed_strings } \\
\text { batt_computed_stacks_series } \\
\text { batt_power_discharge_max } \\
\text { batt_power_charge_max } \\
\text { batt_time_capacity } \\
\text { batt_current_discharge_max } \\
\text { batt_current_charge_max } \\
\text { batt_c_rate_max_discharge } \\
\text { batt_c_rate_max_charge }\end{array}$ \\
\hline $\begin{array}{l}\text { DC- or AC-connected battery } \\
\text { DC to DC conversion efficiency }(\%) \\
\text { AC to DC conversion efficiency }(\%) \\
\text { DC to AC conversion efficiency }(\%) \\
\text { DC power optimizer loss }(\%)\end{array}$ & $\begin{array}{l}\text { Converters } \\
\text { batt_ac_or_dc }(0=\mathrm{DC}, 1=\mathrm{AC}) \\
\text { batt_dc_dc_efficiency } \\
\text { batt_ac_dc_efficiency } \\
\text { batt_dc_ac_efficiency } \\
\text { dcoptimizer_loss }\end{array}$ \\
\hline Inverter model & $\begin{array}{l}\text { ter Efficiency } \\
\text { inverter_model }(0=\text { cec, } 1=\text { datasheet }, 2=\text { partload, } \\
3=\text { coefficientgenerator }, 4=\text { generic })\end{array}$ \\
\hline $\begin{array}{l}\text { CEC weighted efficiency }(\%) \\
\text { Datasheet weighted efficiency }(\%) \\
\text { Partload CEC efficiency }(\%) \\
\text { Inverter Coefficient Generator CEC Efficiency }(\%) \\
\text { Generic Inverter Efficiency }(\%)\end{array}$ & $\begin{array}{l}\text { inv_snl_eff_cec } \\
\text { inv_ds_eff_cec } \\
\text { inv_pd_eff_cec } \\
\text { inv_cec_cg_eff } \\
\text { inverter_efficiency }\end{array}$ \\
\hline $\begin{array}{l}\text { Loss input mode } \\
\text { Charging mode }(\mathrm{kW}) \\
\text { Discharging mode }(\mathrm{kW}) \\
\text { Idle mode }(\mathrm{kW}) \\
\text { Time series }(\mathrm{kW})\end{array}$ & $\begin{array}{l}\text { Equipment Losses } \\
\text { batt_loss_choice }(0=\text { operating mode, } 1=\text { time series }) \\
\text { batt_losses_charging } \\
\text { batt_losses_discharging } \\
\text { batt_losses_idle } \\
\text { batt_losses }\end{array}$ \\
\hline
\end{tabular}


Table 30. Battery Controller Inputs

\begin{tabular}{|c|c|}
\hline Description / Name in SAM & Name in SSC \\
\hline \multicolumn{2}{|c|}{ Storage Dispatch Controller } \\
\hline Dispatch model option & $\begin{array}{l}\text { batt_dispatch_choice }(0=\text { peak shave day ahead, } \\
\text { ak shave day behind, } 2=\text { automated grid target, } 3=\text { manual })\end{array}$ \\
\hline PV dispatch priority choice & batt_pv_choice $(0=$ load first, $1=$ battery first $)$ \\
\hline Target grid power input type & batt_target_choice $(0=$ monthly, $1=$ time series $)$ \\
\hline Target grid power time series $(\mathrm{kW})$ & batt_target_power \\
\hline Target grid power single or monthly $(\mathrm{kW})$ & batt_target_power_monthly \\
\hline \multicolumn{2}{|c|}{ Charge Limits and Priority } \\
\hline Minimum state of charge (\%) & batt_minimum_soc \\
\hline Maximum state of charge (\%) & batt_maximum_soc \\
\hline Initial state of charge (\%) & batt_initial_soc \\
\hline Minimum time at charge state (min) & batt_minimum_modetime \\
\hline \multicolumn{2}{|c|}{ Manual Dispatch Model } \\
\hline Charge from grid (six periods) & dispatch_manual_gridcharge \\
\hline Charge from PV (six periods) & dispatch_manual_charge \\
\hline Allow discharge (six periods) & dispatch_manual_discharge \\
\hline$\%$ capacity to discharge (\%) (six periods) & batt_discharge_percent_discharge \\
\hline$\%$ capacity to charge from grid (\%) (six periods) & batt_gridcharge_percent_gridcharge \\
\hline Manual dispatch schedule (weekday) & dispatch_manual_sched \\
\hline Manual dispatch schedule (weekend) & dispatch_manual_sched_weekend \\
\hline
\end{tabular}

Table 31. Battery Lifetime and Replacement Inputs

\begin{tabular}{|c|c|}
\hline Description / Name in SAM & Name in SSC \\
\hline \multicolumn{2}{|c|}{ Battery Lifetime Inputs } \\
\hline Battery lifetime matrix & batt_lifetime_matrix \\
\hline Calendar degration option & batt_calendar_choice ( $0=$ none, $1=$ Li-ion, $2=$ custom $)$ \\
\hline Li-ion degradation coefficient $\mathbf{q 0}$ & batt_calendar_q0 \\
\hline Li-ion degradation coefficient a & batt_calendar_a \\
\hline Li-ion degradation coefficient $\mathbf{b}$ & batt_calendar_b \\
\hline Li-ion degradation coefficient $\mathbf{c}$ & batt_calendar_c \\
\hline Custom lifetime capacity vs days matrix & batt_calendar_lifetime_matrix \\
\hline \multicolumn{2}{|c|}{ Battery Bank Replacement Inputs } \\
\hline Battery bank replacement cost $(\$)$ & batt_replacement_cost \\
\hline Battery cost escalation above inflation (\%) & batt_replacement_cost_escal \\
\hline Battery bank replacement threshold & batt_replacement_capacity \\
\hline Battery bank replacement schedule & batt_replacement_schedule \\
\hline \multicolumn{2}{|c|}{ Thermal Behavior Inputs } \\
\hline Battery specific heat capacity $(\mathrm{J} / \mathrm{kg} / \mathrm{K})$ & batt_Cp \\
\hline Battery heat transfer coefficient $(\mathrm{W} / \mathrm{m} 2 / \mathrm{K})$ & batt_h_to_ambient \\
\hline Battery room temperature $(\mathrm{C})$ & T_room \\
\hline Battery capacity vs. temperature table & cap_vs_temp \\
\hline Specific energy per mass $(\mathrm{Wh} / \mathrm{kg})$ & batt_specific_energy_per_mass \\
\hline Specific energy per volume $(\mathrm{Wh} / \mathrm{L})$ & batt_specific_energy_per_volume \\
\hline
\end{tabular}


Table 32. Battery Outputs

\begin{tabular}{|c|c|}
\hline Description / Name in SAM & Name in SSC \\
\hline \multicolumn{2}{|c|}{ Variable Length Outputs* } \\
\hline Annual energy exported to grid (kWh) & annual_export_to_grid_energy \\
\hline Annual energy imported from grid (kWh) & annual_import_from_grid_energy \\
\hline Battery annual energy charged $(\mathrm{kWh})$ & batt_annual_charge_energy \\
\hline Battery annual energy charged from grid (kWh) & batt_annual_charge_from_grid \\
\hline Battery annual energy charged from pv (kWh) & batt_annual_charge_from_pv \\
\hline Battery annual energy discharge $(\mathrm{kWh})$ & batt_annual_discharge_energy \\
\hline Battery annual energy loss (kWh) & batt_annual_energy_loss \\
\hline Battery bank replacements per year & batt_bank_replacement \\
\hline Battery replacement cost $(\$)$ & cf_batt_bank_replacement_cost \\
\hline Battery replacement cost schedule & cf_batt_replacement_cost_schedule \\
\hline \multicolumn{2}{|c|}{ Single Value Outputs } \\
\hline Average battery cycle efficiency (\%) & average_cycle_efficiency \\
\hline Battery bank installed capacity $(\mathrm{kWh})$ & batt_bank_installed_capacity \\
\hline Battery percent charged from PV (\%) & batt_pv_charge_percent \\
\hline \multicolumn{2}{|c|}{ Monthly Value Outputs } \\
\hline Energy to load from PV (kWh) & monthly_pv_to_load \\
\hline Energy to load from battery (kWh) & monthly_batt_to_load \\
\hline Energy to load from grid (kWh) & monthly_grid_to_load \\
\hline \multicolumn{2}{|c|}{ Lifetime Outputs at Simulation Time Step } \\
\hline Battery capacity percent for lifetime (\%) & batt_capacity_percent \\
\hline Battery cycle depth of discharge $(\%)$ & batt_DOD \\
\hline Battery number of cycles & batt_cycles \\
\hline Battery state of charge $(\%)$ & batt_SoC \\
\hline Power of PV+ battery $(\mathrm{kW})$ & pv_batt_gen \\
\hline Power to battery from PV $(\mathrm{kW})$ & pv_to_batt \\
\hline Power to battery from grid $(\mathrm{kW})$ & grid_to_batt \\
\hline Power to load from PV (kW) & pv_to_load \\
\hline Power to load from battery $(\mathrm{kW})$ & batt_to_load \\
\hline Power to load from grid $(\mathrm{kW})$ & grid_to_load \\
\hline Power to/from battery (kW) & batt_power \\
\hline Power to/from grid (kW) & grid_power \\
\hline \multicolumn{2}{|c|}{ Outputs at Simulation Time Step } \\
\hline Battery capacity percent for temperature $(\%)$ & batt_capacity_thermal_percent \\
\hline Battery cell voltage $(\mathrm{V})$ & batt_voltage_cell \\
\hline Battery current (A) & batt_I \\
\hline Battery max charge (Ah) & batt_qmax \\
\hline Battery temperature $\left({ }^{\circ} \mathrm{C}\right)$ & batt_temperature \\
\hline Battery total charge (Ah) & batt_q0 \\
\hline Battery voltage (V) & batt_voltage \\
\hline
\end{tabular}


Table 33. Battery Lead-Acid Specific Outputs

\begin{tabular}{|c|c|}
\hline Description / Name in SAM & Name in SSC \\
\hline \multicolumn{2}{|c|}{ Variable Length Outputs } \\
\hline Battery available charge (Ah & batt_q1 \\
\hline Battery bound charge (Ah) & batt_q2 \\
\hline
\end{tabular}

- The Automated grid power target dispatch option (batt_dispatch_choice $=2$ ) allows you to set a maximum grid power target for each simulation time step of the year. It dispatches the battery in each time step to reduce grid demand when it exceeds the target threshold for that time step. For time steps when the grid power is less than the threshold, the battery can charge from the grid at a power level up to the threshold. You can either specify a single threshold value that applies to all time steps of the year, specify a value for each of the twelve months in the year, or a value for each time step. In SSC, to specify monthly limits, set batt_target_choice $=0$ and set batt_target_power_monthly equal to an array of twelve values. To specify a limit for each time step, set batt_target_choice $=1$ and set batt_target_power equal to an array whose length is the same as the number of data rows in the weather file.

The Manual dispatch option (batt_dispatch_choice =3) is described in detail in (DiOrio 2015a). It allows you to define up to six dispatch periods. Each dispatch period has a setting to allow the battery to be charged from photovoltaic inverter output and grid, and to allow battery discharge. The grid discharge and battery charge settings also have capacity limits to control the rate of discharge, or rate of charge from grid. 


\section{System AC Output}

The system AC output is the electricity generated by the photovoltaic system and may be delivered to any of the following, depending on the financial model that is coupled with the photovoltaic performance model:

- Electric power grid

- Building or facility electric load

- Electric storage battery

\subsection{AC Losses}

SAM models electrical losses on the AC side of the system using a single AC loss percentage. In SAM, the model calculates the $\mathrm{AC}$ loss percentage from the $\mathrm{AC}$ wiring and step-up transformer loss percentages on the Losses input page:

$$
\begin{aligned}
L_{a c} & =100\left(1-F_{1} F_{2}\right) \\
F_{1} & =1-\frac{L_{\text {acwiring }}}{100} \\
F_{2} & =1-\frac{L_{\text {transformer }}}{100}
\end{aligned}
$$

In the SSC pvsamv1 module, the AC loss $L_{a c}$ is the single value input ac_loss. SSC applies the loss categories (AC wiring and step-up transformer losses) to the total $\mathrm{AC}$ loss to estimate the contribution of each category to the total loss. It does not calculate the value of the total loss from the AC wiring and transformer loss categories as SAM does. In order for the AC wiring loss and step-up transformer losses to be consistent with the total AC loss, you must calculate the value of the $L_{a c}$ input using Equation 15.1 and the values you assign to $L_{\text {acwiring }}$ (acwiring_loss) and $L_{\text {transformer }}$ (transformer_loss).

\subsection{Curtailment and Availability Losses}

Curtailment and availability losses may be used to account for operating losses imposed on the system by factors other than the solar resource and system's design, such as forced, scheduled, and unplanned outages, or other factors that reduce the system's AC power output.

SAM models curtailment and availability losses using an array of hourly loss values that apply to each time step of the simulation. In SAM, the losses are defined using the Edit Losses window, which is accessible from the Losses input page.

Table 34. System AC Output Variable Definitions

\begin{tabular}{lll}
\hline Symbol & Description / Name in SAM & Name in SSC \\
\hline \multicolumn{3}{c}{ Inputs } \\
$N_{i n v}$ & Number of inverters & inverter_count \\
$P_{a c}$ & AC output of a single inverter $(\mathrm{W})$ & - \\
$L_{a c}$ & Total AC power loss (\%) & ac_loss \\
$L_{a d j u s t}$ & Curtailment and availability losses $(\%)$ & adjust \\
\hline \multicolumn{3}{c}{ Outputs } \\
$P_{\text {gen }}$ & Power generated by system (W) & gen \\
\hline
\end{tabular}


In SSC, the losses may be defined in any of three ways:

- Constant loss (adjust: constant) is a single loss percentage that applies to all hours of the year.

- Hourly losses (adjust : hourly) is an $8760 \times 1$ array of loss percentages that apply to each hour of the year.

- Hourly losses with custom periods (adjust:periods) is an $n \times 3$ matrix that defines losses over ranges of hours. For example this $2 \times 3$ array, adjust: periods $=[[12,99,5][3146,3916,3]]$, would apply a loss of $5 \%$ to hours 12 through 99 , and a loss of $3 \%$ to hours 3146 through 3916.

\subsection{Power Generated by System}

The Power generated by system result variable is the electricity generated by the renewable energy system after all losses and adjustments.

$$
P_{g e n}=N_{i n v} P_{a c}\left(1-\frac{L_{a c}}{100}\right)\left(1-\frac{L_{a d j u s t}}{100}\right)
$$

For a photovoltaic project that uses one of the Utility IPP financial models, Power generated by system is the electricity delivered to the grid and sold at a negotiated power price. For projects with either the residential or commercial financing options it is the electricity generated by the system that may meet all or part of a building or facility's electric load, or be delivered the grid. For a photovoltaic system with battery storage, the power generated by the system is negative for time steps when the battery is charged by the grid. 


\section{References}

Appelbaum, J.; Bany, J. "Shadow effect of adjacent solar collectors in large scale systems." Solar Energy (23) 1979; pp. 497-507.

Blair, N.; Dobos, A.; Freeman, J., Neises, T.; Wagner, M.; Ferguson, T.; Gilman, P.; Janzou, S. (February 2014). "System Advisor Model, SAM 2014.1.14: General Description." NREL/TP-6A20-61019. Golden, CO: National Renewable Energy Laboratory. http://www.nrel.gov/docs/fy14osti/61019.pdf

Blair, N.; Dobos, A.; Gilman, P. (April 2013). "Comparison of Photovoltaic Models in the System Advisor Model." Preprint. Prepared for American Solar Energy Society National Solar Conference Solar 2013, April 16-20, 2013. NREL/CP-6A20-58057. Golden, CO: National Renewable Energy Laboratory, 6 pp. http: / /www . nrel . gov/ docs/fy130sti/58057.pdf

De Soto, W.; Klein, S.; Beckman, W. (2004) "Improvement and Validation of a Model for Photovoltaic Array Performance." Solar Energy (80:1); pp. 78-88.

De Soto, W. (2004). "Improvement and Validation of a Model for Photovoltaic Array Performance." University of Wisconsin-Madison. http://sel.me.wisc.edu/publications/theses/desoto04.zip

Deline, C.; Dobos, A.; Janzou, S.; Meydbrey, J.; Donoval, M. (2013). "A Simplified Model of Uniform Shading in Large Photovoltaic Arrays." Solar Energy (96); pp. 274-282. http: / / www . sciencedirect . com/ science/article/pii/s0038092X13002739

Deline, C. (2013). "SAM Shade Geometry V3." Unpublished. Golden, CO: National Renewable Energy Laboratory.

DiOrio, N.; Dobos, A.; Janzou, S.; Nelson, A.; Lunstrom, B. (2015). "Technoeconomic Modeling of Battery Energy Storage in SAM." NREL/TP-6A20-64641. Golden, CO: National Renewable Energy Laboratory. http: / / www . nrel.gov/docs/fy15osti/64641.pdf

DiOrio, N.; Dobos, A.; Janzou, S.; (2015). "Economic Analysis Case Studies of Battery Energy Storage with SAM." NREL/TP-6A20-64987. Golden, CO: National Renewable Energy Laboratory. http: / / www . nrel . gov/ docs/fy16osti/64987.pdf

DiOrio, N.; (2017). "An Overview of the Automated Dispatch Controller Algorithms in the System Advisor Model (SAM)." NREL/TP-6A20-68614. Golden, CO: National Renewable Energy Laboratory. https : / /www . nrel . gov/docs/fy180sti/68614.pdf

Dobos, A. (2012). "An Improved Coefficient Calculator for the California Energy Commission 6 Parameter Photovoltaic Module Model." Journal of Solar Energy Engineering (134:2).

Dobos, A. (June 2012). "Modeling of Annual DC Energy Losses due to Off Maximum Power Point Operation in PV Arrays." Prepared for 38th IEEE Photovoltaic Specialists Conference (PVSC 2012). 3 pp. http : //ieeexplore. ieee.org/xpl/articleDetails.jsp?arnumber $=6318207$

Dobos, A. (2013). "PVWatts Version 1 Technical Reference." TP-6A20-60272. Golden, CO: National Renewable Energy Laboratory. http://www.nrel.gov/docs/fyl4osti/60272.pdf

Dobos, A. (2013). "5-Parameter PV Module Model." Presented at the 2013 Sandia PV Performance Modeling Workshop on May 1, 2013. http: //pvpmc.org/home/2013-pv-performance-modeling-workshop/

Dobos, A.; MacAlpine, S. "Procedure for Applying IEC-61853 Test Data to a Single Diode Model." Prepared for 40th IEEE Photovoltaic Specialist Conference (PVSC 2014). 4 pp. http: / / ieeexplore. ieee. org/xpl / articleDetails.jsp?arnumber $=6925525$

Duffie, J.; Beckman, W. (2013). Solar Engineering of Thermal Processes, 4th ed. New York, NY: Wiley. 
Dunlap, J. (2007). Photovoltaic Systems. Homewood, IL: American Technical Publishers.

"EnergyPlus Energy Weather Data." U.S. Department of Energy. https://energyplus. net/weather

Freeman, J.; Freestate, D.; Hobbs, W.; Riley, C. (2016). "Using Measured Plane-of-Array Data Directly in Photovoltaic Modeling: Methodology and Validation." [Poster] 43rd IEEE Photovoltaic Specialists Conference, 5-10 June 2016, Portland, Oregon. 1 pp. NREL/PO-6A20-66524. http: / /www . nrel . gov/docs/fy16osti / $66524 \cdot \mathrm{pdf}$

Gilman, P.; "SAM Photovoltaic Model Technical Reference". NREL/TP-6A20-64102. Golden, CO: National Renewable Energy Laboratory. http://www.nrel.gov/docs/fy15osti/64102.pdf

Goswami, D.; Stefanakos, E.; Hassan A.; Collis,W. (1989). "Effect of Row-to-Row Shading on the Output of FlatPlate South-Facing Photovoltaic Arrays." Journal of Solar Energy Engineering (111:3); pp. 257-259.

"Incentive Eligible Photovoltaic Modules in Compliance with SB1 Guidelines." (2014). Go Solar California. http: //www.gosolarcalifornia.ca.gov/equipment/pv_modules.php

Iqbal, M. (1983) An Introduction to Solar Radiation. New York, NY: Academic Press.

King, D.; Boyson, W.; and Kratochvil, J. (2004). "Photovoltaic Array Performance Model." 41 pp.; Albuquerque, NM: Sandia National Laboratories. SAND2004-3535. http: / / prod.sandia.gov/techlib/ access-control.cgi/2004/043535.pdf

King, D.; Gonzalez, S.; Galbraith, G.; Boyson, W. (2007). "Performance Model for Grid-Connected Photovoltaic Inverters." 47 pp.; Albuquerque, NM: Sandia National Laboratories. SAND2007-5036. http: //prod. sandia . gov/techlib/access-control.cgi/2007/075036.pdf

Liu, B.; Jordan, R. (1963). "A Rational Procedure for Predicting The Long-term Average Performance of Flat-plate Solar-energy Collectors." Solar Energy (7:2); pp. 53-74.

Michalsky, J. (1988). “The Astronomical Almanac's Algorithm for Approximate Solar Position (1950-2050)." Solar Energy (40:3); pp. 227-235.

Neises, T. (2011). "Development and Validation of a Model to Predict the Temperature of a Photovoltaic Cell." University of Wisconsin-Madison. http://sel.me.wisc.edu/publications/theses/neises 11 . zip

"Incentive Eligible Photovoltaic Modules in Compliance with SB1 Guidelines." (2014). Go Solar California. http: //www.gosolarcalifornia.ca.gov/equipment/pv_modules.php

"List of Eligible Inverters per SB1 Guidelines." (2016). Go Solar California. http : / / www . gosolarcalifornia.ca.gov/equipment/inverters.php

"New Solar Homes Partnership Calculator." (2014). Go Solar California. http: / /www . gosolarcalifornia . ca.gov/tools/nshpcalculator/index.php

MacAlpine, S.; Deline, C. (2016) "Simplified Method for Modeling the Impact of Arbitrary Partial Shading Conditions on PV Array Performance." CP-5J00-64570. Golden, CO: National Renewable Energy Laboratory. http: //wWw.nrel.gov/docs/fy12osti/54039.pdf

Marion, W. (2015). "A model for deriving the direct normal and diffuse horizontal irradiance from the global tilted irradiance," Solar Energy Vol. 122; pp. 1037-1046.

Marion, W. (2013). "Measured and modeled photovoltaic system energy losses from snow for Colorado and Wisconsin locations." Solar Energy 97 (2013): pp. 112-121. 
"National Solar Radiation Database (NSRDB)." (2016). National Renewable Energy Laboratory. https : //nsrdb.nrel.gov/.

"National Solar Radiation Data Base 1991 - 2010 Update" (2010). National Renewable Energy Laboratory. http: //rredc.nrel.gov/solar/old_data/nsrdb/1991-2010/.

"National Solar Radiation Data Base 1961 - 1990" (1990). National Renewable Energy Laboratory. http : / / rredc.nrel.gov/solar/old_data/nsrdb/1961-1990/.

O'Brien, J. (2012)."Position of the sun given time of day, latitude and longitude." stackoverflow.com. http://stackoverflow.com/questions/8708048/ position-of-the-sun-given-time-of-day-latitude-and-longitude

"PVCDROM." (2014) pveducation.org. http: / / www . pveducation . org/pvcdrom

"PVPMC: Modeling Steps." (2014) PV Performance Modeling Collaborative. http: / / pvpmc . org/ modeling-steps/.

"PVPMC: Irradiance and Insolation." (2014). PV Performance Modeling Collaborative. https : //pvpmc.sandia.gov/modeling-steps/1-weather-design-inputs/ irradiance-and-insolation-2/

Passias, D.; Kallback, B. (1984). "Shading effects in rows of solar cell panels", Solar Cells (11); pp. $281-291$.

Perez, R.; Stewart, R.; Seals, R.; Guertin, T. (1988) “The Development and Verification of the Perez Diffuse Radiation Model." SAN88-7030. Albuquerque, NM: Sandia National Laboratories. http: / / prod.sandia.gov/ techlib/access-control.cgi/1988/887030.pdf

Perez, R.; Ineichen, P.; Seals, R.; Michalsky, J.; Stewart, R. (1990) “Modeling Daylight Availability and Irradiance Components from Direct and Global Irradiance." Solar Energy (44:5); pp. 271-289.

"Perez Sky Diffuse Model." Modeling Steps. PV Performance Modeling Collaborative. Albuquerque, NM: Sandia National Laboratories. https://pvpmc.sandia.gov/ modeling-steps/1-weather-design-inputs/plane-of-array-poa-irradiance/ calculating-poa-irradiance/poa-sky-diffuse/perez-sky-diffuse-model/

Reindl, D. (1988). "Estimating Diffuse Radiation on Horizontal Surfaces and Total Radiation on Tilted Surfaces." Masters Thesis. University of Wisconsin Madison, Solar Energy Laboratory. http: / / sel . me.wisc.edu/ publications/theses/reindl88.zip

Ryberg, D.; Freeman, J. (2015). "Integration, Validation and Application of a PV Snow Coverage Model in SAM." TP-6A20-64260. Golden, CO: National Renewable Energy Laboratory. http: / / www . nrel . gov/docs / fy150sti/64260.pdf

"Download SAM." https://sam.nrel.gov/download

"SAM Help: 3D Shade Calculator." (2018). SAM 2017.9.5 Help System. National Renewable Energy Laboratory. Available as a PDF on the SAM website at https://sam.nrel.gov/sites/default/files/ content/help/sam-help-2017-9-5.pdf

"SAM Help: Photovoltaic Systems, Detailed Photovoltaic Model, Losses, Curtailment and Availability." (2016). SAM 2016.3.14 Help System. National Renewable Energy Laboratory. Available as a PDF on the SAM website at https://sam.nrel.gov/sites/default/files/content/help/sam-help-2016-3-14.pdf

"SAM Help: Photovoltaic Systems, Edit Shading Data." (2018). SAM 2017.9.5 Help System. National Renewable Energy Laboratory. Available as a PDF on the SAM website at https: / / sam.nrel.gov/sites / default/files/content/help/sam-help-2016-3-14.pdf 
"SAM Help: Photovoltaic Systems, Detailed Photovoltaic Model, Shading and Snow." (2016). SAM 2016.3.14 Help System. National Renewable Energy Laboratory. Available as a PDF on the SAM website at https://sam. nrel.gov/sites/default/files/content/help/sam-help-2016-3-14.pdf

"SAM Help: Photovoltaic Systems, Detailed Photovoltaic Model, System Design, System Sizing" (2016). SAM 2016.3.14 Help System. National Renewable Energy Laboratory. Available as a PDF on the SAM website at https://sam.nrel.gov/sites/default/files/content/help/sam-help-2016-3-14.pdf

"SAM Help: Weather Data, Weather File Formats." (2016). SAM 2016.3.14 Help System. National Renewable Energy Laboratory. Available as a PDF on the SAM website at https://sam.nrel.gov/sites/ default/files/content/help/sam-help-2016-3-14.pdf

"System Advisor Model (SAM) Release Notes." (2016). National Renewable Energy Laboratory. https : / sam . nrel.gov/sites/default/files/content/updates/releasenotes.html

"SAM Simulation Core SDK." (2016). National Renewable Energy Laboratory. https://sam. nrel.gov/sdk

"SAM Source Code: Self-shading Geometry Calculations for One-axis Trackers." (2016). National Renewable Energy Laboratory. https://sam.nrel.gov/source

"Sandia National Laboratories Photovoltaic Test and Evaluation Program." Sandia National Laboratories. Accessed March 7, 2014: http://energy.sandia.gov/?page_id=279

Van Schalkwijk, M.; Kil, T.; Van der Weiden, J. (1991). "Dependence of diffuse light blocking on the ground cover ratio for stationary PV arrays", Solar Energy (61:1); pp. 381-387.

Wilcox, S.; Marion, W. (2008). "Users Manual for TMY3 Datasets." TP-581-43156. Golden, CO: National Renewable Energy Laboratory. http: //www.nrel.gov/docs/fy08osti/43156.pdf. 